\title{
Co-firing Coal, Feedlot, and Litter Biomass (CFB and LFB) Fuels in Pulverized Fuel and Fixed Bed Burners
}

\author{
Semi-Annual Technical Report \\ 6/16/2001-12/15/2001
}

\author{
Kalyan Annamalai, \\ John Sweeten, \\ Saqib Mukhtar, \\ Ben Thien, \\ Gengsheng Wei, \\ Soyuz Priyadarsan,
}

Texas A\&M University, College Station, Texas

January 15, 2002

Contract \#: DE-FG26-00NT40810

Texas Engineering Experiment Station, Texas A\&M University, College Station, TX 77843

Submitted to

National Energy Technology Laboratory, Department of Energy, Pittsburgh, Pa. 


\section{Table of Contents}

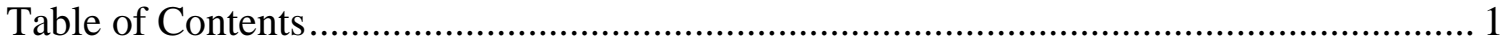

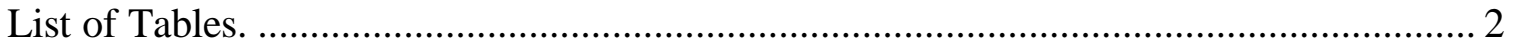

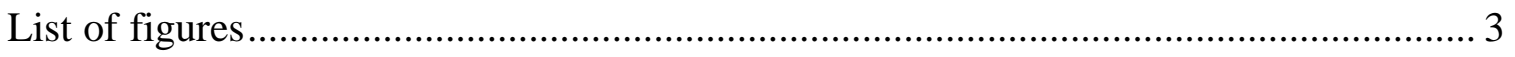

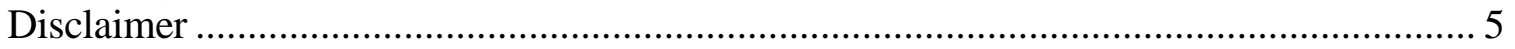

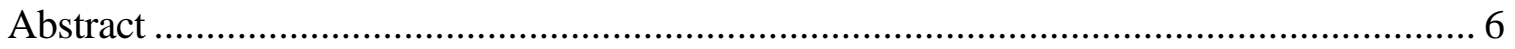

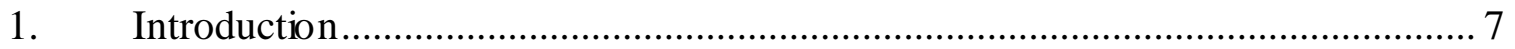

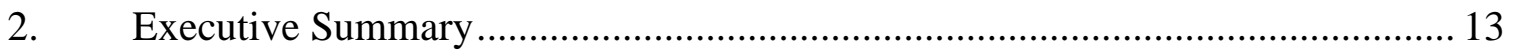

3. Project Tasks, Results, and Discussion..................................................... 15

3.1. Task 1: Fundamental experiments on fuel characterization........................................................... 15

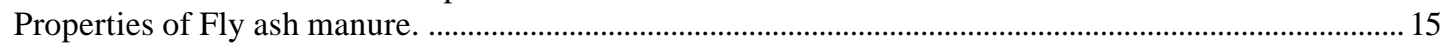

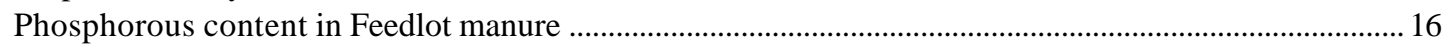

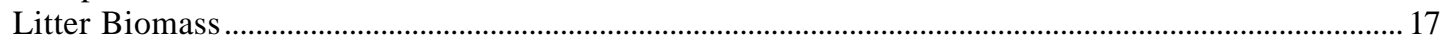

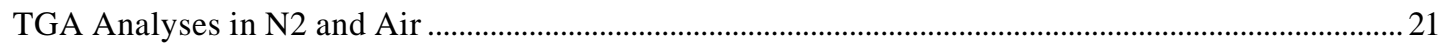

LB Pyrolysis Parameter Analysis ...................................................................................................... 28

3.2. Task 2: Boiler burner experiments for cofiring of CFB and CLB fuels and Reburn tests...........29

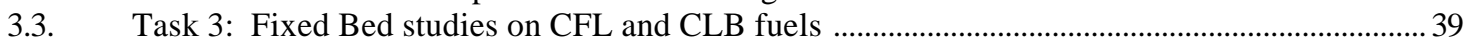

3.4. Task 4: Numerical Modeling of pf fired and fixed bed burners ...................................................... 42

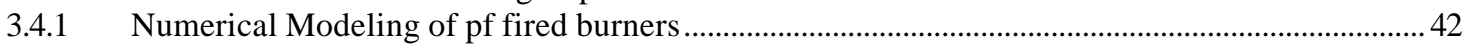

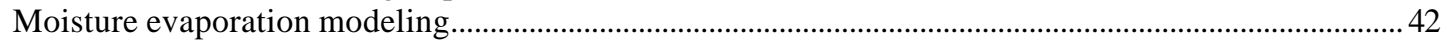

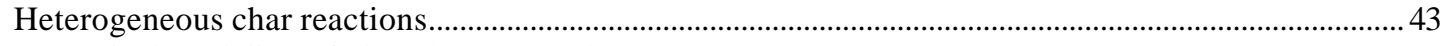

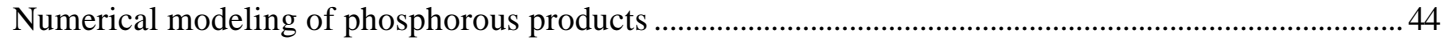

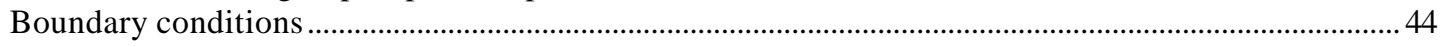

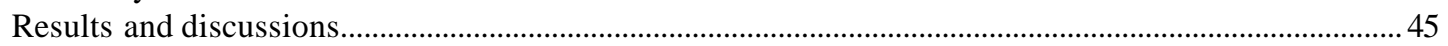

3.4.2. One Dimensional Modeling of the Fixed Bed Gasifier ................................................................... 51

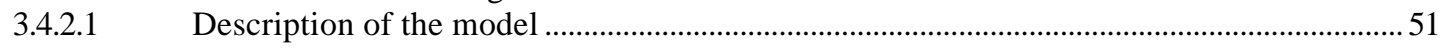

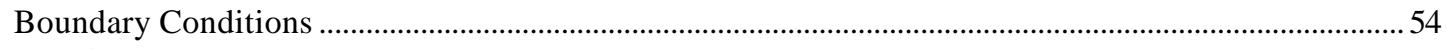

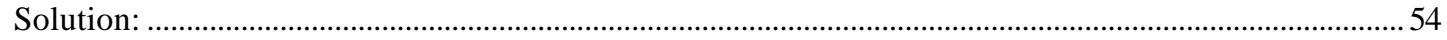

3.5. Task 5:Fuel Collection, transportation, and Economic analyses of feedlot and litter biomass fuel

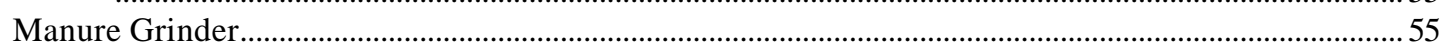

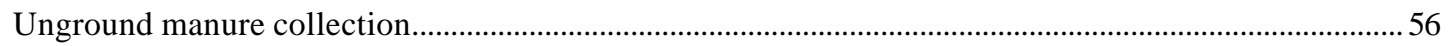

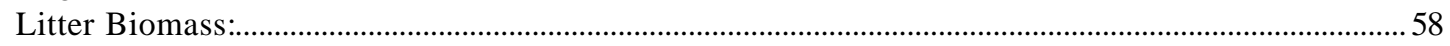

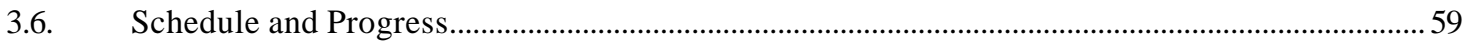

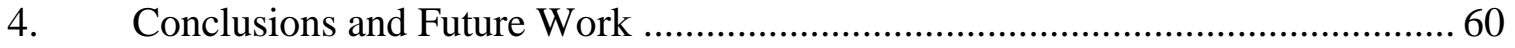

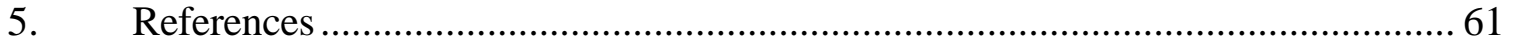

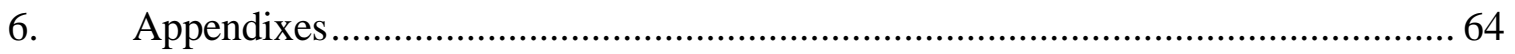

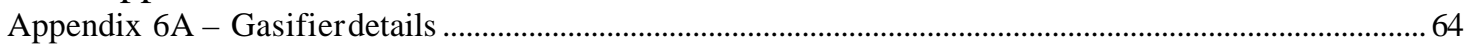

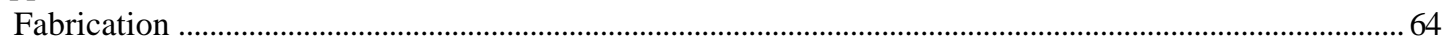

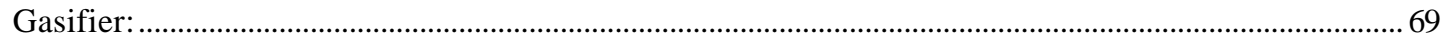

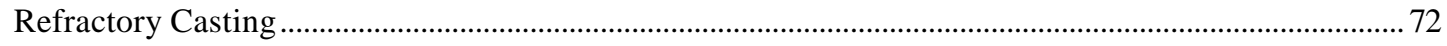

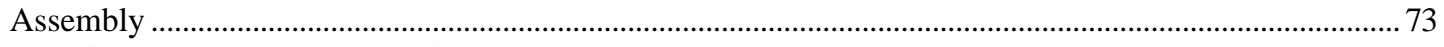

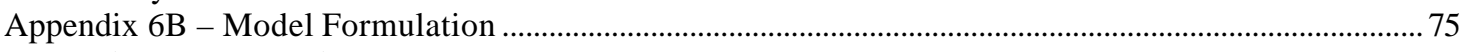

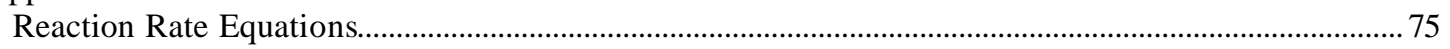

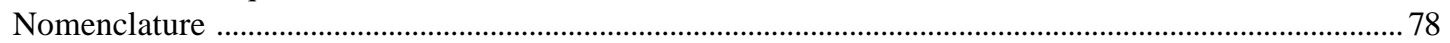




\section{List of Tables.}

Table 1.1: A quick overview of some of the selected works on co-firing........................................................ 9

Table 3.1.1: Properties of manure collected from a fly ash surface.................................................................. 15

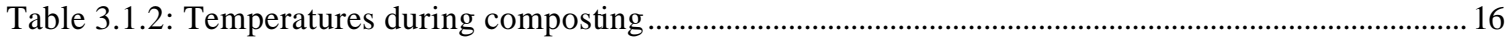

Table 3.1.3: Moisture levels during composting .............................................................................................. 16

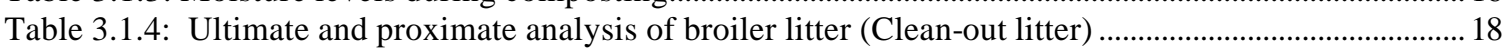

Table 3.1.5: Ash (Mineral) analysis of broiler litter (Clean-out Litter) ……………………………................... 19

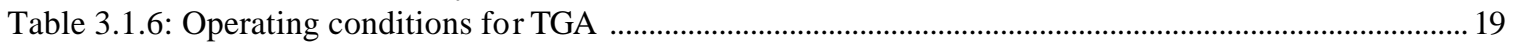

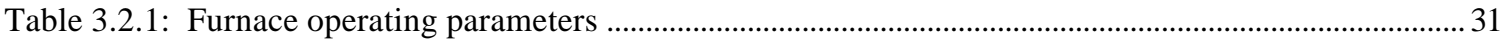

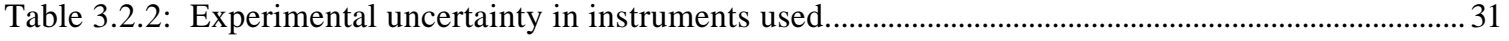

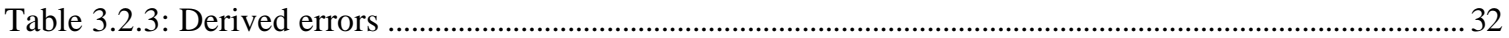

Table 3.4.1.1: Constants of specific reaction rate for char ................................................................................ 44

Table 3.4.1.2: Fuel ultimate and proximate analyses and other parameters ...................................................... 45

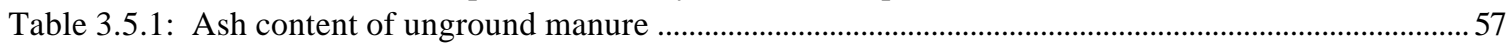

Table 3.5.2: Moisture of unground manure ………………............................................................................ 


\section{List of figures}

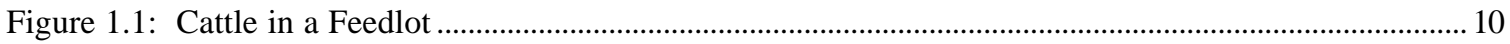

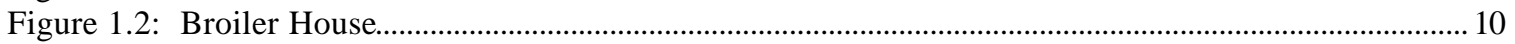

Figure 1.3: Cakeout Litter from Broiler House ................................................................................................. 11

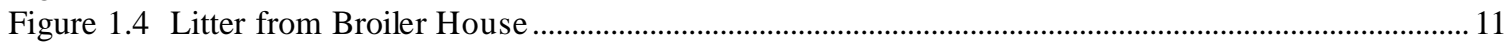

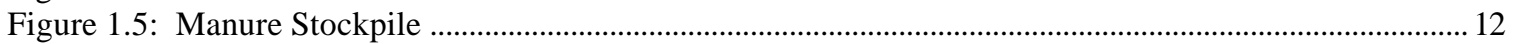

Figure 3.1.1. Comparison of N Contents on heat basis for various fuels .......................................................... 20

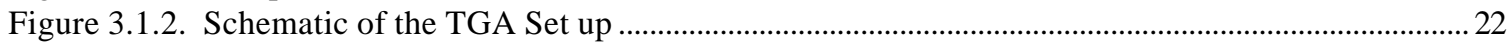

Figure 3.1.3: TGA traces of Coal, FB, and 90:10 FB blend (full size) in nitrogen with moisture loss

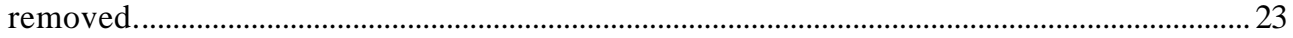

Figure 3.1.4: TGA traces of Coal (full size) in air with moisture loss removed................................................2 23

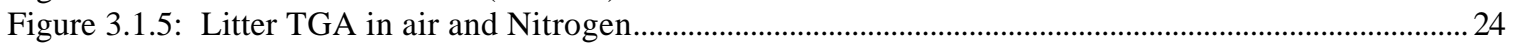

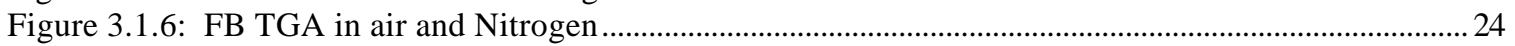

Figure 3.1.7: Mean activation energy for parallel reaction model ……………………………………...........2

Figure 3.1.8: Standard deviation for parallel reaction model.......................................................................... 26

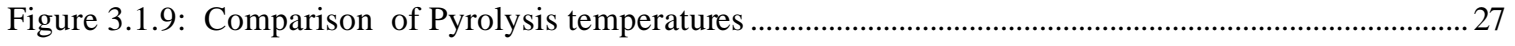

Figure 3.1.10: Curve Fitting (dashed line is curve fitting, solid is measurement)...........................................2 28

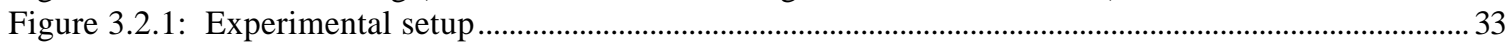

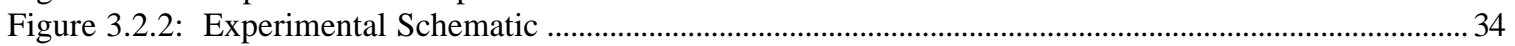

Figure 3.2.3: Modified Furnace Dimensions in inches ................................................................................ 35

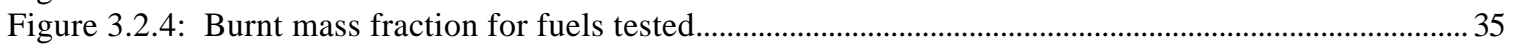

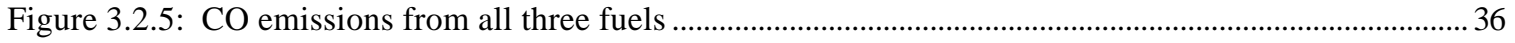

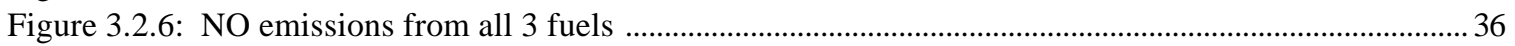

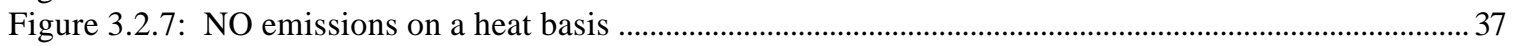

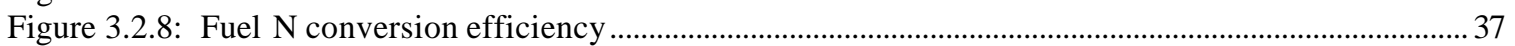

Figure 3.2.9: Relation between $\mathrm{NO}$ and $\mathrm{CO}$ in unmodified (short) Reactor ....................................................... 38

Figure 3. 2.10: Comparison of $\mathrm{NO}_{\mathrm{x}}$ reduction in the modified furnace at $\mathrm{A} \& \mathrm{M}$ facility (patent in process) 38

Figure 3.3.1a: Grate support mechanism before modification.......................................................................... 40

Figure 3.3.1b: Modified grate support mechanism...................................................................................... 40

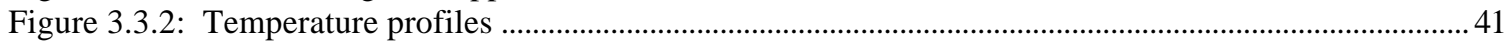

Fig. 3.4.2.1a: Distribution of mixture fraction $\eta_{3}$. Coal is dry.and Moisture in $\mathrm{LB}=10 \%$........................... 46

Fig. 3.4.2.1b: Distribution of mixture fraction $\eta_{3}$. Coal is dry and Moisture in $L B=20 \%$......................... 46

Fig. 3.4.2.1c: Distribution of mixture fraction $\eta_{3}$. Coal is dry.and Moisture in $L B=30 \%$............................ 47

Fig. 3.4.1.2a: Distribution of temperature $(\mathrm{K})$ when Coal is dry. and Moisture in $\mathrm{LB}=0 \%$.......................... 47

Fig. 3.4.1.2b: Distribution of temperature (K) when Coal is dry and Moisture in LB $=10 \%$....................... 47

Fig. 3.4.1.2c: Distribution of temperature $(\mathrm{K})$ when Coal is dry and Moisture in $\mathrm{LB}=20 \%$........................ 48

Fig. 3.4.1.3a: Distribution of NO mole fraction when Coal is dry and Moisture in LB $=0 \%$....................... 49

Fig. 3.4.1.3b: Distribution of NO mole fraction. Coal is dry. (a) Moisture in $\mathrm{LB}=10 \%$............................... 49

Fig. 3.4.1.3c: Distribution of NO mole fraction. Coal is dry. (a) Moisture in $L B=20 \%$.............................. 49

Fig. 3.4.1.3d: Distribution of NO mole fraction when Coal is dry and Moisture in LB $=30 \% \ldots \ldots \ldots \ldots \ldots \ldots \ldots . . .50$

Fig. 3.4.1.3: Velocity vector distribution of cross section around burner for dry coal and $30 \%$ moisture in LB

Figure 3.4.2.1: Schematic of the modeled Gasifier........................................................................................... 51

Figure 3.4.2.2a: A schematic of various stages of countercurrent gasification ............................................. 52

Figure 3.4.2.2b: A schematic of various stages and reactions within a countercurrent gasifier .....................53

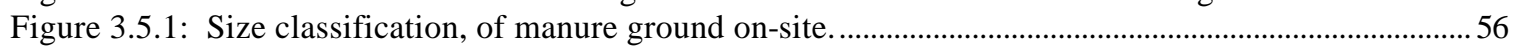

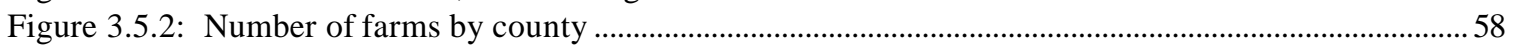

Figure 3.6.1: Progress on the five tasks ................................................................................................5

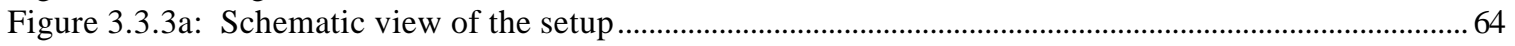

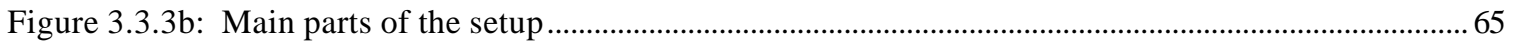

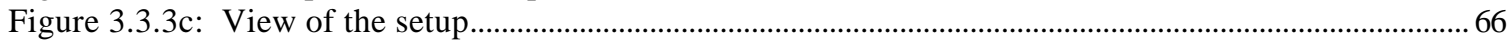

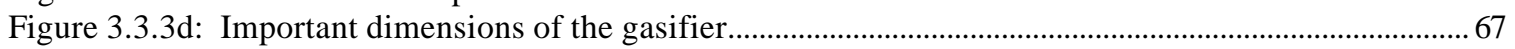

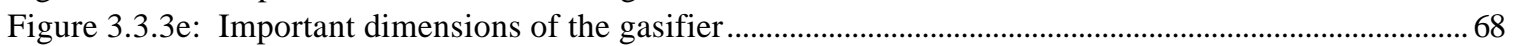

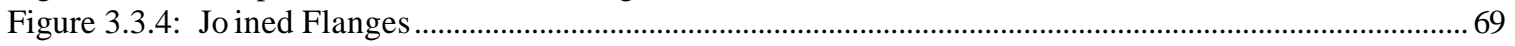




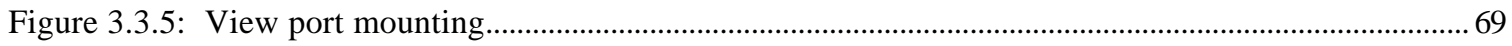

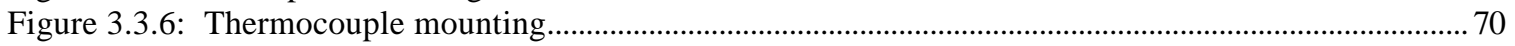

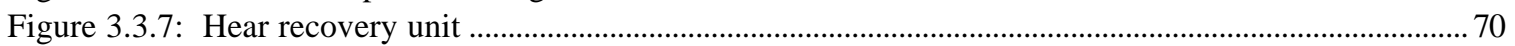

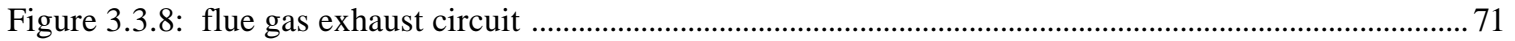

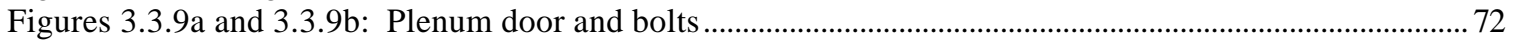

Figure 3.3.10: Cross section of section 1 of the gasisfier .............................................................................. 72

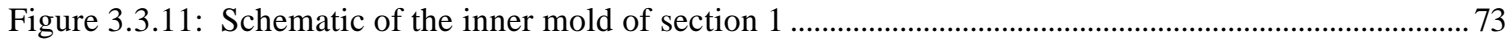


Disclaimer

"This report was prepared as an account of work sponsored by an agency of the Untied States Government. Neither the United States Government nor any agency thereof, nor any of their employees, makes any warranty, express or implied, or assumes any legal liability or responsibility for the accuracy, completeness, or usefulness of any information, apparatus, product, or process disclosed, or represents that its use would not infringe privately owned right. Reference herein to any specific commercial product, process, or service by trade name, trademark, manufacturer, or otherwise does not necessarily constitute or imply its endorsement, recommendation, or favoring by the Untied States Government or any agency thereof. The views and opinions of authors expressed herein do not necessarily state or reflect those of the United States Government or any agency thereof." 


\section{Abstract}

Intensive animal feeding operations create large amounts of animal waste that must be safely disposed of in order to avoid environmental degradation. Cattle feedlots and chicken houses are two examples. In feedlots, cattle are confined to small pens and fed a high calorie grain diet in preparation for slaughter. In chicken houses, thousands of chickens are kept in close proximity. In both of these operations, millions of tons of manure are produced every year. In this project a co-firing technology is proposed which would use manure that cannot be used for fertilizer, for power generation. Since the animal manure has economic uses as both a fertilizer and as a fuel, it is properly referred to as feedlot biomass (FB) for cow manure, or litter biomass (LB) for chicken manure. The biomass will be used a as a fuel by mixing it with coal in a 90:10 blend and firing it in existing coal fired combustion devices. This technique is known as co-firing, and the high temperatures produced by the coal will allow the biomass to be completely combusted. Therefore, it is the goal of the current research to develop an animal biomass cofiring technology.

A cofiring technology is being developed by performing: 1) studies on fundamental fuel characteristics, 2) small scale boiler burner experiments, 3) gasifier experiments, 4) computer simulations, and 5) an economic analysis. The fundamental fuel studies reveal that biomass is not as high a quality fuel as coal. The biomass fuels are higher in ash, higher in moisture, higher in nitrogen and sulfur (which can cause air pollution), and lower in heat content than coal. Additionally, experiments indicate that the biomass fuels have higher gas content, release gases more readily than coal, and less homogenous. Smallscale boiler experiments revealed that the biomass blends can be successfully fired, and $\mathrm{NO}_{\mathrm{x}}$ pollutant emissions produced will be similar to or lower than pollutant emissions when firing coal. This is a surprising result as the levels of $\mathrm{N}$ are higher in the biomass fuel than in coal. Further experiments showed that biomass is twice or more effective than coal when used in a reburning process to reduce $\mathrm{NO}_{\mathrm{x}}$ emissions. Since crushing costs of biomass fuels may be prohibitive, stoker firing may be cost effective; in order simulate such a firing, future work will investigate the performance of a gasifier when fired with larger sized coal and biomass. It will be a fixed bed gasifier, and will evaluate blends, coal, and biomass. Computer simulations were performed using the PCGC -2 code supplied by BYU and modified by A\&M with three mixture fractions for handling animal based biomass fuels in order to include an improved moisture model for handling wet fuels and phosphorus oxidation. Finally the results of the economic analysis show that considerable savings can be achieved with the use of biomass. In the case of higher ash and moisture biomass, the fuel cost savings will be reduced, due to increased transportation costs. A spreadsheet program was created to analyze the fuel savings for a variety of different moisture levels, ash levels, and power plant operating parameters. 


\section{Introduction}

Since 1978, the average number of animal units and hence animal waste has increased by $56 \%$ (cattle) and $176 \%$ (poultry litter). Beef cattle are fattened for slaughter in large industrial feeding operations known as feedlots. Cattle are confined to small pens and fed a high calorie ration to induce weight gain. In Texas, feedlots are found mainly in the panhandle area near Amarillo. Cattle in a typical feedlot pen, on a typical feedlot in the Amarillo area are shown in figure 1.1 (all the figures of a particular section are at the end of that section). The average feedlot can have over 10,000 head of cattle, and it is estimated that at any given time there are over 10,000,000 cattle in feedlots in the United States [Eghball, et al, 1994]. Each calf is typically fed over a period of 4 months. For example, if 1.6 million heads are fed over a 4 month period, the feedlot processes 4.8 millions cattle over 1 year. If you include Oklahoma, New Mexico, and the Texas Panhandle area, 6-7 million heads are processed every year. Each of these cows produces about $62 \mathrm{lbs}$ of wet manure per day containing 35\% moisture and $65 \%$ solids including combustibles and ash [Sweeten, Pub L-1094]. Large concentrated animal feeding operations (CAFO) have expanded all over the country including Texas. The Texas Panhandle region covering adjacent areas of Oklahoma and New Mexico is the largest cattle feeding region in the nation, producing about 6-7 million fed cattle annually, $32 \%$ of the fed cattle produced and slaughtered in the U.S., and contributing $\$ 14$ billion per year to the regional economy. The cattle feeding industry in the Texas Panhandle area is growing at the rate of approximately 100,000 head of feedlot capacity per year. The waste production is estimated to be 18 wet tons per year for Texas high Plains area, 22-26 wet tons per year for Texas Pan handle area and 110 million wet tons for USA.

Broiler producers under contract from poultry integrators raise birds for slaughter in broiler houses that may contain 10,000 to 30,000 birds (Figure 1.2). Manure excreted by the birds is mixed with feed, water (called cake out litter, Figure 1.3), feathers and bedding material. In the USA alone there were 8 billion heads per year produced for slaughter. With an average litter production of $0.20 \mathrm{lb}$ per day (Figure 1.4), the total poultry waste is estimated to be approximately 15 million tons per year while about 600,000 tons of litter was generated in Texas in 1998. Most of the Texas poultry farms are located near the lignite seam belt. Sanderson Farms located in Brazos County, Texas processes more than 50 million broiler/year. They kill one million chickens per week. Most of their broiler houses are located within a 70-mile radius of their feed mill in Franklin, Robertson County.

More manure is produced than can be applied to farmland. Land application of manure is the preferred solution, but manure is a dilute nutrient and transportation costs can be prohibitive. Beyond a certain radius, manure cannot compete with commercial fertilizer as a nutrient. Some landowners are not willing to accept the use of confinement facility manure as fertilizer, and finding enough land near the facilities to spread manure is difficult because at high rates of land application, water and air quality problems become more serious.

If the manure is not properly collected from the pens, the odor can become quite intense and irritate local residents. The manure cannot be allowed to build up in the pens as it will build up to the point where it crowds out the cattle and interferes with the drainage of the pens. Manure releases gases that can cause air pollution. In particular, manure is known to release $\mathrm{CH}_{4}$ and $\mathrm{CO}_{2}$, which have been identified as two of the most important gases in global warming. The manure is also an ideal breeding ground for flies and contains pathogenic bacteria. When the manure gets very wet, the cattle expend more energy moving around in their pens, and gain weight at a slower rate [Hutchinson, et al, 1995]. When the manure gets very dry, the cattle's feet grind the dry manure, creating a dust problem. The total suspended particles (TSP) in feedlot dust can range from 150-260 (Ca) to $400 \mu \mathrm{g} / \mathrm{m}^{3}$ (TX). Particulate matter (PM) or dust from feedlot ranges from 8.5 to 12 microns. The PM 10 regulation requires concentration of particles less than $10 \mu \mathrm{m}$ to be less than $150 \mu \mathrm{g} / \mathrm{m}^{3}$. High levels of dust can irritate cattle, resulting in slower weight gain and occasionally pneumonia.

In many places the manure is piled into large stockpiles. A relatively small stockpile is depicted in figure 1.5 (notice the person in the figure for scale). At some feedlots, the manure has been stockpiled for over 50 years, and the resulting stockpiles can be very large. A stockpile is the worst method for dealing with the problems of manure disposal, as stockpiles can be very dangerous. In stockpiles, the insulation provided by the manure allows temperatures to rise, and smoldering or spontaneous combustion can result in stockpile fires. Stockpile fires are very dangerous, and are very hard to put out. There is also always the danger of runoff from stockpiles in the event of heavy rains, and stockpiles require their own 
holding ponds. Over time the manure in stockpiles looses its heat content and value as a fertilizer and cannot be easily disposed because it still retains its high phosphorus content.

A viable solution to the disposal problem is to use feedlot and litter biomass as fuel for energy conversion. Various technologies, which utilize feedlot biomass as a sole energy source, are summarized in tabular form in Sweeten et al, (1986) and Annamalai et al (1987a). Some of these technologies have met with limited technical success. The limitations were primarily due to relying on manure as the sole-source of fuel, despite the highly variable properties (i.e. ash percentage, moisture percentage, salts etc.) of manure and the associated flame stability problems. Another technology used for the reduction of feedlot waste is anaerobic digestion. Unfortunately, anaerobic digestion is a slow process that results in the release of emissions over a longer period of time. Anaerobic digestion also requires liquefaction, the use of precious water, difficulty in transporting digested slurry, and the ash content of the leftover solids poses chronic mechanical problems.

Most of these problems could be eliminated by blending waste/biomass with coal and firing it in existing boiler burners since feedlot and litter waste could be readily combusted in the presence of high heat value coal. A blend instead of a solitary fuel is used due to the high variability and high moisture content of animal waste and the possibility of immediate transfer of technology. A state of art review on cofiring has been recently undertaken [Sami et al, 2000]. The review summarizes various biomass fuels, their properties, their combustion behavior, existing literature on co-firing, fundamental concepts related to coal:biomass blend combustion, and modeling studies. Apart from the disposal of waste, other advantages of cofiring coal with biomass are: i) energy conversion to useful form, ii) reduction of fossil fuel based $\mathrm{CO} 2$, iii) reduction in $\mathrm{NO}_{\mathrm{x}}$, iv) reduction in fuel cost, v) minimization of waste and reduction in soil, water, and air pollution, vi) possible use as reburn fuel, vii) improvement of hygienic conditions through reduction of pathogens, worm eggs and flies and environmental protection of soil, water, air, and vegetation, viii) reduction of anaerobic release of $\mathrm{CH}_{4}, \mathrm{NH}_{3}, \mathrm{H}_{2} \mathrm{~S}$, amides, volatile organic acids, mercaptans, esters, and other chemicals, ix) additional income source, and x) great potential for immediate commercialization.

On the other hand the problems with manure are: $2-2.5 \% \mathrm{~N}, 0.8-1 \% \mathrm{P}$, and $1.5-2 \% \mathrm{~K}$ on a dry weight basis which may cause emission and fouling problems. High moisture and ash contents in biomass fuels cause ignition and combustion problems. The melting point of the dissolved ash is also low which causes fouling and slagging problems.

The overall goal of the project is to demonstrate the co-firing technology of coal with FB and LB fuels and reburn technology with $\mathrm{FB}$ and $\mathrm{LB}$ for reduction of $\mathrm{NO}_{\mathrm{x}}$. In order to achieve the overall objective, the following tasks must be performed:

\section{Task 1.Fundamental experiments on fuel characterization}

Task 2.Boiler burner experiments for cofiring of CFB and CLB fuels and reburn tests

Task 3. Fixed Bed studies on CFL and CLB fuels

Task 4. Numerical Modeling of pf fired and fixed bed burners

Task 5. Fuel Collection, transportation, and Economic analyses of feedlot and litter biomass fuel

Biomass as mentioned in the current research is a general term describing a variety of animal waste products. Note that task 3 arises due to grinding problems associated with biomass fuels and stoker firing (which resembles a fixed bed) may be necessary. The present program on fuel properties, cofiring, and reburn experiments supplements several of the on going sponsored research programs on i) Coal:Feedlot Biomass or Cattle Manure (CFB) cofiring [Texas ATP, 1997-2001, Annamalai, K., and Sweeten, J.], ii) Moisture and Ash Effects on Cofiring of CFB [DOE- Western Biomass, 1999-2001, Annamalai, K., and Sweeten, J.], iii) Coal:Litter Biomass or Poultry Litter waste (CLB) Cofiring [Texas ATP 2000-2002, Annamalai, K., and Sweeten, J.], iv) Study of Odors and Arsenic Emissions from Poultry Growing Operations [Mukhtarand, S., Carey, J., TNRCC, 1999-2001]. 


\begin{tabular}{|c|c|c|c|c|c|c|c|c|}
\hline Author & Reburn Fuel & $\begin{array}{l}\text { Reburn } \\
\text { minimum SR }\end{array}$ & Particle size & Temp & Residence time & $\begin{array}{l}\text { Burnout } \\
\text { zone }\end{array}$ & $\begin{array}{l}\text { Max } \\
\text { Reduction }\end{array}$ & Conclusion \\
\hline $\begin{array}{l}\text { Adams et all, } \\
1998\end{array}$ & Wood & 0.9 & $1 / 16$ to $1 / 32$ in & $1370^{\circ} \mathrm{C}$ & .4 to $1.2 \mathrm{~s}$ & YES & $55 \%$ & $\begin{array}{l}\text { Wood can successfully } \\
\text { used a reburn fuel in a } \\
\text { cyclone combustor }\end{array}$ \\
\hline $\begin{array}{l}\text { Bilboa et al, } \\
1994\end{array}$ & Natural Gas & N/A & gas & $\begin{array}{l}1200- \\
1500^{\circ} \mathrm{C}\end{array}$ & $98-280 \mathrm{~ms}$ & $\mathrm{NO}$ & $<90 \%$ & $\begin{array}{l}\text { Found that high } \\
\text { temperature and low } \\
\text { oxygen are good for } \\
\text { NO reduction }\end{array}$ \\
\hline $\begin{array}{l}\text { Bilboa at al, } \\
1995\end{array}$ & Natural Gas & 0.94 & gas & $\begin{array}{l}1200- \\
1500^{\circ} \mathrm{C}\end{array}$ & $95-280 \mathrm{~ms}$ & YES & $95 \%$ & $\begin{array}{l}\text { Successful reburn at } \\
\text { temperatures above } \\
1200^{\circ} \mathrm{C}\end{array}$ \\
\hline $\begin{array}{l}\text { Bilboa et al, } \\
1997\end{array}$ & $\begin{array}{l}\text { Natural gas, } \\
\text { methane, ethane }\end{array}$ & 0.93 & gas & $1100^{\circ} \mathrm{C}$ & $220 \mathrm{~ms}$ & $\mathrm{NO}$ & $87.5 \%$ & $\begin{array}{l}\text { Reburning with natural } \\
\text { gas most effective at } \\
0.93 \text { SR }\end{array}$ \\
\hline $\begin{array}{l}\text { Chen et al } \\
1996\end{array}$ & $\begin{array}{l}\text { Coal, and coal } \\
\text { char }\end{array}$ & $\begin{array}{l}0.8 \text { for those } \\
\text { that reached a } \\
\text { min }\end{array}$ & NA & $1100^{\circ} \mathrm{C}$ & $.2 \mathrm{~s}$ & $\mathrm{NO}$ & $80-95 \%$ & $\begin{array}{l}\text { Heterogeneous } \\
\text { mechanisms accounted } \\
\text { for the majority of the } \\
\mathrm{NO}_{\mathrm{x}} \text { reduction, chars } \\
\text { can be used in } \\
\text { reburning }\end{array}$ \\
\hline $\begin{array}{l}\text { Kicherer et } \\
\text { al. } 1994\end{array}$ & $\begin{array}{l}\text { Coal, natural gas } \\
\text { straw, light fuel } \\
\text { oil }\end{array}$ & $\begin{array}{l}\text { minimum at } \\
0.76, \text { but little } \\
\text { change after } \\
0.85 \sim 0.9\end{array}$ & $\begin{array}{l}2,15,30,40 \\
\text { wt } \%<90 \mu \mathrm{m}\end{array}$ & NA & $\begin{array}{l}.5 \text { to } 1.3 \text { seconds, } \mathrm{NO} \\
\text { continually } \\
\text { decreasing }\end{array}$ & YES & $77.6 \%$ & $\begin{array}{l}\text { To maximize NO } \\
\text { reduction: small } \\
\text { particles, high volatile } \\
\text { fuel, long residence } \\
\text { time, good mixing }\end{array}$ \\
\hline $\begin{array}{l}\text { Maly, P. et } \\
\text { al, } 1999\end{array}$ & $\begin{array}{l}\text { natural gas, coal, } \\
\text { pond fines, RDF, } \\
\text { Orimulsion, and } \\
\text { wood }\end{array}$ & & $\sim 200 \mu \mathrm{m}$ & $1430^{\circ} \mathrm{C}$ & .2 to $.9 \mathrm{~s}$ & YES & $70-95 \%$ & $\begin{array}{l}\text { Alternate fuels can be } \\
\text { more effective than } \\
\text { reburning with natural } \\
\text { gas }\end{array}$ \\
\hline $\begin{array}{l}\text { Miller et al, } \\
1996\end{array}$ & $\begin{array}{l}\text { Tire derived Fuel, } \\
\text { and Natural gas }\end{array}$ & NA & $<.25$ in & $\begin{array}{l}1260^{\circ} \mathrm{C} \\
-820^{\circ} \mathrm{C}\end{array}$ & NA & YES & $63 \%$ & $\begin{array}{l}\text { TDF can be used } \\
\text { successfully as a reburn } \\
\text { fuel }\end{array}$ \\
\hline
\end{tabular}

Table 1.1: A quick overview of some of the selected works on co-firing. 


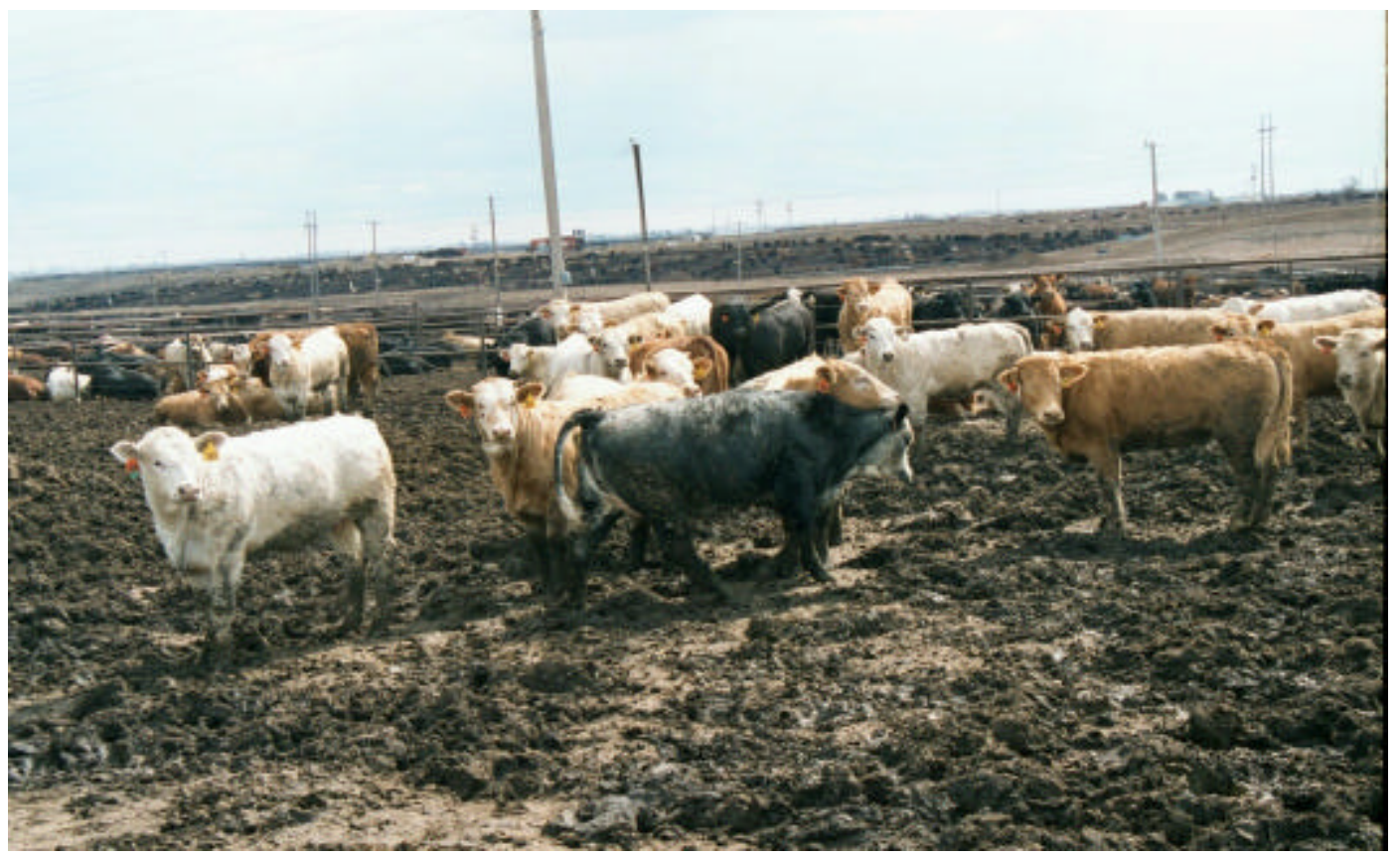

Figure 1.1: Cattle in a Feedlot

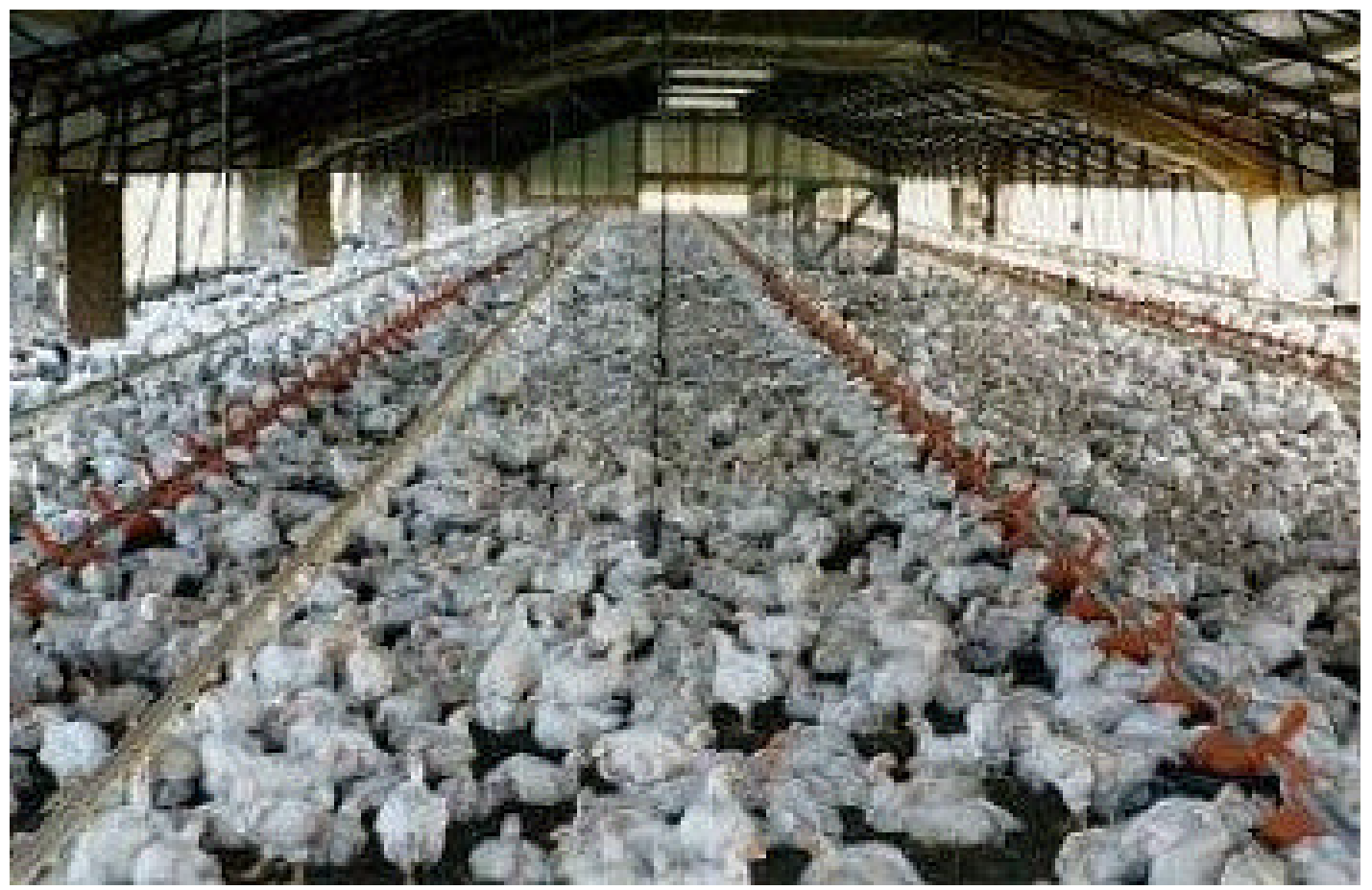

Figure 1.2: Broiler House 


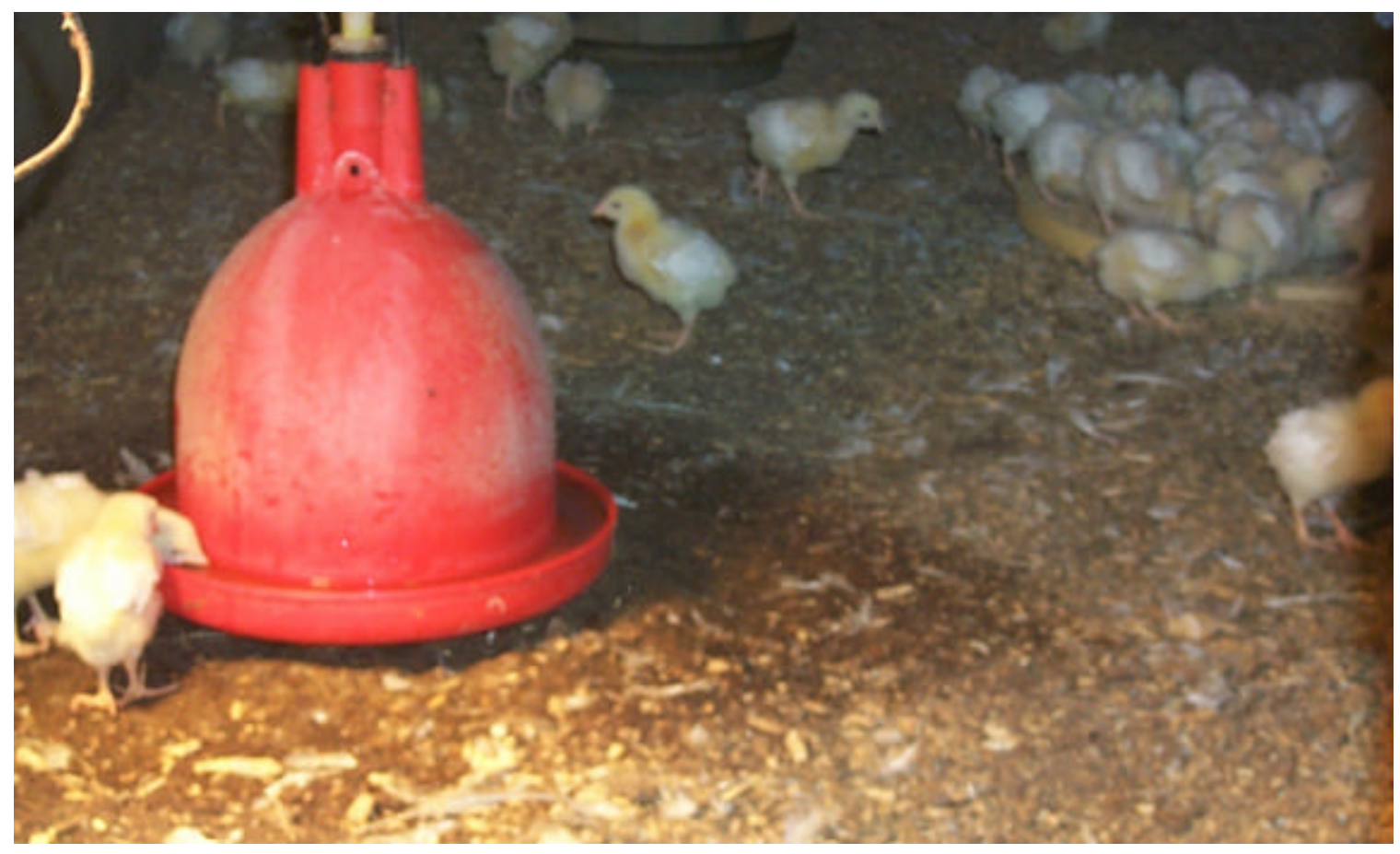

Figure 1.3: Cakeout Litter from Broiler House

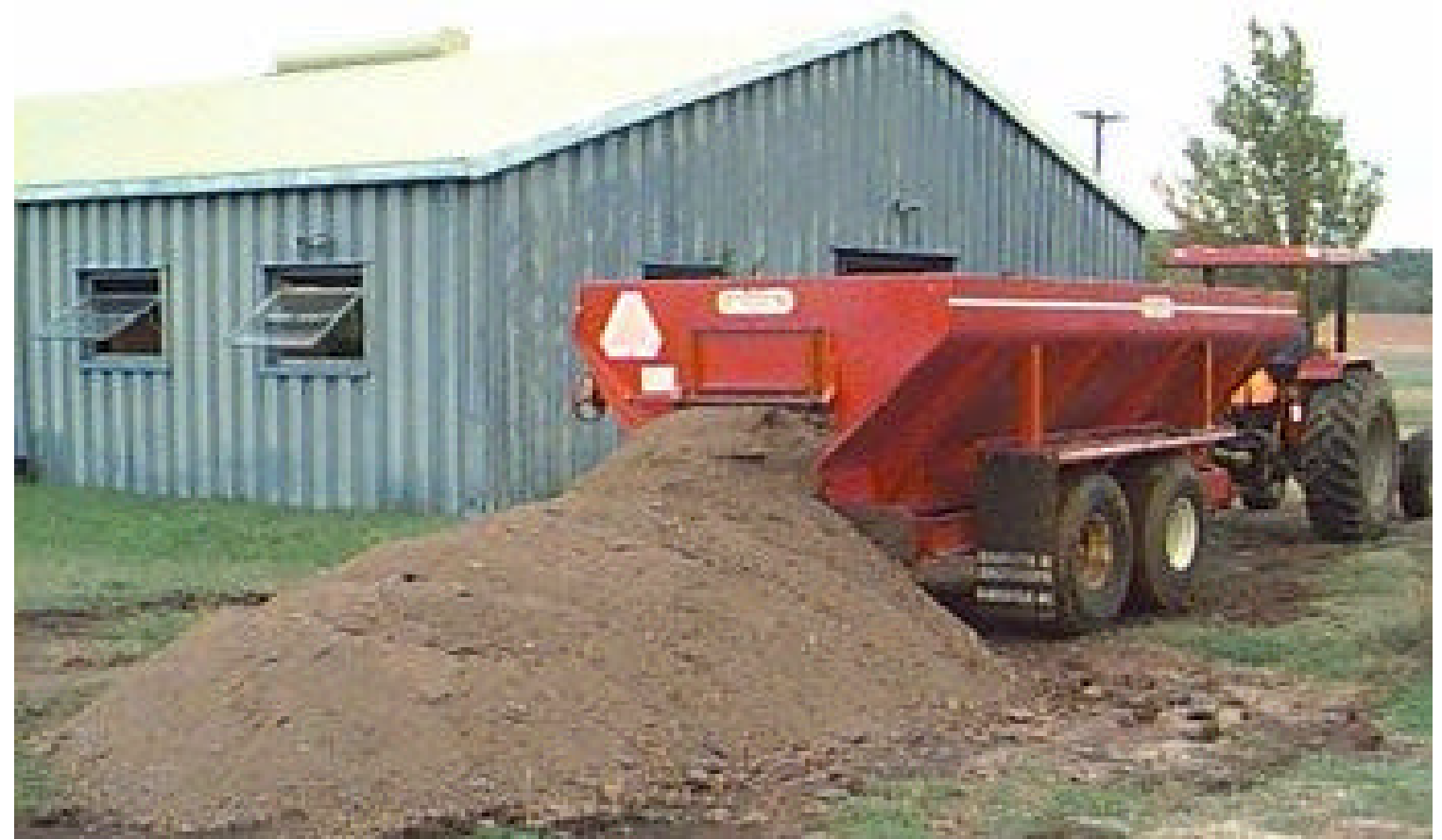

Figure 1.4 Litter from Broiler House 


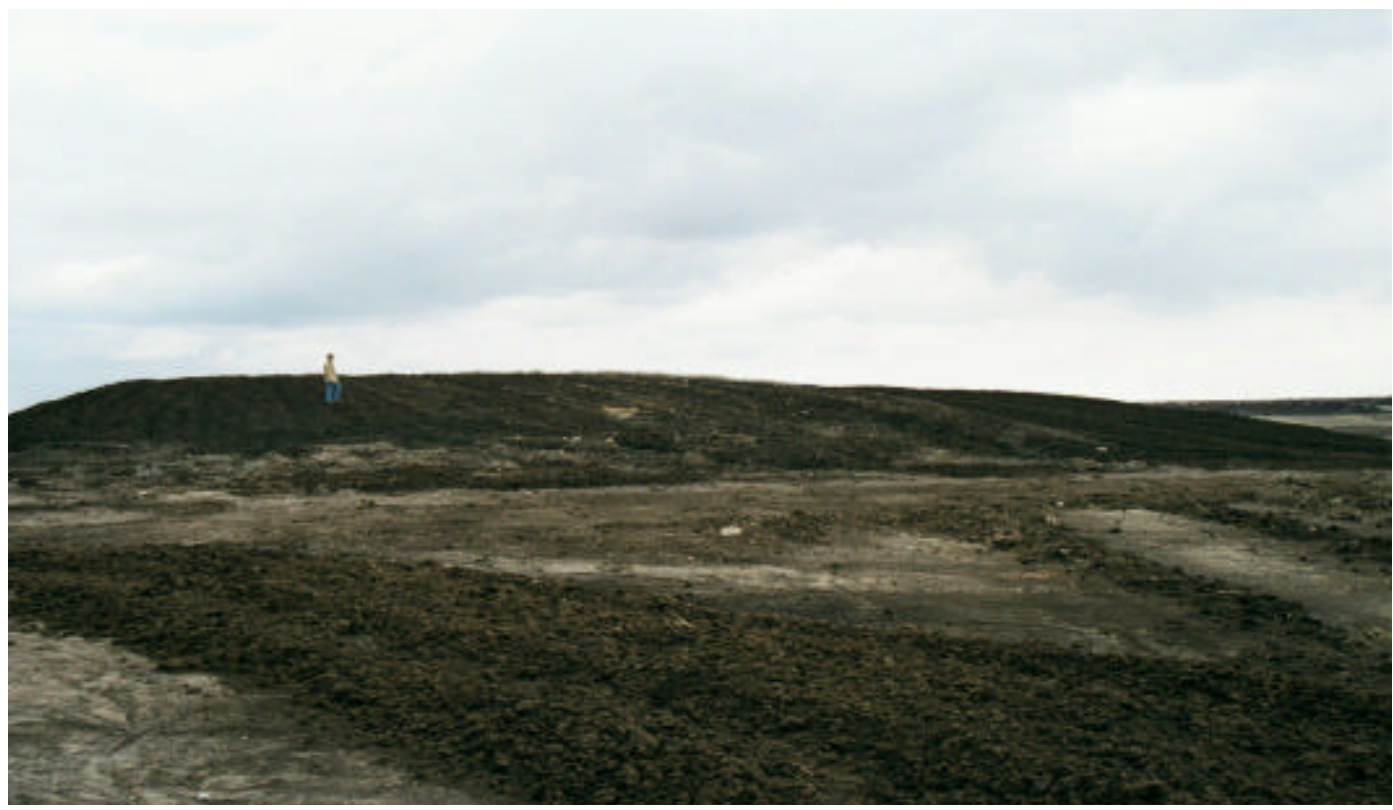

Figure 1.5: Manure Stockpile 


\section{Executive Summary}

Since 1978, the average number of animal units and hence animal waste has increased by $56 \%$ (cattle) and $176 \%$ (poultry litter). Large concentrated animal feeding operations (CAFO) have expanded all over the country including Texas. The Texas Panhandle region covering adjacent areas of Oklahoma and New Mexico is the largest cattle feeding region in the nation, producing about 7.2 million fed cattle annually, $32 \%$ of the fed cattle produced and slaughtered in the U.S., and contributing $\$ 14$ billion per year to the regional economy. The cattle feeding industry in the Texas Panhandle area is growing at the rate of approximately 100,000 head of feedlot capacity per year. The cattle feedlot industry is a major industry in several other major farming areas of the United States. Each animal fed leaves approximately one ton of collectable manure containing 35\% moisture and 65\% solids (combustible and ash). Broiler producers under contract from poultry integrators raise birds for slaughter in broiler houses that may contain 10,000 to 30,000 birds per house. Manure excreted by the birds is mixed with feathers, feed, water, and bedding material. In the USA alone there were 8 billion heads produced for slaughter. With an average litter production of $0.20 \mathrm{lb}$ per day, the poultry waste produced is estimated to be approximately 15 million tons per year nationwide, while about 600,000 tons of litter were generated in Texas in 1998. About 110 million tons of cattle manure (Feedlot Biomass, FB) and poultry manure (Litter Biomass, LB) are produced annually on a dry matter basis. In Texas alone, 10 million dry tons of livestock and poultry waste are produced. In many cases, the production of manure is in excess of what can be applied to farmland. The stock piled waste poses economic and environmental liabilities. The animal bio-waste from CAFO's lead to ground water contamination, and air pollution problems with the release of $\mathrm{CH}_{4}$ (a greenhouse gas), $\mathrm{NH}_{3}$, $\mathrm{H}_{2} \mathrm{~S}$, amides, volatile organic acids, mercaptans, esters, and other chemicals. The $\mathrm{CH}_{4}$ emissions from stored animal waste account for about $8 \%$ of U.S. greenhouse gas methane emissions.

Previous attempts to utilize FB as a solitary fuel met with only limited success due to the high ash and moisture of biomass and its inconsistent properties. Thus, a co-firing technology is proposed where FB and LB are ground, mixed with coal, and then fired in existing pulverized coal fired boiler burner facilities. The coal's higher BTU content enables the low quality FB and LB to burn. The overall objective of the present work is to address the research aspects of combustion of $\mathrm{FB}$ and $\mathrm{LB}$ with coal and undertake an inter-disciplinary program to generate a data base on i) physical and chemical properties of FB, LB, and CFB and CLB fuels, ii) co-firing manure with coal in a pulverized fuel (pf) fired boiler burner and a fixed bed reactor (which simulates stoker firing), and iii) optimize the operating parameters for maximum combustion efficiency and minimum emission of pollutants $\left(\mathrm{NO}_{\mathrm{x}}\right.$ and $\mathrm{SO}_{\mathrm{x}}$ ).

This report describes in detail the methodology of fuel collection, fuel characteristics of the FB, its relation to ration fed, changes in fuel characteristics due to composting, fuel properties, data on co-firing generated by $30 \mathrm{~kW}(100,000 \mathrm{BTU} / \mathrm{hr}$ ) A\&M pulverized fuel (pf) fired Boiler burner facility, and numerical results obtained with a 3 mixture fraction based turbulent combustion code.

Fuel Properties: Samples have been collected from feedlots with a flyash surface, (named as advanced feedlot biomass, AFB) and fuel characterization is being conducted to determine what the effect of a flyash surface is. Samples are also being collected in an effort to produce low phosphorus feedlot manure. Only preliminary samples are available from both of these studies. The ash \% in AFB is $22 \%$ while for FB collected soil surfaced feedlot is $43 \%$. A new grinder has also been obtained to make grinding of fuel samples more economical, and different methods of grinding are being investigated to determine the optimal procedure. Litter from the Brazos Valley has been collected and analyzed, with the samples showing little variation.

Cofiring Data:. Experiments were performed in the extended boiler burner with coal, FB 90:10 blend, and LB 90:10 blend. The CO in the modified boiler burner ( i.e with extended burner section) is of the order 100- $400 \mathrm{ppm}$ while for the unmodified shorter burner) it is of the order of 5000-20000 ppm at $20 \%$ excess air with the larger value typically for coal: biomass blends. Similarly, the NO in the modified boiler burner 400-450 ppm while for the unmodified shorter burner) it is of the order of 250$350 \mathrm{ppm}$ at $20 \%$ excess air with the smaller value typically for coal: biomass blends; the results for the modified reactor show that there is no change in the NO emissions when switching to a 90:10 coal:animal biomass fuel blend. This is a surprising result as the animal biomass blended fuels can contain 8-20 percent more fuel nitrogen than coal. It is believed that the rapid release of volatiles from the biomass, combined with the release of the biomass fuel nitrogen in the form of $\mathrm{NH}_{3}$ instead of $\mathrm{HCN}$ is responsible for keeping the NO levels similar. Thus the fuel $\mathrm{N}$ conversion efficiency is $20 \%$ for coal:FB and coal:LB blends while for coal it is $28 \%$. The burnt mass fractions were found to be similar for both coal and the blended 
fuels. The reburn experiments with coal, coal:LB and LB indicate a reduction of almost $80 \%$ NOx for LB while for coal it is only $40 \%$

Fixed Bed Studies: Since crushing costs of biomass fuels may be prohibitive, stoker firing may be cost effective; in order simulate such a firing, future work will investigate the performance of a gasifier when fired with larger sized coal and biomass. A fixed bed gasifer, has been completely built, and preliminary temperature studies have been conducted. During the preliminary studies, a lot of tar was produced, which limits the use of the existing gas analyzers. An alternate method of gas sampling is being pursued. Simulation of fixed bed combustion is also being conducted. A set of fundamental equations to describe the gasifier has been, developed, but no results have been obtained yet due to problems with the energy balance equations.

Modeling Studies for Boiler burner: Computer simulations were performed using the PCGC -2 code supplied by BYU and modified by A\&M with three mixture fractions for handling animal based biomass fuels in order to include an improved moisture model for handling wet fuels and phosphorus oxidation. The modified PCGC code include; a) gradual moisture release, b) heterogeneous oxidation to $\mathrm{CO} 2$, c) reduction reactions with $\mathrm{CO} 2$ and $\mathrm{H} 2 \mathrm{O}$, and d) the oxidation phosphorus. Plans have been made to examine the effect of different boundary conditions, and conduct parametric studies.

Economic Analyses: In the case of higher ash and moisture biomass, the fuel cost savings will be reduced, due to increased transportation costs. A spreadsheet program was created to analyze the fuel savings for a variety of different moisture levels, ash levels, and power plant operating parameters. 


\section{Project Tasks, Results, and Discussion}

\subsection{Task 1: Fundamental experiments on fuel characterization.}

\section{Properties of Fly ash manure.}

The ultimate and proximate analyses and heating values of raw, partially (PC) and finished (FC) composted manure collected from soil-surfaced feedlot were reported previously [Sweeten et al., 2000, Annamalai et al, 2001]. The N content of PC and coal are shown in Figure 3.1.1. The properties of manure collected from a flyash surface, were analyzed to determine the effect of collection from a fly ash surface on fuel properties. Manure from the TAES Bushland Environmental Feedyard (feedyard C) has consistently shown to have manure that is very low in ash content when it is scraped from fly ash surfaced pens. For this project manure was scraped from a flyash surface pen (environmental pen 11) and from a soil surface pen (environmental pen 1), and partially composted. The manure was placed in conical shaped piles approximately 4' in height and 10' in diameter on September 7 and 12, 2001. The manure was turned on September 21,28, and Oct 10, 2001. Water was added to help the compost process on September 28, 2001 (300 gallons of water for manure from pen 11 and 200 gallons of water for manure from pen 1).

As per the request of DOE in Pittsburgh, $1000 \mathrm{lbs}$ of partially composted manure from the flyash surface, and $500 \mathrm{lbs}$ of partially composted manure from the soil surface pen were dried down in the USDA greenhouse in Bushland, Texas. As per the request of Texas A\&M, $300 \mathrm{lbs}$ of partially composted manure from the flyash surface, and $300 \mathrm{lbs}$ of partially composted manure from the soil surface was dried down in the USDA greenhouse in Bushland, Texas. The following tables show the \% moisture (w.b.) and \% ash content for project VI. Each sample in the table below is a composite sample of 5 sub-samples taken about 12" from the surface and prepared by Kevin Heflin. The results are shown in table 3.1.1.

Table 3.1.1: Properties of manure collected from a fly ash surface.

TAES Bushland Environmental Feedyard Manure

Partially composted cattle manure from fly ash and soil surface pens currently drying in the USDA greenhouse Bushland, TX

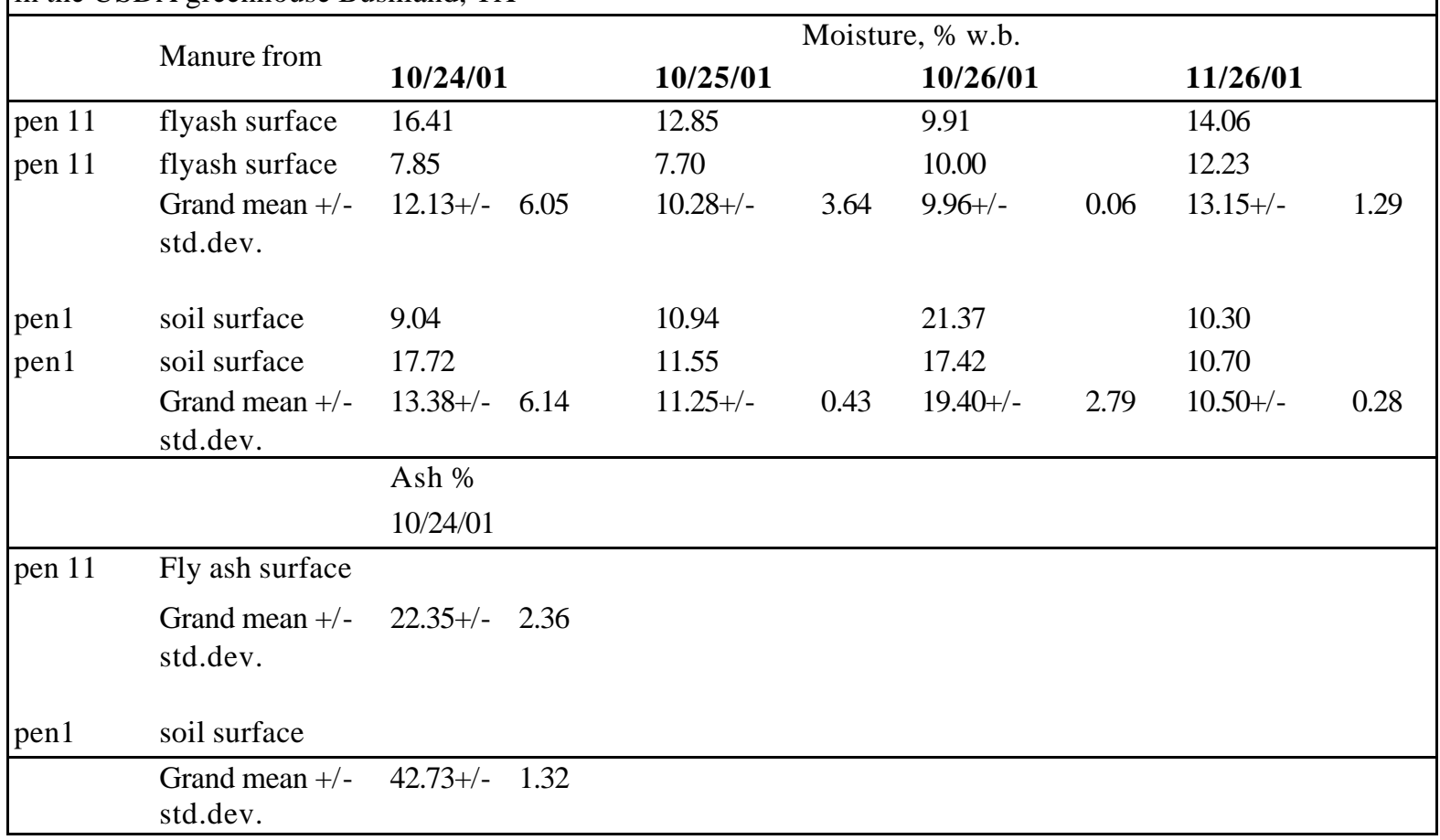




\section{Phosphorous content in Feedlot manure}

This project is an attempt to reduce phosphorus levels in manure/compost by and thus further reduce the fouling content when feedlot biomass is used in the co-firing study. By manipulating cattle feed rations, manure phosphorus levels should be reduced [Heflin, K]. Two types of manure were produced for this project, low phosphorus (LP, obtained with low P ration, analysis in progress) and high phosphorus (HP, analysis in progress). The HP manure is the typical or normal manure that is excreted from feedlot cattle. This study consisted of 75 cattle equally divided into 6 randomly selected fly ash surfaced feedpens. All 75 cattle were fed for 31 days, then 43 cattle were removed for slaughter (due to their large size) and the remaining 32 cattle were fed for an additional 20 days. The TAES/USDA feedyard in Bushland Texas was the location for this study and pens 10, 13, 14 contained cattle on the LP ration and pens 11, 12, 13 contained cattle on the HP ration.

Once a week, a composite manure sample was taken for each of the two treatments. The samples were comprised of 9 sub-samples, three from each pen in the treatment group. Ration samples were taken 5 times per week consisting of three sub-samples from each feed bunk and composted into 1 sample for each treatment. Manure was removed from the feedpens and placed in the manure storage area at Bushland to begin the composting process. On November 7\&8, 2001, $5800 \mathrm{lbs}$ of HP manure from pens 11, 12, and 15, and $7020 \mathrm{lbs}$ of LP manure from pens 10, 13, and 14 was harvested for the co-fire project. The manure from each treatment was placed in a separate windrow to start the composting process immediately. Water was added on 11/19/01 to both compost piles in the amount of 300 gallons for the LP compost and 250 gallons for the HP compost. Water was also added on 12/7/01 in the amount of 375 gallons for the LP compost and 225 gallons for the HP compost. Temperature and moisture contents were also monitored and appear in the tables below. Temperatures were recorded in ${ }^{\circ} \mathrm{F}$ at 24 inches from the surface at middle location and moisture samples were dried down at $100{ }^{\circ} \mathrm{C}$ for 24 hours in a drying oven. The information on the composting process is detailed in Tables 3.1.2 and 3.1.3.

Table 3.1.2: Temperatures during composting

TAES Bushland Environmental Feedyard Manure Project VII

Cattle manure that is currently being composted from fly ash surfaced pens 10-15

Temperature $\mathrm{F}$

\begin{tabular}{|c|c|c|c|c|c|c|c|c|c|}
\hline & Date & $11 / 19 / 01$ & & $11 / 30 / 01$ & & $12 / 7 / 01$ & & $12 / 10 / 01$ & \\
\hline LP Compost & $\begin{array}{l}\text { Grand mean } \\
+/- \text { std.dev. }\end{array}$ & $102.67+/-$ & 1.15 & $119.43+/-$ & 11.86 & $109.69+/-$ & 8.45 & $105.67+/-$ & 7.87 \\
\hline HP Compost & $\begin{array}{l}\text { Grand mean } \\
+/- \text { std.dev. }\end{array}$ & $90.67+/-$ & 8.08 & $127.57+/-$ & 14.77 & $120.00+/-$ & 8.02 & $123.33+/-$ & 6.38 \\
\hline
\end{tabular}

Table 3.1.3: Moisture levels during composting

TAES Bushland Environmental Feedyard Manure Project VII

Cattle manure that is currently being composted from fly ash surfaced pens 10-15

\begin{tabular}{|c|c|c|c|c|c|}
\hline & & $11 / 19 / 01$ & $12 / 3 / 01$ & $12 / 7 / 01$ & $12 / 10 / 01$ \\
\hline LP Compost & $\begin{array}{l}\text { Grand mean } \\
+/- \text { std.dev. }\end{array}$ & Pending & Pending & Pending & Pending \\
\hline HP Compost & $\begin{array}{l}\text { Grand mean } \\
+/- \text { std.dev. }\end{array}$ & Pending & Pending & Pending & Pending \\
\hline
\end{tabular}




\section{Litter Biomass}

The ultimate, proximate and heating values of cake out litter are presented in Table 3.1.4.

Figure 3.1.1 compares the $\mathrm{N}$ content of litter with coal and FB. It is seen that litter has the highest $\mathrm{N}$ content compared to coal and FB.

During this period, clean-out litter was collected for the fuel analysis on litter biomass. A poultry farm under contract with a large poultry broiler integrator in the Brazos River valley was contacted and clean-out litter from one of the barns housing 28,000 broilers was obtained. Representative samples were collected from the litter piles and then combined to get a 5-pound $(2 \mathrm{~kg})$ composite sample. The sample was delivered to Dr. Annamalai's laboratory for further processing and fuel analysis.

Another set of 3 composite samples from the same clean-out litter piles were collected, ground and sent to the Huffman Laboratories Inc., Golden, Colorado to be analyzed for ultimate, proximate, heat of combustion, and ash (mineral). The analysis results are presented in tables' 3.1.3 and 3.1.4. Table 1 shows the results on as received basis and on a dry basis. Means and standard deviations of parameters are also presented. As indicated by small standard deviations, the values for all parameters exhibited little variation across samples. Average moisture content of the clean-out litter samples was $11.18 \%$. Based upon this mean value, the adjusted mean values (from as received to dry basis) of all the parameters are shown in Table 3.1.3. Ash or mineral analyses for 11 parameters are presented in Table 3.1.4. Values of each parameter were similar to one another, as indicated by the small standard deviations for each parameter. Mean values of the mineral content are also presented in this table.

The next step is to collect pure excreta from the broilers. We have identified an experimental laboratory in the Poultry Science Department at Texas A\&M for securing excreta from broiler chicken under trials. Once the excreta is collected, it will be dried, ground and sent to the Huffman Laboratories for all of the above mentioned analyses conducted on the clean-out broiler litter. 
Table 3.1.4: Ultimate and proximate analysis of broiler litter (Clean-out litter)

\begin{tabular}{|c|c|c|c|c|c|c|c|c|}
\hline Parameter & $\begin{array}{l}\text { Sample } 1 \\
\text { As received }\end{array}$ & Dry basis & $\begin{array}{l}\text { Sample } 2 \\
\text { As received }\end{array}$ & Dry basis & $\begin{array}{l}\text { Sample } 3 \\
\text { As received }\end{array}$ & Dry basis & $\begin{array}{l}\text { Mean (S.D) } \\
\text { As received }\end{array}$ & Dry basis \\
\hline Moisture*, \% & 11.05 & ------ & 10.83 & ------ & 11.65 & $\begin{array}{ll}----- \\
\end{array}$ & 11.18 & ----- \\
\hline Carbon, Fixed $\%$ & 14.3 & 15.9 & 14.41 & 16.16 & 14.65 & 16.58 & $14.45(0.18)$ & $16.21(0.35)$ \\
\hline Hydrogen, $\%$ & 5.62 & 6.25 & 5.67 & 6.36 & 5.74 & 6.50 & $\begin{array}{ll}5.67 \quad(0.06) \\
\end{array}$ & $6.37(0.12)$ \\
\hline Nitrogen, $\%$ & 3.83 & 4.26 & 3.53 & 3.95 & 3.33 & 3.77 & $3.56 \quad(0.25)$ & $4.00(0.24)$ \\
\hline Sulfur, $\%$ & 0.63 & 0.70 & 0.60 & 0.67 & 0.62 & 0.70 & $0.61 \quad(0.01)$ & $0.69(0.02)$ \\
\hline Ash, \% & 14.41 & 16.02 & 14.14 & 15.86 & 14.61 & 16.54 & $14.38(0.23)$ & $16.14(0.35)$ \\
\hline Oxygen (diff.) $\%$ & 40.07 & 44.54 & 40.63 & 45.57 & 40.58 & 45.93 & $40.42(0.31)$ & $45.35(0.72)$ \\
\hline Volatiles, $\%$ & 61.24 & 68.08 & 60.62 & 67.98 & 59.09 & 66.88 & $60.31(1.10)$ & $67.65(0.67)$ \\
\hline Total Carbon, $\%$ & 35.44 & 39.39 & 35.43 & 39.73 & 35.12 & 39.75 & $35.33(0.18)$ & $39.63(0.20)$ \\
\hline $\begin{array}{l}\text { Heating values } \\
\text { (BTU/Lb)** }\end{array}$ & 6161 & 6849 & 6177 & 6928 & 6036 & 6832 & $6124 \quad(77)$ & $6870 \quad(51)$ \\
\hline
\end{tabular}

*Measured from 1 gram of sub sample by drying in air @ 105 deg. C for one hour.

**heating values corrected for Sulfur content (ASTM D2015) 
Table 3.1.5: Ash (Mineral) analysis of broiler litter (Clean-out Litter)

\begin{tabular}{|c|c|c|c|c|}
\hline Parameter & Sample 1 & Sample 2 & Sample 3 & Mean (S.D) \\
\hline $\begin{array}{l}\text { Aluminum, } \% \text { as } \\
\mathrm{AL}_{2} \mathrm{O}_{3}\end{array}$ & 1.34 & 1.24 & 1.22 & $1.23 \quad(0.05)$ \\
\hline Calcium, $\%$ as $\mathrm{CaO}$ & 20.84 & 21.33 & 22.35 & $21.50(0.63)$ \\
\hline Iron, $\%$ as $\mathrm{Fe}_{2} \mathrm{O}_{3}$ & 0.99 & 1.01 & 1.18 & $1.06 \quad(0.08)$ \\
\hline $\begin{array}{l}\text { Magnesium, \% as } \\
\mathrm{MgO}\end{array}$ & 5.77 & 5.89 & 6.06 & $5.9 \quad(0.12)$ \\
\hline $\begin{array}{l}\text { Manganese, } \% \text { as } \\
\mathrm{MnO}\end{array}$ & 0.22 & 0.21 & 0.23 & $0.22 \quad(0.008)$ \\
\hline Phosphorous, $\% \mathrm{P}_{2} \mathrm{O}_{5}$ & 24.07 & 25.08 & 26.22 & $25.12(0.88)$ \\
\hline Potassium, $\%$ as $\mathrm{K}_{2} \mathrm{O}$ & 15.62 & 17.18 & 16.73 & $16.51(0.65)$ \\
\hline Silicone, $\%$ as $\mathrm{SiO}_{2}$ & 6.87 & 6.18 & 5.98 & $6.34 \quad(0.38)$ \\
\hline Sodium, $\%$ as $\mathrm{Na}_{2} \mathrm{O}$ & 6.16 & 6.69 & 6.72 & $6.52 \quad(0.26)$ \\
\hline Sulfur, $\% \mathrm{SO}_{3}$ & 7.29 & 7.11 & 7.31 & $7.23 \quad(0.09)$ \\
\hline Titanium, $\%$ as $\mathrm{TiO}_{2}$ & 0.10 & 0.10 & 0.10 & $0.10 \quad(0)$ \\
\hline
\end{tabular}

Table 3.1.6: Operating conditions for TGA

\begin{tabular}{|l|l|}
\hline Heating Rate & $10 \mathrm{C} / \mathrm{min}$ \\
\hline Sample Size & $25 \mathrm{mg}$ \\
\hline Purge gas & $80 \mathrm{~cm}^{3} / \mathrm{min}$ \\
\hline Fuels tested & $\begin{array}{l}\text { Coal, FB, Coal:FB Blend, } \\
\text { LB, Coal:LB Blend }\end{array}$ \\
\hline Size range & $\begin{array}{l}\text { full, }<45,45-75, \text { and }>75 \\
\mu \mathrm{m}\end{array}$ \\
\hline
\end{tabular}




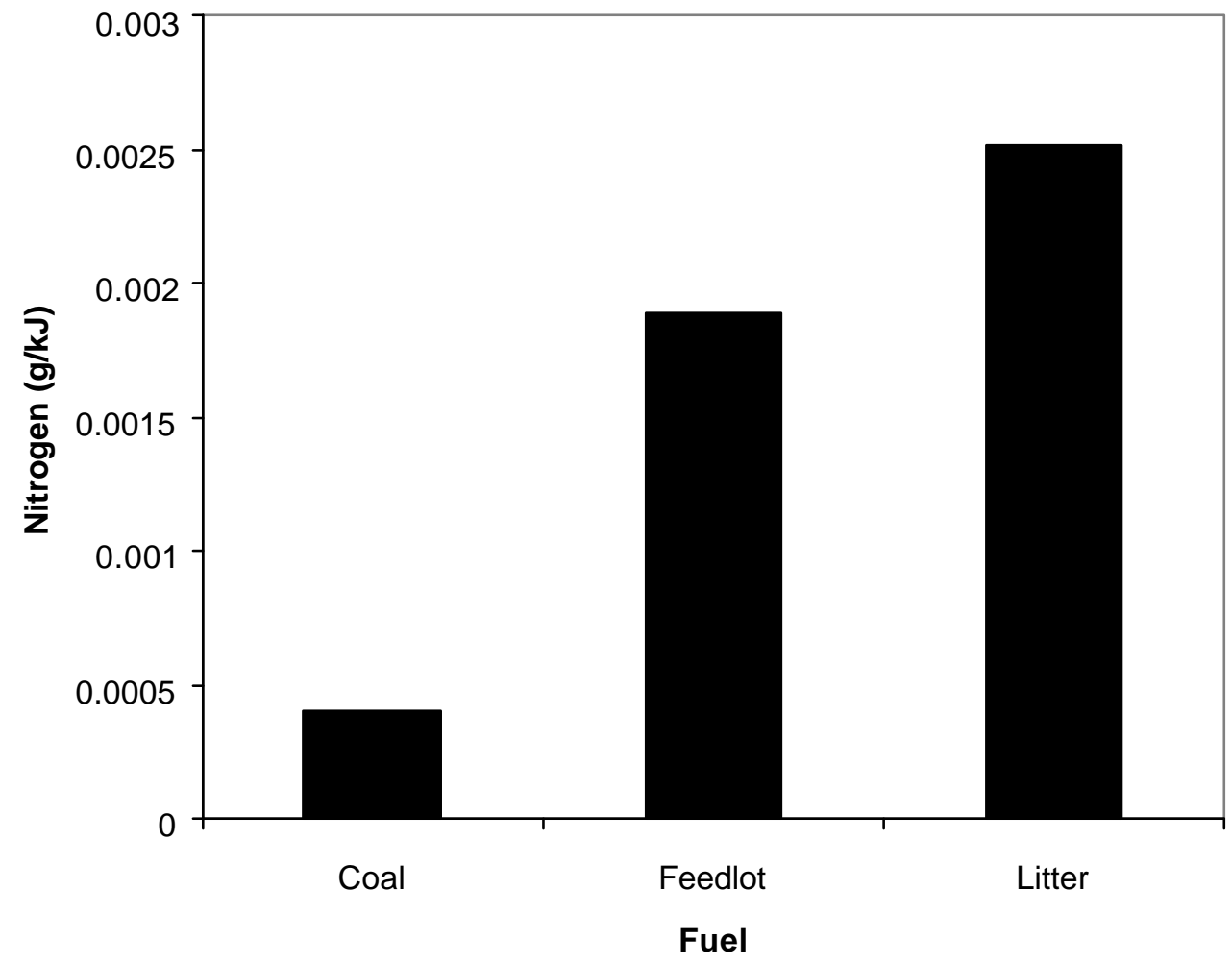

Figure 3.1.1. Comparison of N Contents on heat basis for various fuels 


\section{TGA Analyses in N2 and Air}

\section{Experimental Set up:}

The TGA analyzer used was a TA instruments 2960 Simultaneous DTA/TGA. A schematic of the setup is shown in Figure 3.1.2. The unit is equipped with a digital scale capable of measuring up to $350 \mathrm{mg}$ to with $1 \%$ accuracy, including the alumina sample cups. The heater is capable of variable heating rates up to $100^{\circ} \mathrm{C} / \mathrm{min}$ to $1000^{\circ} \mathrm{C}$, and air, oxygen, helium, or argon purge gas can be applied at rates up to 80 $\mathrm{cm}^{3} / \mathrm{min}$. The thermocouple was built into the metal bar supporting the sample cup holder. Procedure:

Coal, LB, and FB were selected for TGA analyses in nitrogen and air to determine the devolatization characteristics and the ignition characteristics. The full size distribution was used for all for all of the TGA traces presented in the report. The samples were pulverized, characterized, and sieved using a sieve shaker and divided into three size groups: $d_{p}<45 \mu \mathrm{m}, 45<d_{p}<75 \mu m$ and $d_{p}>75 \mu m$, and an unsieved fourth group containing a distributed size as fired in a boiler burner. The feedlot biomass has a greater ash content, lower carbon content and a lower heating value than coal. In contrast with typical feedlot biomass fuels, this batch of biomass fuels has lower moisture content.

Samples of $25 \mathrm{mg}$ of specified size group were loaded into the TGA analyzer and the controller was programmed to the heat the sample from the ambient temperature at the rate of $10^{\circ} \mathrm{C} / \mathrm{min}$ to $1000{ }^{\circ} \mathrm{C}$. Nitrogen was used as the purge gas. The TGA analyzer then recorded the mass-temperature vs. time traces. The analysis was repeated for the three size groups and finally on the unsieved fuels for coal, FB, and a 90:10 Coal FB blend. The operating conditions are summarized in Table 3.1.6. Under identical conditions experiments were repeated using air as purging gas.

The actual mass vs. temperature trace with $\mathrm{N}_{2}$ purge gas is shown in Figure3.1.3 and while in air are shown in Figures 3.1.4 to 3.1.6. It is noted from Figure 3.1.3 that the moisture loss continues up to $400^{\circ}$ $\mathrm{K}$. The coal is approximately $26 \%$ moisture and $35 \%$ volatile matter, while the biomass is approximately $6 \%$ moisture and 10\% volatile matter). The behavior of the 90:10 blend falls in between the 2 pure fuels, but is closer to the behavior of the coal as the blend contains $90 \%$ coal. In order to compare the pyrolysis characteristics of coal and FB of differing moisture contents, the mass loss is normalized on a dry basis. The TGA traces were used to determine the kinetics of pyrolysis of FB with the parallel reaction model. In this model, it is assumed that the pyrolysis process consists of a series of reactions proceeding in parallel [Anthony, et al, 1974]. Details of determination of mean activation energy $\left(\mathrm{E}_{\mathrm{m}}\right)$ and standard deviation $(\sigma)$ are given elsewhere [Thien et al, 2001, Annamalai et al, 1987b]. Figures 3.1.7 an 3.1.8 present $\mathrm{E}_{\mathrm{m}}$ and $\sigma$. The TGA traces show that the coal will begin to loose volatiles at a lower temperature and at a faster rate than the FB. A comparison of pyrolysis start temperatures is presented in Figure 3.1.9

The curve traces in air were compared to the traces in nitrogen, and the where the curves diverged was defined as the ignition temperature. The determination of the ignition temperature for coal is demonstrated in figure 3.1.4. For all of the coal TGA traces, a definite ignition temperature was obtained, but for FB and LB as shown in figures 3.1.5 and 3.1.6 there was not a clear ignition temperature where the curves sharply diverged from each other. Oxidation of char and volatiles and heat liberation occurs when solid is subjected to heating in the presence of air. Particles in the interior of sample are almost in an adiabatic environment and hence may ignite. The group theory presented elsewhere uses such a hypothesis [Annamalai et al, 1987b]. Such a theory for ignition was used to interpret the data on ignition of coal using TGA traces [Thien et al, 2001]. However this theory does not account for convective heat loss transport of heat associated with volatiles liberated from solid fuels. Since biomass liberates volatiles at lower temperatures compared to coal, there is increased heat loss associated with transport of volatiles away from the interior. Hence the traces in N2 and air appear similar for FB and LB. 


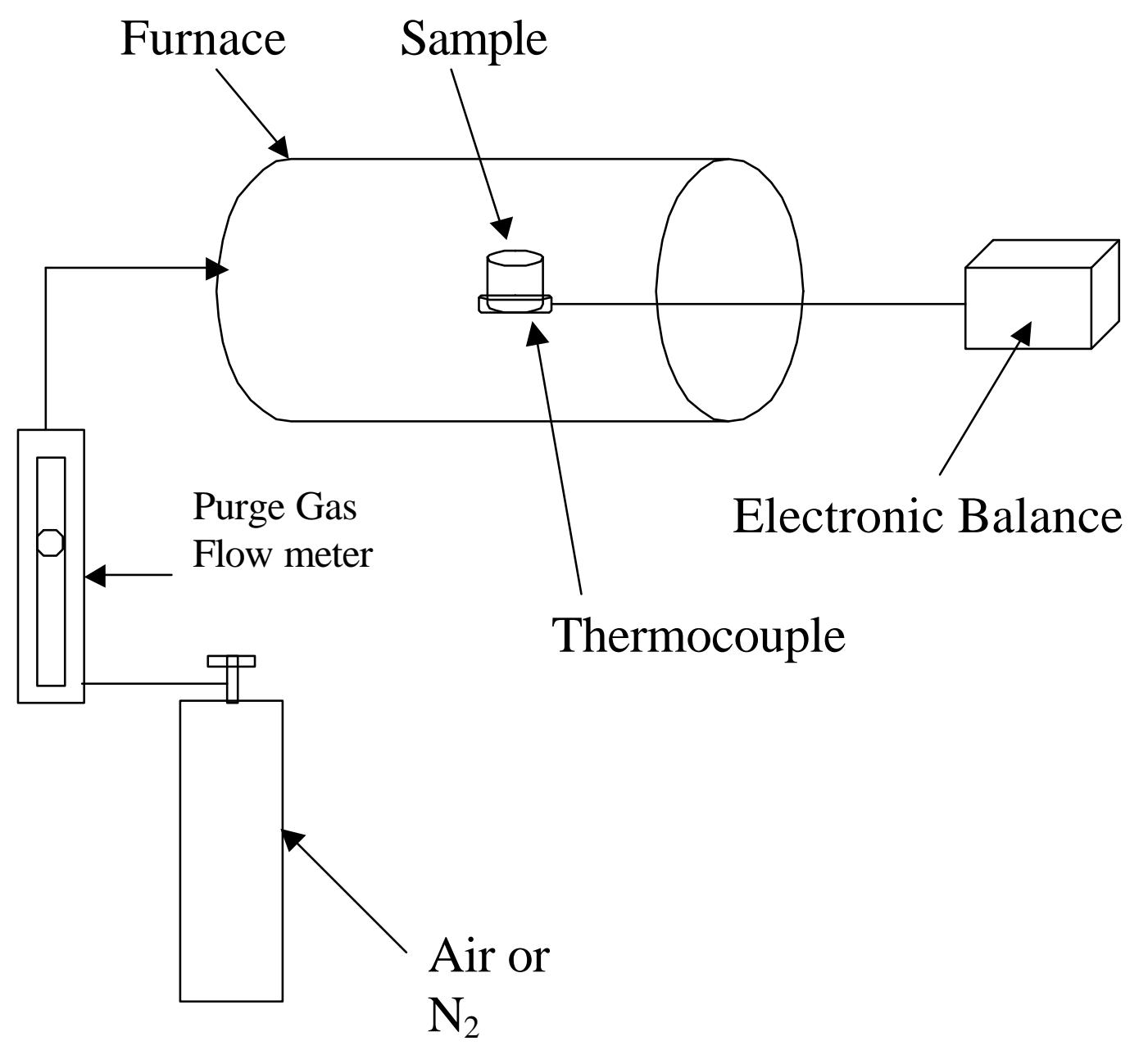

Figure 3.1.2. Schematic of the TGA Set up 


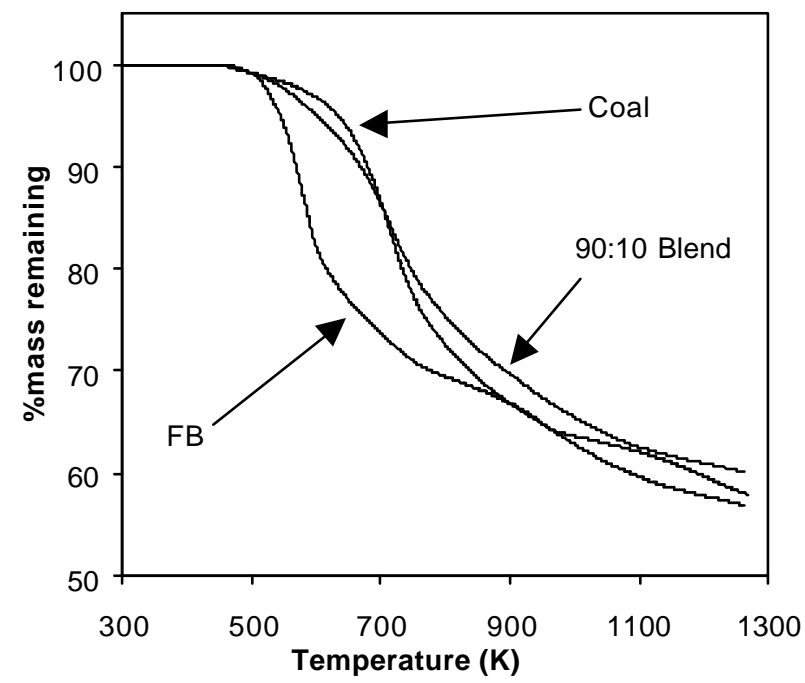

Figure 3.1.3: TGA traces of Coal, FB, and 90:10 FB blend (full size) in nitrogen with moisture loss removed.

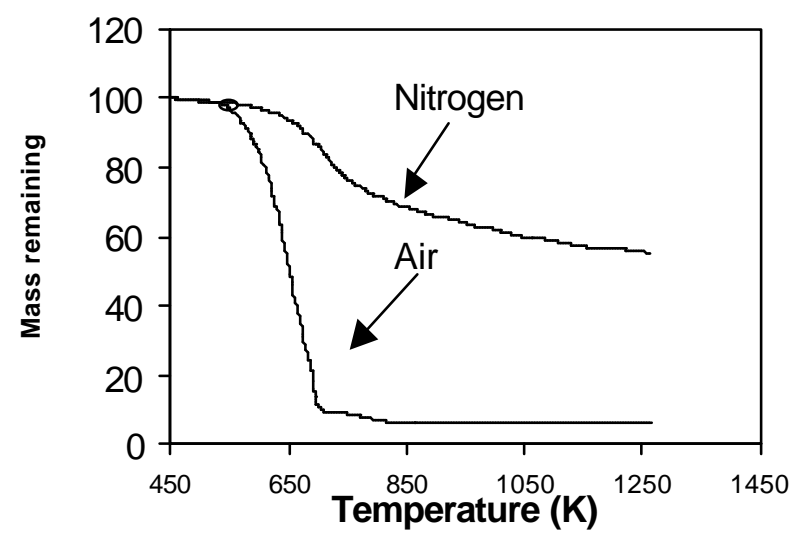

Figure 3.1.4: TGA traces of Coal (full size) in air with moisture loss removed 


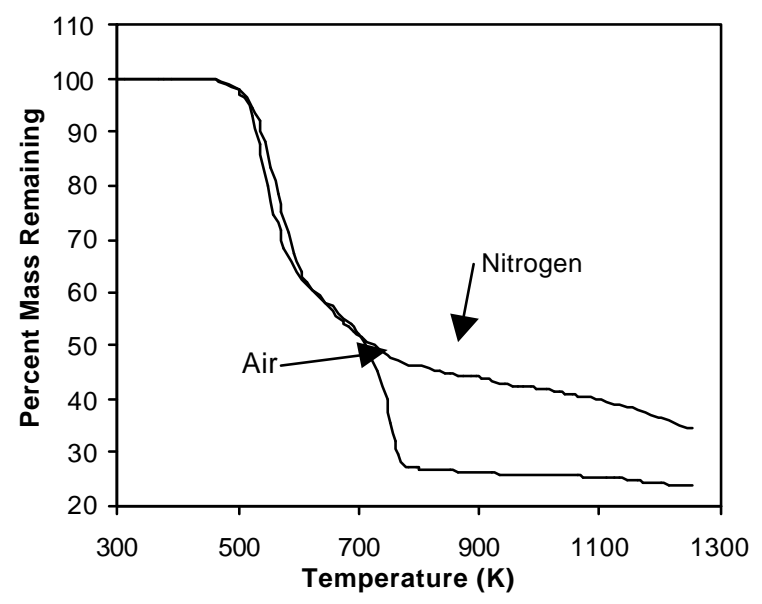

Figure 3.1.5: Litter TGA in air and Nitrogen

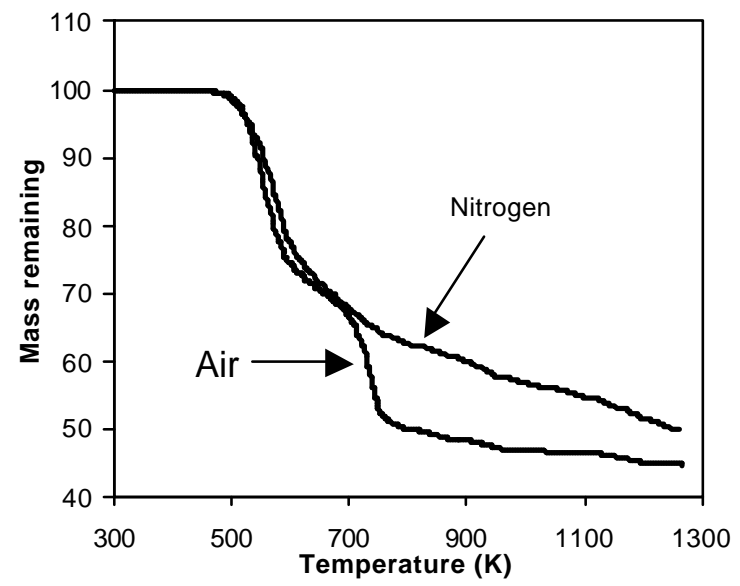

Figure 3.1.6: FB TGA in air and Nitrogen 


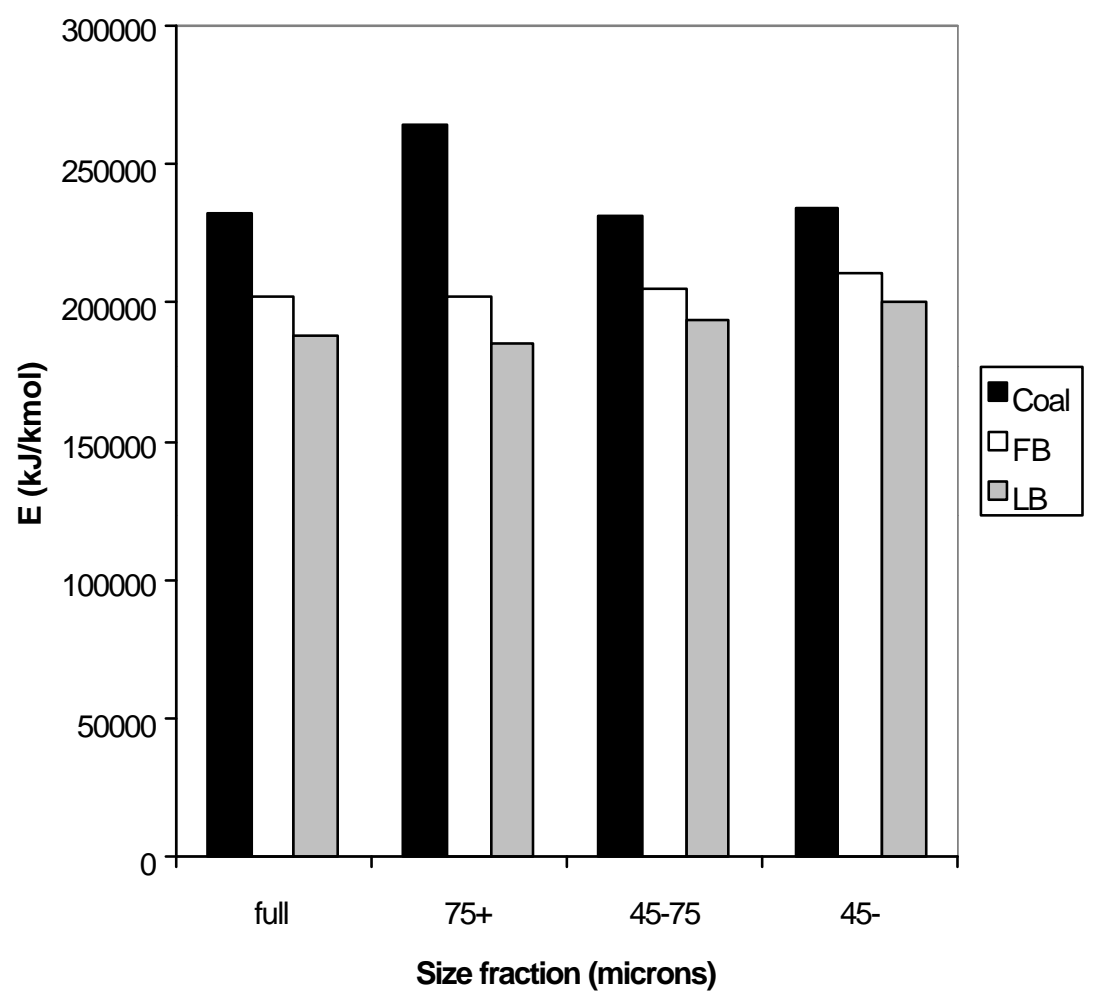

Figure 3.1.7: Mean activation energy for parallel reaction model 


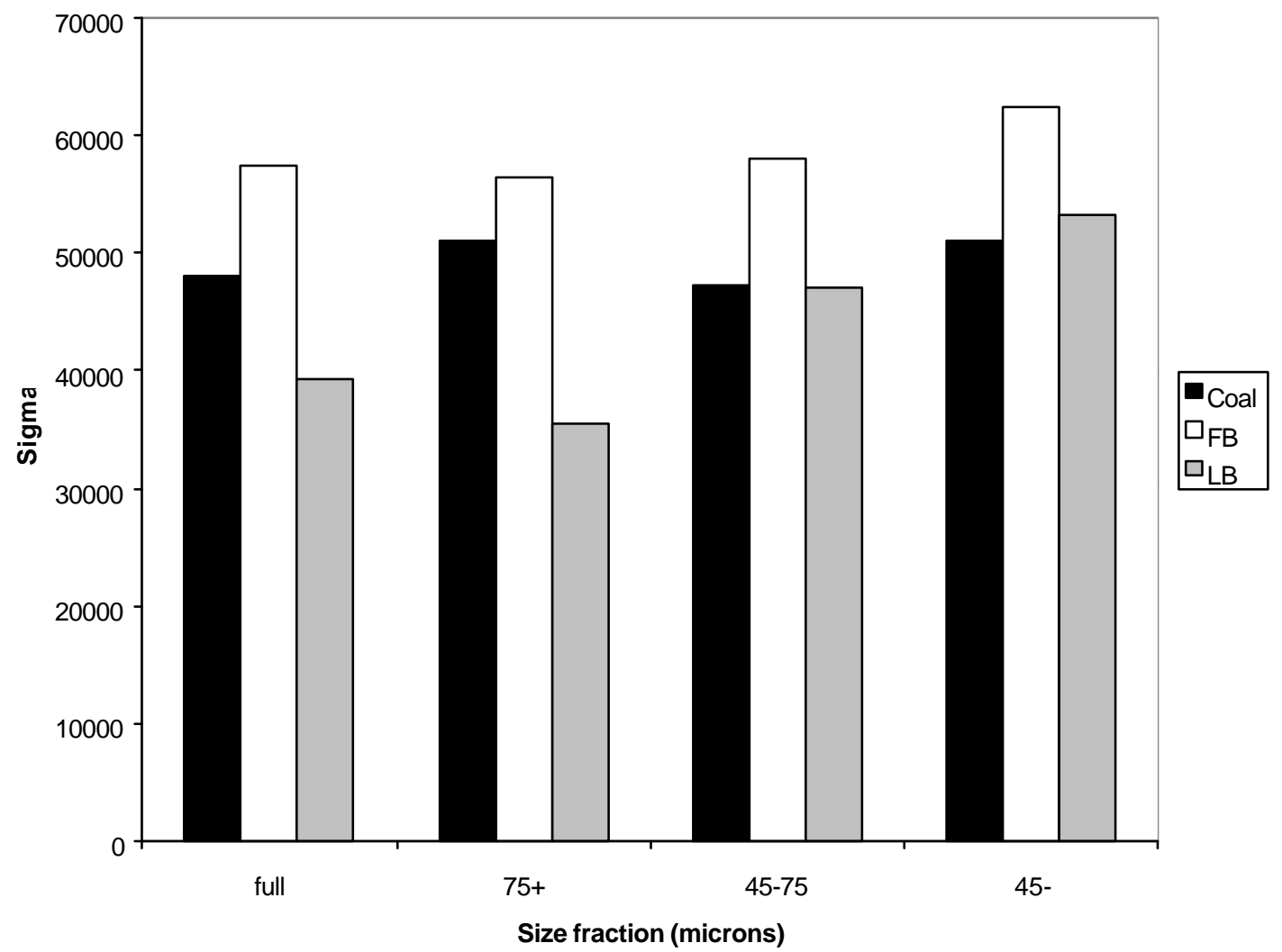

Figure 3.1.8: Standard deviation for parallel reaction model 


\section{Pyrolysis Start Temperatures}

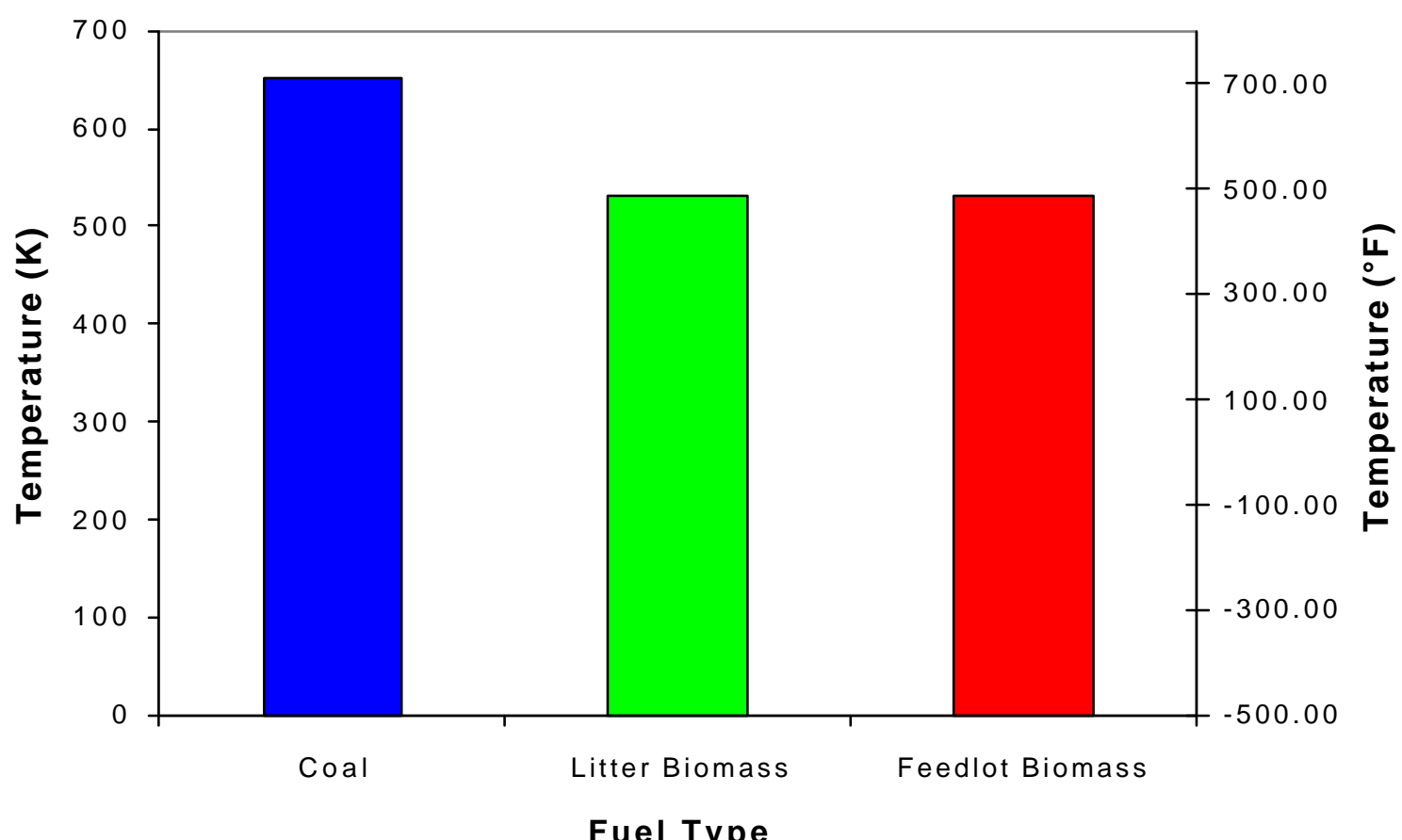

Figure 3.1.9: Comparison of Pyrolysis temperatures 


\section{LB Pyrolysis Parameter Analysis}

To obtain LB pyrolysis rate, TGA was conducted, and variation of LB mass with temperature measured and displayed as solid line in Figure 1. The heating rate for TGA is $10 \mathrm{~K} / \mathrm{min}$. The curve can be divided into three parts: the moisture lose stage from point $\mathrm{A}$ to $\mathrm{B}$, the fast VM loss stage from $\mathrm{B}$ to $\mathrm{C}$, and the slow VM loss stage from $\mathrm{C}$ to D. The fast stage (B to C) is the main stage of VM loss, and we assume it satisfies the following equation:

$$
\frac{1}{m_{v m}} \frac{d m_{v m}}{d t}=-A \exp \left(-\frac{E}{R T}\right)
$$

where $m_{v m}$ is VM $(\mathrm{kg})$ remain in LB, $t$ is time (s), $T$ is temperature $(\mathrm{K}), E$ is activation energy $(\mathrm{J} / \mathrm{kmole}-\mathrm{K}), A$ is exponential coefficient $(1 / \mathrm{s}), R$ is the universal gas constant $(=8315 \mathrm{~J} / \mathrm{kmole}-\mathrm{K}) . A$ and $E$ are obtained by curve fitting from $B$ to $C$ as

$$
A=6 \times 10^{7} 1 / \mathrm{s}, E=8 \times 10^{7} \mathrm{~J} / \mathrm{kmole}-\mathrm{K} .
$$

The dashed curve in Figure 3.1.10 is the curve fitting result. It is noted that the last stage of VM loss (C to D) does not satisfy equation (1) thus curve fitting was not conducted for that part.

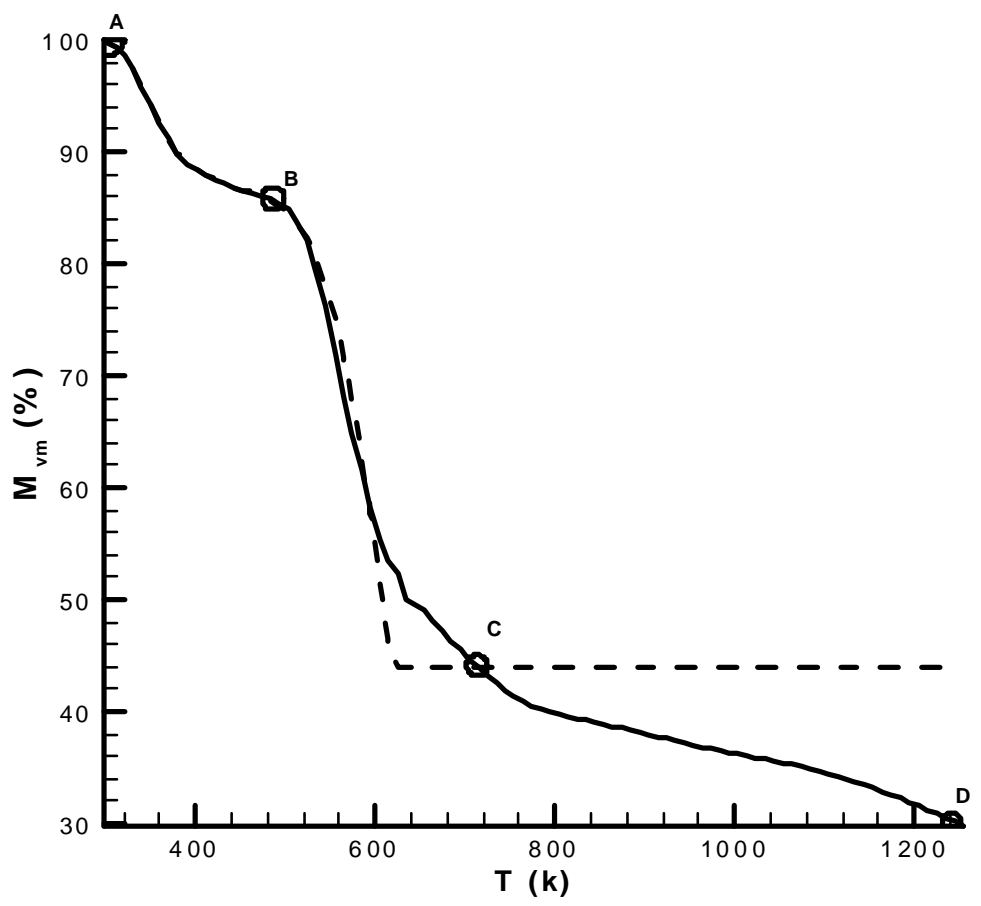

Figure 3.1.10: Curve Fitting (dashed line is curve fitting, solid is measurement) 


\subsection{Task 2: Boiler burner experiments for cofiring of CFB and CLB fuels and Reburn tests}

Combustion performance with three fuels was evaluated in the current boiler burner facility: coal, a 90:10 coal:LB blend, and a 90:10 coal:FB blend. All of the fuels were blended on a mass basis. The Texas A\&M boiler burner is a $30 \mathrm{~kW}(100,000 \mathrm{BTU} / \mathrm{hr}$ ) downward-fired furnace (figures 3.2.1 and 3.2.2). The dimensions of the furnace are shown in figure 3.2.3, and the operating parameters are shown in table 3.2.1. The pulverized fuel and air enter through a swirl burner at the top where they are ignited by a pair of propane torches. The swirl burner creates a recirculation zone inside of the furnace, and as the fuel burns gas readings are taken from sampling ports along the side of the furnace. All of the readings presented here will be taken from the final sampling port where the combustion is most complete and representative of exhaust gas concentrations. A water spray at the bottom of the furnace is used to cool the combustion gases, and afterwards the gases are exhausted out of the building. The experimental uncertainty of the results was analyzed using a standard uncertainty analysis. The uncertainty of the instruments used is shown in table 3.2.2, and the uncertainty of the calculated parameters is shown in table 3.3. A more complete description of the setup, and the experimental procedure can be found elsewhere [Annamalai et al, 2001].

The ultimate and proximate analyses of the fuels used in the experiments are shown in table 3.2.1. The analysis shows that both of the biomass fuels are higher in ash, nitrogen, and sulfur, but lower in heating value. The volatile matter of the biomass is almost twice as high compared to coal on a DAF (dry ash free) basis. It is hoped that the increased nitrogen levels in the fuel will not translate directly to greater $\mathrm{NO}$ emissions when the biomass is blended with coal and fired. The coal used is Powder River Basin (PBR) coal from Wyoming that has been ground to $70 \%$ passing through 200 mesh $(60 \mu \mathrm{m})$. The feedlot biomass is partially composted manure collected from feedlots in the Amarillo, TX area and the littler biomass was collected from Sanderson Farms chicken houses in Denton, TX. Both fuels were dried to less than 10 percent moisture and then ground by a commercial company in California. Both of the biomass fuels had to be dried to allow for sufficient grinding. The biomass fuels were not ground as finely as the coal, but 70 percent of the biomass particles were ground to less than $170 \mu \mathrm{m}$. A more complete description of the fuel properties and the collection procedure can be found in Sweeten et al (2001).

Gas analyses of $\mathrm{CO}$ and $\mathrm{O}_{2}$ were used to determine the burnt mass fraction (bmf) and the variation with excess air percentage is shown Fig 3.2.4. Each of the data points in the figures is the average of about 10 readings taken from the furnace on one day, from one firing. For each of the fuels and for each of the excess air percentages, there are 2 data points. In the figures, the labels FB and LB refer to a 90:10 blend of biomass and coal. All of the fuels had a burnt mass fraction between about 0.8 and 0.95 and all were similar. It was initially expected that the biomass fuels would not burn as completely as the coal, due to the larger particle size, lower heating value, and greater ash percentage. It is believed that the greater volatile matter of the biomass fuels on a dry ash free basis combined with the faster release of volatiles leads to similar levels of particle burnout [Thien, et al, 2001]. These results are mirrored in the $\mathrm{CO}$ emission levels from the furnace as shown in Fig 3.2.5. Although there is some variation in the readings, the levels for the three different fuels are similar with less $\mathrm{CO}$ being emitted at greater excess air percentages. The burnt mass fraction and the $\mathrm{CO}$ emissions do not reach the same levels expected in a large-scale boiler burner $(<0.95 \mathrm{bf})$ due to the limited residence time in the laboratory burner and the high heat loss due to the small diameter of the combustor (6 in).

Figure 3.2.6 shows the emission of $\mathrm{NO}$ from the furnace on a concentration basis at a series of excess air percentages, and Fig 3.2.7 shows the NO emissions on a heat basis. The results show that the NO concentrations did not change with addition of biomass (10\% on mass basis) to the fuel, either on a concentration basis or on a heat basis, despite the higher nitrogen content in the blended fuels. More NO is produced at higher excess air percentages, as more $\mathrm{O}_{2}$ is available to produce NO. The addition of the biomass to the coal raised the nitrogen in the resulting fuel by $8.25 \%$ for the FB fuel blend and by $21 \%$ for the LB fuel blend, but there was not a corresponding increase in the NO emissions when the fuels were fired in the furnace. This effect is illustrated by the $\mathrm{N}$ fuel conversion fraction (Fig 3.2.8), which is the fraction of the $\mathrm{N}$ found in the fuel that is converted to NO, assuming that none of the $\mathrm{NO}$ emissions are formed from atmospheric nitrogen. The figure shows that less of the fuel nitrogen in the LB and the FB blends are converted to NO in the combustion process. It is believed that the this lower conversion percentage is due to the release of nitrogen in the biomass fuel in the form of $\mathrm{NH}_{3}$ (i.e. urea in LB and FB) instead of $\mathrm{HCN}$, and the higher percentage of volatiles in biomass on a dry ash free basis which reduces local $\mathrm{O}_{2}$ concentration near the burner due to rapid combustion. The release of $\mathrm{N}$ in the form of $\mathrm{NH}_{3}$ changes the 
nitrogen-oxidation kinetics, with the result of a lower $\mathrm{N}$ conversion rate, and the greater volatile content of the biomass creates more localized fuel rich zones where less NO is formed.

\section{Reburn Tests}

The experiments were conducted in the Texas A\&M laboratory scale boiler burner that was modified for reburn experiments. The boiler is a $100 \mathrm{~kW}(100,000 \mathrm{Btu} / \mathrm{hr})$ downward-fired furnace made up of a steel shell encasing ceramic insulation. A premixed propane burner is mounted at the top of the furnace to produce hot furnace gases to simulate the products of coal combustion. Ammonia is injected into the premixed propane fuel stream and burnt in the primary zone. The reburn fuel is fed from a dry solids feeder, through a venturi inductor value, and injected through the reburn ports. The reburn injection ports are located below the tip of the premixe d propane flame, after all of the NO has been formed in the primary zone. An Enerac $3000 \mathrm{E}$ gas analyzer is then used to measure the concentration of oxygen and NO in the final sampling port. After passing by the gas sampling port, the furnace gases are cooled by a water spray and exhausted out of the building. There is no burnout zone in the current boiler burner configuration. More experimental details are given elsewhere [Thien at al. 2002, Annamalai et al, 2001].

Reburn test were continued with litter as reburn fuel. Figure 3.2.10 compares the \% NOx reduction for coal, FB and $\mathrm{LB}$ as reburn fuel. 
Table 3.2.1: Furnace operating parameters

\begin{tabular}{|l|l|}
\hline Parameter & Value \\
\hline Primary air & $170 \mathrm{SCFH}$ \\
\hline Fuel flow rate & $\sim 80 \mathrm{~g} / \mathrm{min}$ \\
\hline Loading ratio (fuel/air) & 0.844 \\
\hline Secondary air & $1053-1225 \mathrm{SCFH}$ \\
\hline Secondary air Temp & $\sim 380 \mathrm{~K}$ \\
\hline Heat throughput & $30 \mathrm{~kW}(100,000 \mathrm{BTU} / \mathrm{hr})$ \\
\hline
\end{tabular}

Table 3.2.2: Experimental uncertainty in instruments used.

\begin{tabular}{|l|l|c|c|}
\hline Parameter & Error & Typical Value & Percent error \\
\hline $\mathrm{O}_{2}$ Concentration & $\pm 0.2 \%$ & $3 \%$ & $6.66 \%$ \\
\hline $\mathrm{CO}$ Concentration $_{\mathrm{CO}_{2} \text { Concentration }}^{4 \% \text { of reading }}$ & $500 \mathrm{ppm}$ & $4 \%$ \\
\hline $\mathrm{NO}$ & $\pm 0.1 \%$ & $12 \%$ & $0.83 \%$ \\
\hline $\mathrm{NO}_{2}$ & $4 \%$ of reading & $420 \mathrm{ppm}$ & $4 \%$ \\
\hline $\mathrm{SO}_{2}$ & $4 \%$ of reading & 0 & $4 \%$ \\
\hline Combustibles & $4 \%$ of reading & $60 \mathrm{ppm}$ & $4 \%$ \\
\hline Primary air Gauge & $10 \%$ of reading & 1.33 & $10 \%$ \\
\hline Secondary Air Manometer & $\pm 3 \mathrm{SCFH}$ & $70 \mathrm{SCFH}$ & $4.2 \%$ \\
\hline Solids feeder & $\pm 0.05 \mathrm{in}$ & $5.8 \mathrm{in}$ & $0.86 \%$ \\
\hline $\mathrm{DL}$ & $\pm 2 \mathrm{~g} / \mathrm{min}$ & $80.7 \mathrm{~g} / \mathrm{min}$ & $2.48 \%$ \\
\hline $\mathrm{C}$ & $\pm 0.03 \%$ & 23.60 & $0.13 \%$ \\
\hline $\mathrm{H}$ & $\pm 0.03 \%$ & 2.91 & $1.03 \%$ \\
\hline $\mathrm{O}$ & $\pm 0.03 \%$ & 19.08889 & $0.16 \%$ \\
\hline $\mathrm{N}$ & $\pm 0.03 \%$ & 1.78 & $1.7 \%$ \\
\hline $\mathrm{S}$ & $\pm 0.03 \%$ & 0.71 & $4.2 \%$ \\
\hline Ash & $\pm 0.03 \%$ & 7.73 & $0.39 \%$ \\
\hline Heating value & $\pm 0.03 \%$ & 44.16 & $0.068 \%$ \\
\hline Digital scale & $\pm 221 \mathrm{~kJ} / \mathrm{kg}$ & $9421.9 \mathrm{~kJ} / \mathrm{kg}$ & $2.34 \%$ \\
\hline Package Scale & $\pm 2 \mathrm{~g}$ & $250 \mathrm{~g}$ & $0.8 \%$ \\
\hline Secondary air & $\pm 0.25 \mathrm{lb}$ & $18 \mathrm{lb}$ & $1.39 \%$ \\
\hline & $6 \%$ of reading & 1100 & $2 \%$ \\
\hline
\end{tabular}


Table 3.2.3: Derived errors

\begin{tabular}{|l|l|c|c|}
\hline Parameter & Error & Typical Value & Percent error \\
\hline$\%$ Reburn reduction & $\pm 5 \%$ & $50 \%$ & 2.6 \\
\hline Fraction manure mixed & \pm 0.0026 & 0.1 & 2.6 \\
\hline Primary air & $\pm 5.3 \mathrm{SCFH}$ & $108 \mathrm{SCFH}$ & 4.90 \\
\hline Equivalence Ratio & \pm 0.027 & 0.909 & 2.97 \\
\hline Excess air & \pm 3.925 & $10 \%$ & 39.25 \\
\hline $\mathrm{BF}$ & \pm 0.031 & 0.95 & 3.26 \\
\hline $\mathrm{XCO}{ }_{2}$ & \pm 0.006 & 0.11 & 5.45 \\
\hline $\mathrm{Nconv}$ & \pm 0.016 & 0.16 & 10 \\
\hline $\mathrm{NO}(\mathrm{kJ} / \mathrm{kg})$ & \pm 0.014 & $0.17 \mathrm{~kJ} / \mathrm{kg}$ & 8.23 \\
\hline NO normalized & \pm 21.95 & $381 \mathrm{ppm}$ & 5.76 \\
\hline
\end{tabular}




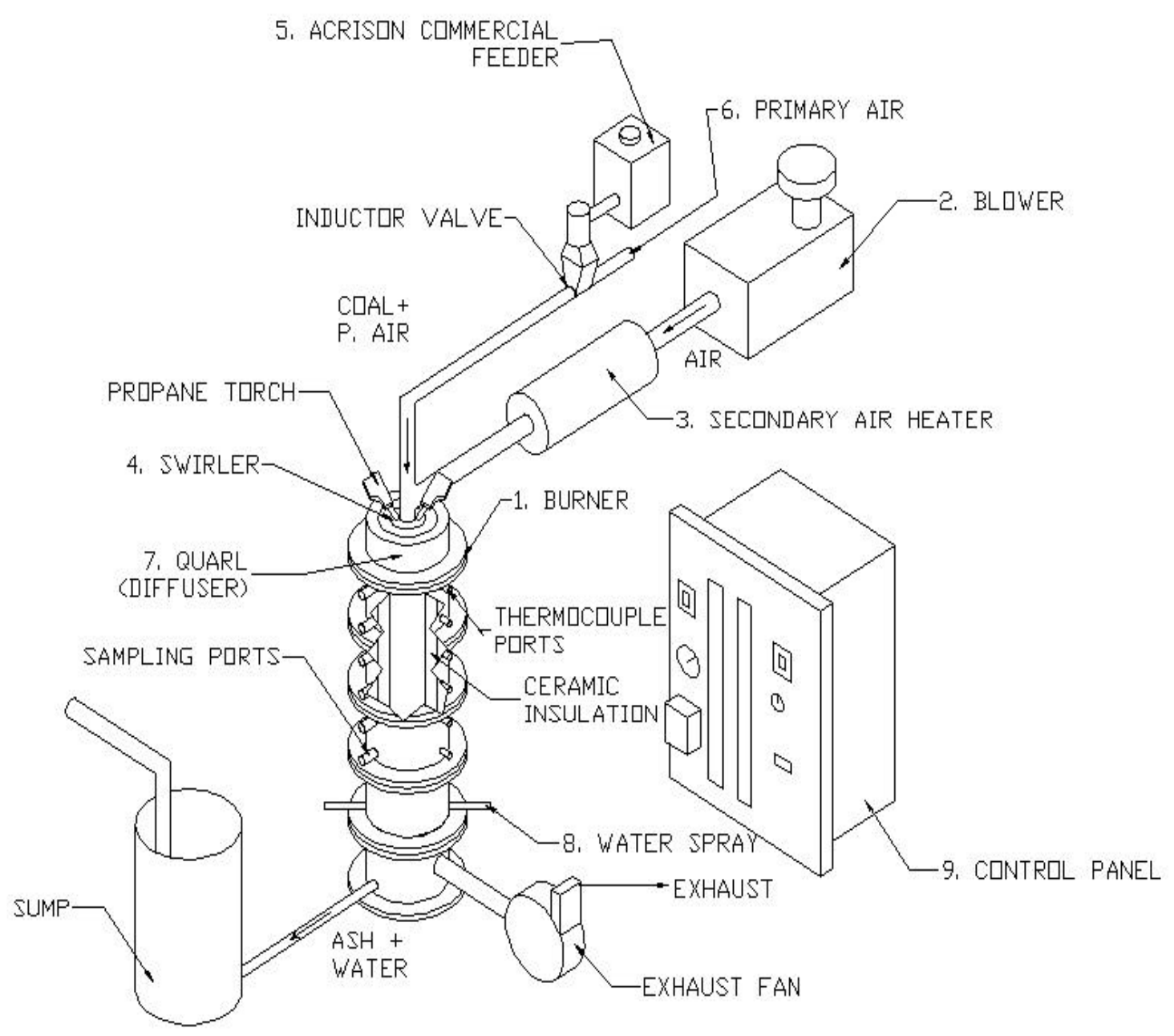

Figure 3.2.1: Exp erimental setup 


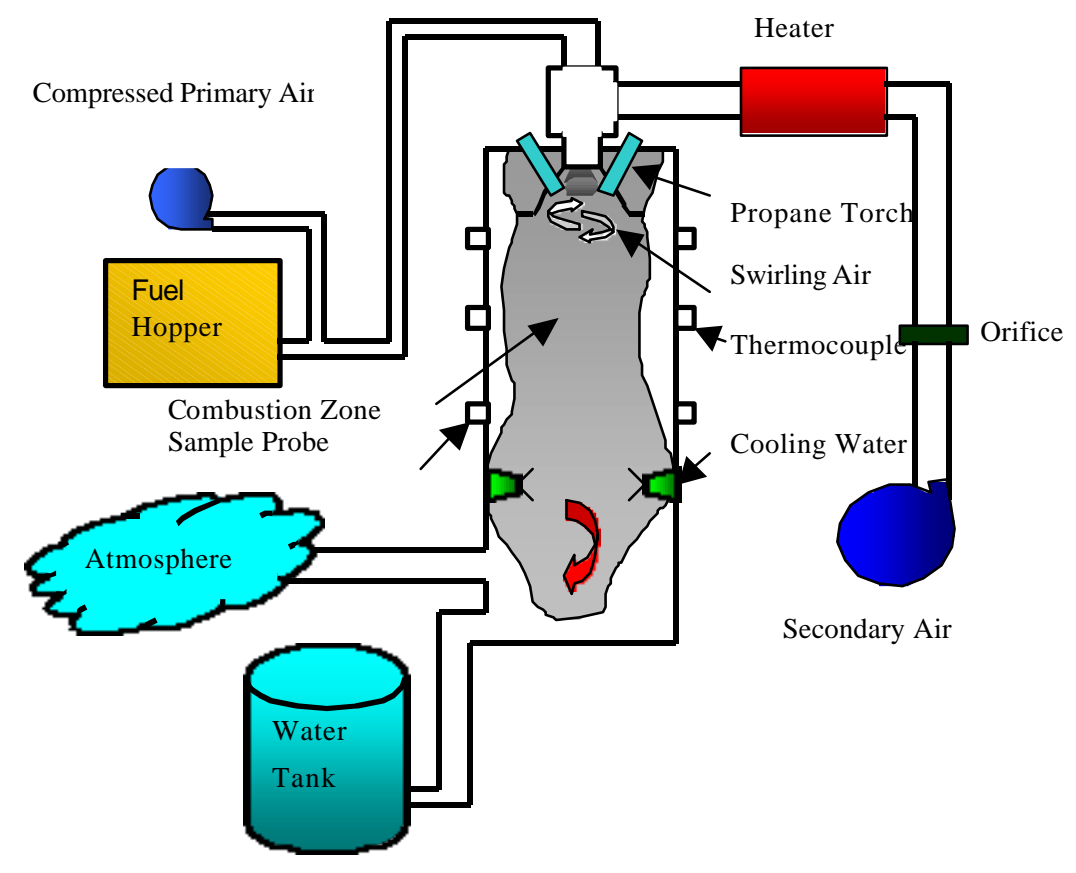

Figure 3.2.2: Experimental Schematic 


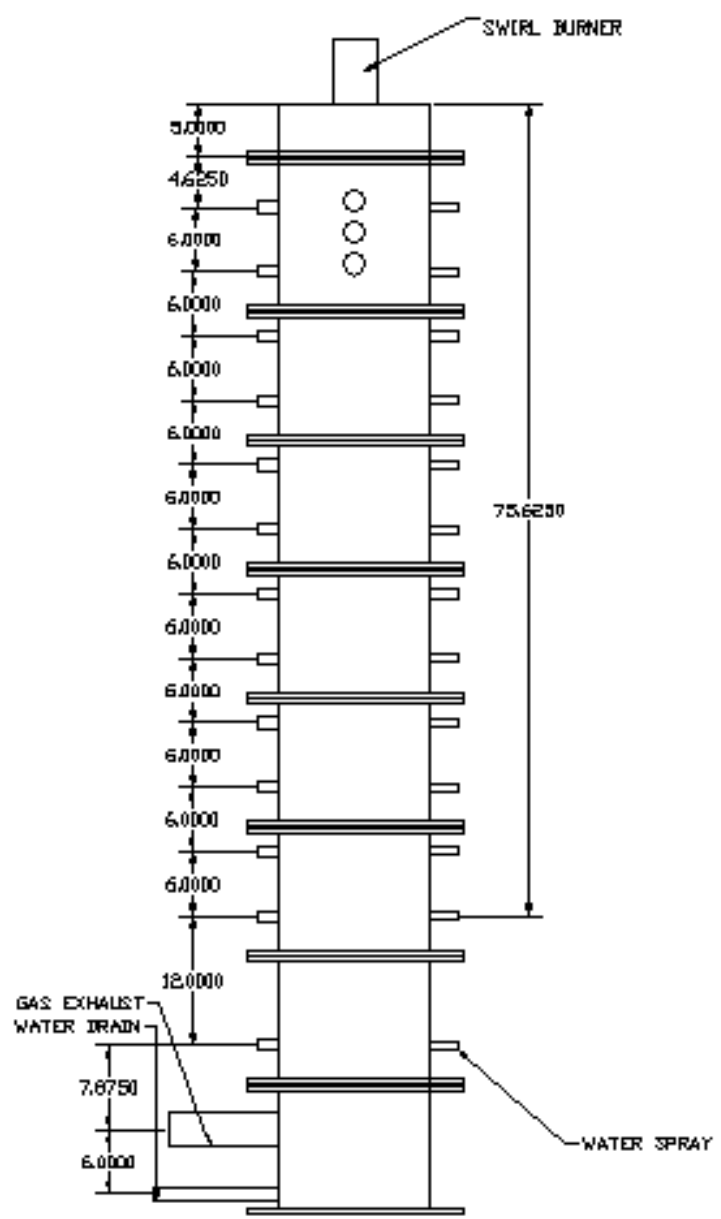

Figure 3.2.3: Modified Furnace Dimensions in inches

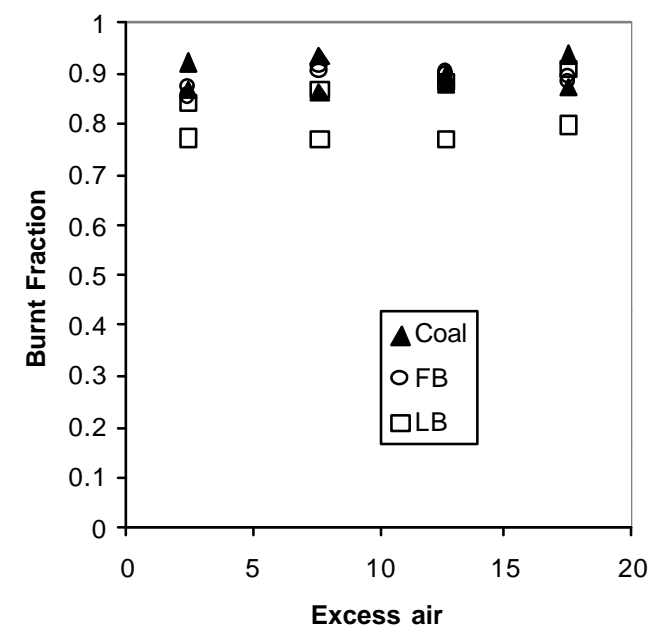

Figure 3.2.4: Burnt mass fraction for fuels tested 


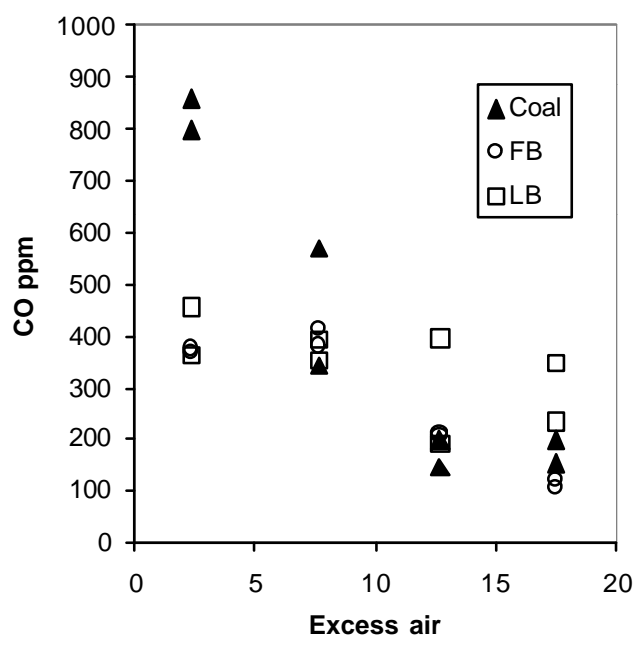

Figure 3.2.5: $\mathrm{CO}$ emissions from all three fuels; FB and LB denote 90:10 blends

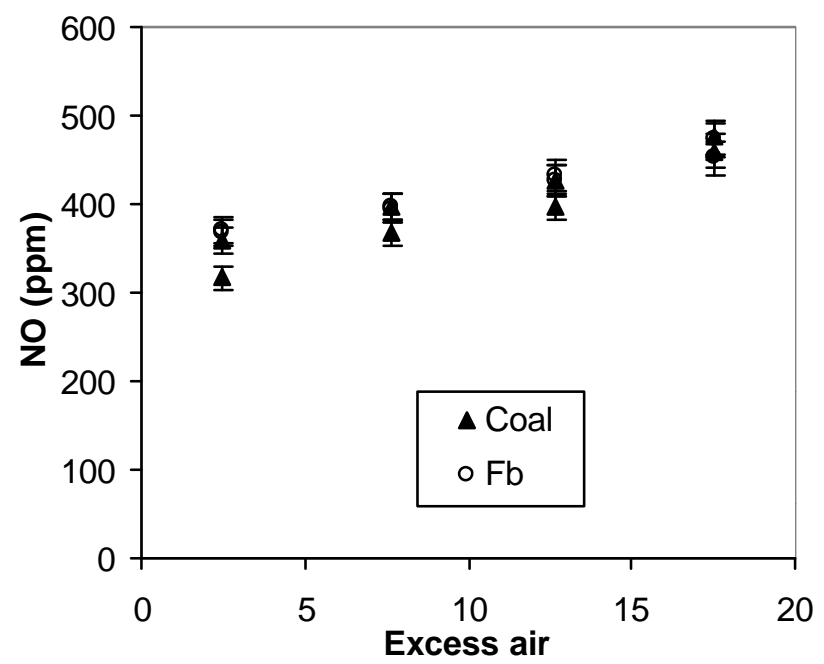

Figure 3.2.6: NO emissions from all 3 fuels; $\mathrm{Fb}$ denote 90:10 Coal:FB Blends 


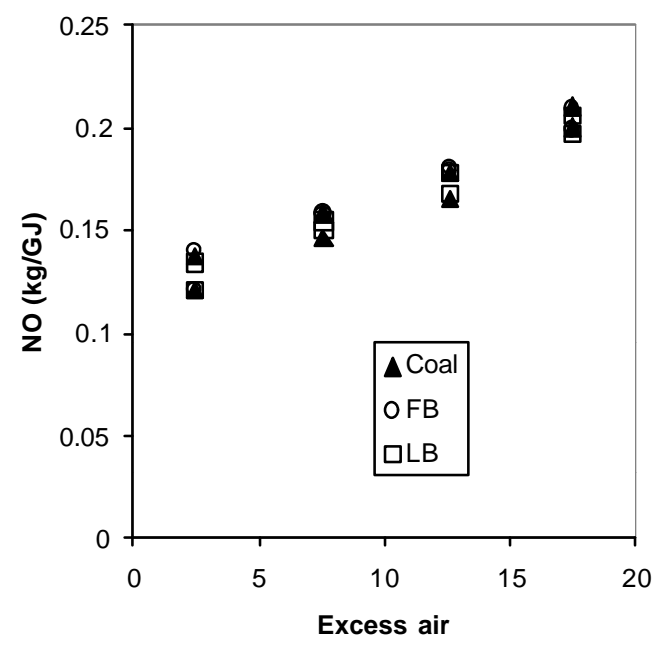

Figure 3.2.7: NO emissions on a heat basis; FB and LB denote 90:10 blends

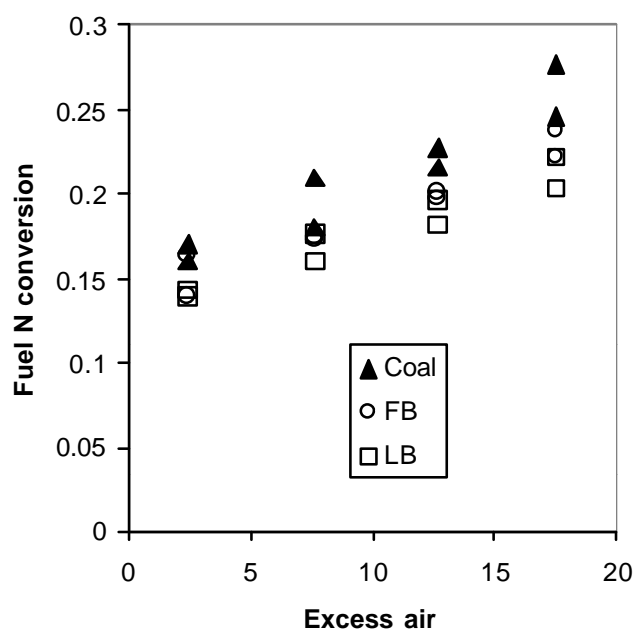

Figure 3.2.8: Fuel N conversion efficiency; FB and LB denote 90:10 blends 


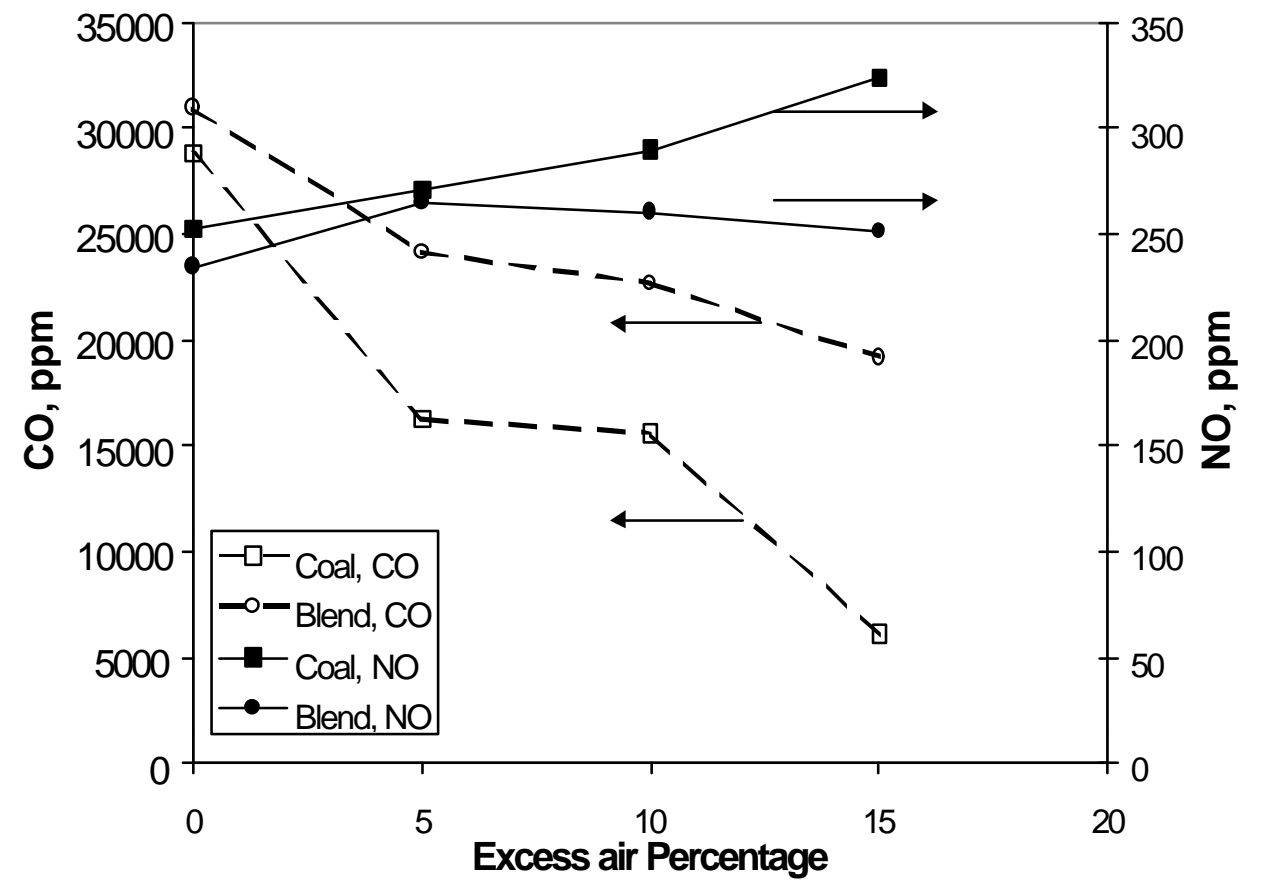

Figure 3.2.9: Relation between $\mathrm{NO}$ and $\mathrm{CO}$ in unmodified (short) Reactor

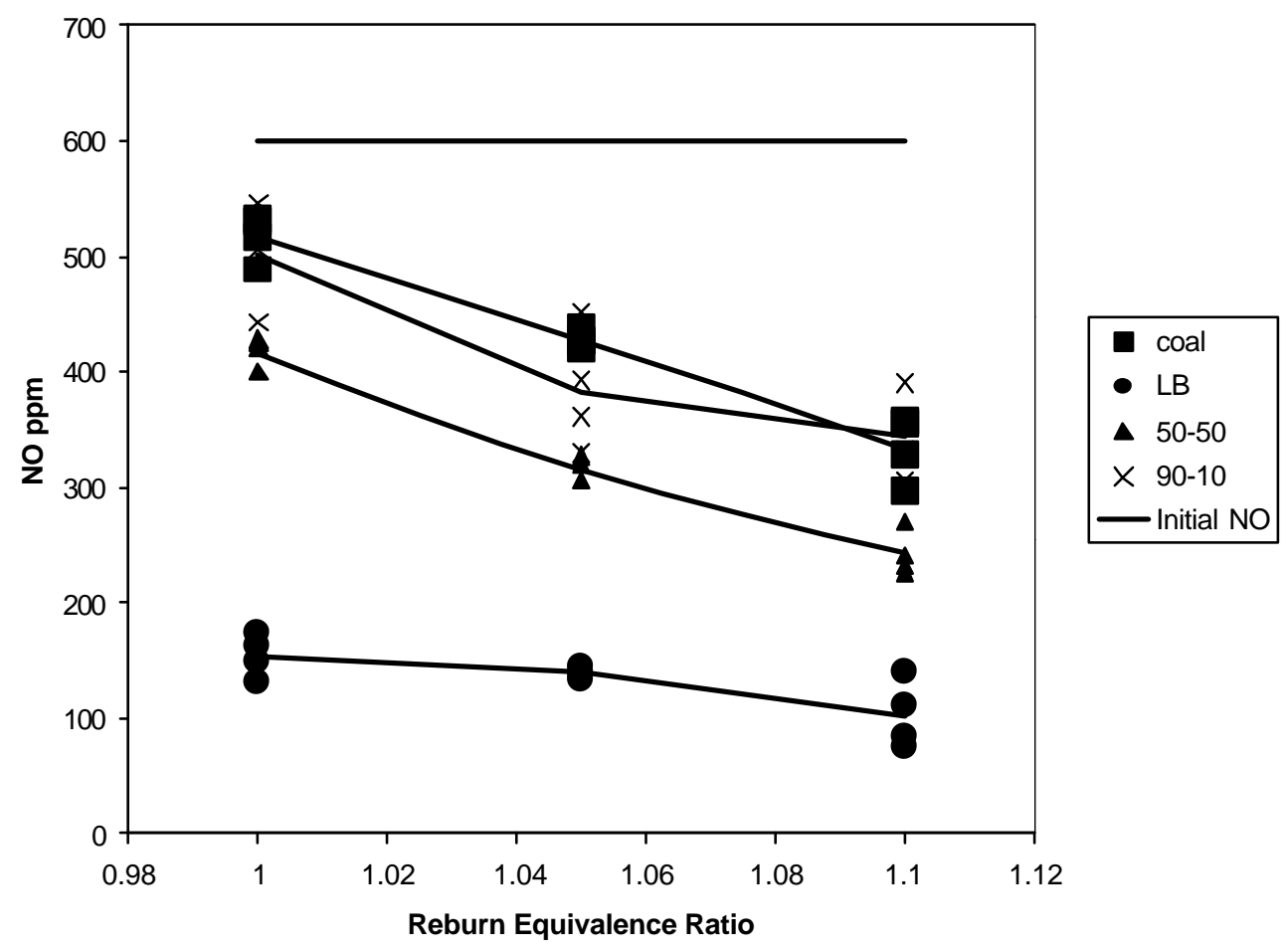

Figure 3. 2.10: Comparison of $\mathrm{NO}_{\mathrm{x}}$ reduction in the modified furnace at $\mathrm{A} \& \mathrm{M}$ facility (patent in process) 


\subsection{Task 3: Fixed Bed studies on CFL and CLB fuels}

This part of the report describes the fabrication and assembly of the setup. Preliminary results of the experiments are presented. There have been some modifications to the setup due to problems encountered while running the experiments, which will also be discussed in the report.

The fabrication has been completed and the details of fabrications and assembly are provided in detail in the Appendix A. For the assembly the inner refractory lining had to be cast in a section wise manner. Figures 3.3.3a - e in Appendix A show the various cut sections of the setup along with all the important parts and dimensions labeled.

The assembly was done from the bottom to top, where the refractory linings were joined together with a refractory adhesive. This was needed in order to minimize the leakage from the gasifier. The conduit between the ports and the refractory lining was made from ceramic boards; this isolated the ports from the ceramic blankets which were wrapped around the refractory lining. After assembling all the four sections, the plumbing work for the water circuits and air circuits was completed.

A few experiments have been conducted in order to ensure the proper operation of the system. The runs were done for coal only. The particle size that was fired was greater than $1 / 4$ ' and less than $\$ / 2$ The mean particle size was 3/8". The graphs of the temperature profiles are shown in figure 3.3.2. The ports 1 through 4 measure the temperature profile in the bed, and the remaining measure the free board temperature. Refer figures $3.3 .3 \mathrm{~b}$ and 3.3.3d for the locations of the ports. The variation in the temperature at a particular port is due to the batch feeding of fuel. The primary air feed rate was kept at $45 \mathrm{scfh}$, and the bed height was kept at a constant height of 4 " above the grate. There was no secondary air feed in to the gasifier. The gas species that are going to be measured are CO, $\mathrm{CO}_{2}, \mathrm{O}_{2}$, and $\mathrm{NO}_{\mathrm{x}}$. The gas species have not been measured as the expected concentration of $\mathrm{CO}$ is expected to be much greater than $40000 \mathrm{ppm}$. This is a limiting factor as the gas analyzers used in the laboratory can measure a maximum CO concentration of $40000 \mathrm{ppm}$. This has prohibited the use of the gas analyzers to measure the gas species concentrations.

While running the experiments, there was a problem with tar. Tar deposition on the view ports made it difficult to visually check the height of the bed. The view ports had to be frequently removed and cleaned. Tar deposition at the grate caused clogging of the holes, due to which the grate had to be cleaned after every experiment. This caused the failure of the ceramic boards, which chipped away while cleaning the holes. Due to this problem the ceramic board grate had to be replaced by a castable refractory. The new castable refractory grate was made by an investment casting process. Figures 3.3.1a and 3.3.1b show the grate modification. Also refer Annual Technical Report on Co-firing Coal, Feedlot, and Litter Biomass (CFB and LFB) Fuels in Pulverized Fuel and Fixed Bed Burners, July 2001 [Annamalai, et al, 2001], figure 3.3.4 for details of the grate support mechanism. The dimensions of the grate are 1" $\mathrm{x}$ 7" (diameter). The pattern and the number of holes are the same as the previous ceramic board design. The grate has a different support mechanism, refer to figure 3.3.1b. The new grate not only is much stronger, and resistant to the tar corrosion, but it is much more easier to handle and clean.

The extra gas sampling and temperature measurement ports that are added are going to be used when secondary air is fired into the gasifier. This is necessary as there is no gas sampling or temperature measurement port beyond the secondary fire zone.

Future work is to run the gasifier with coal and feedlot biomass blends, and with coal and chicken litter blends. The gas species concentrations and the temperature profiles shall be measured. 


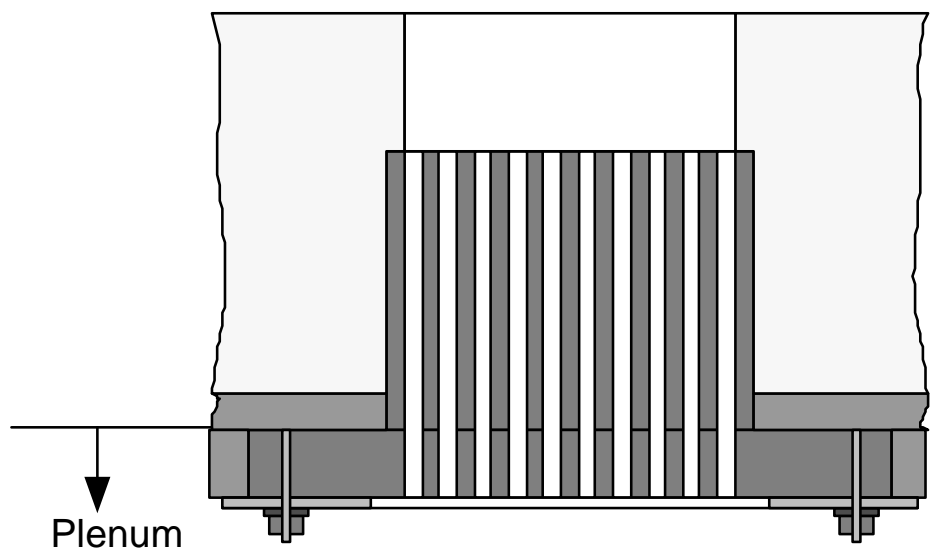

Prenumber

Figure 3.3.1a: Grate support mechanism before modification

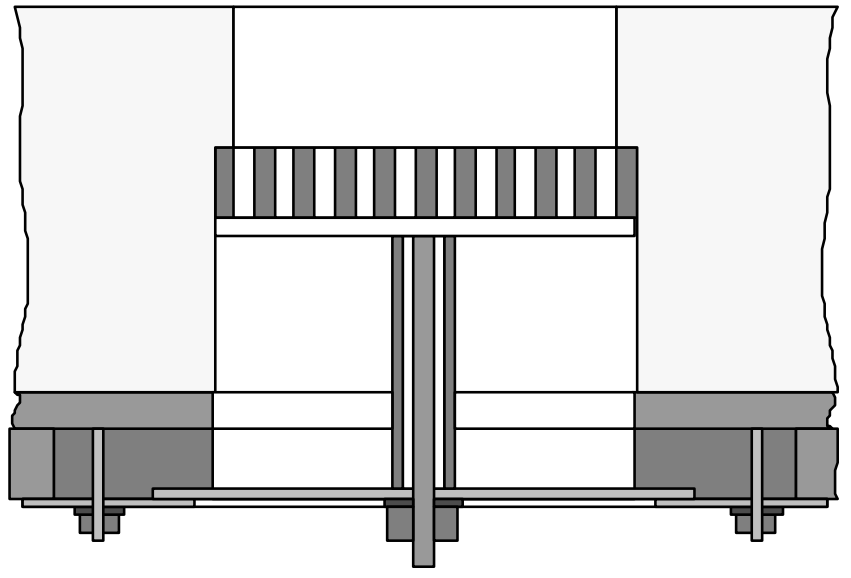

Figure 3.3.1b: Modified grate support mechanism 
Temperature Profile

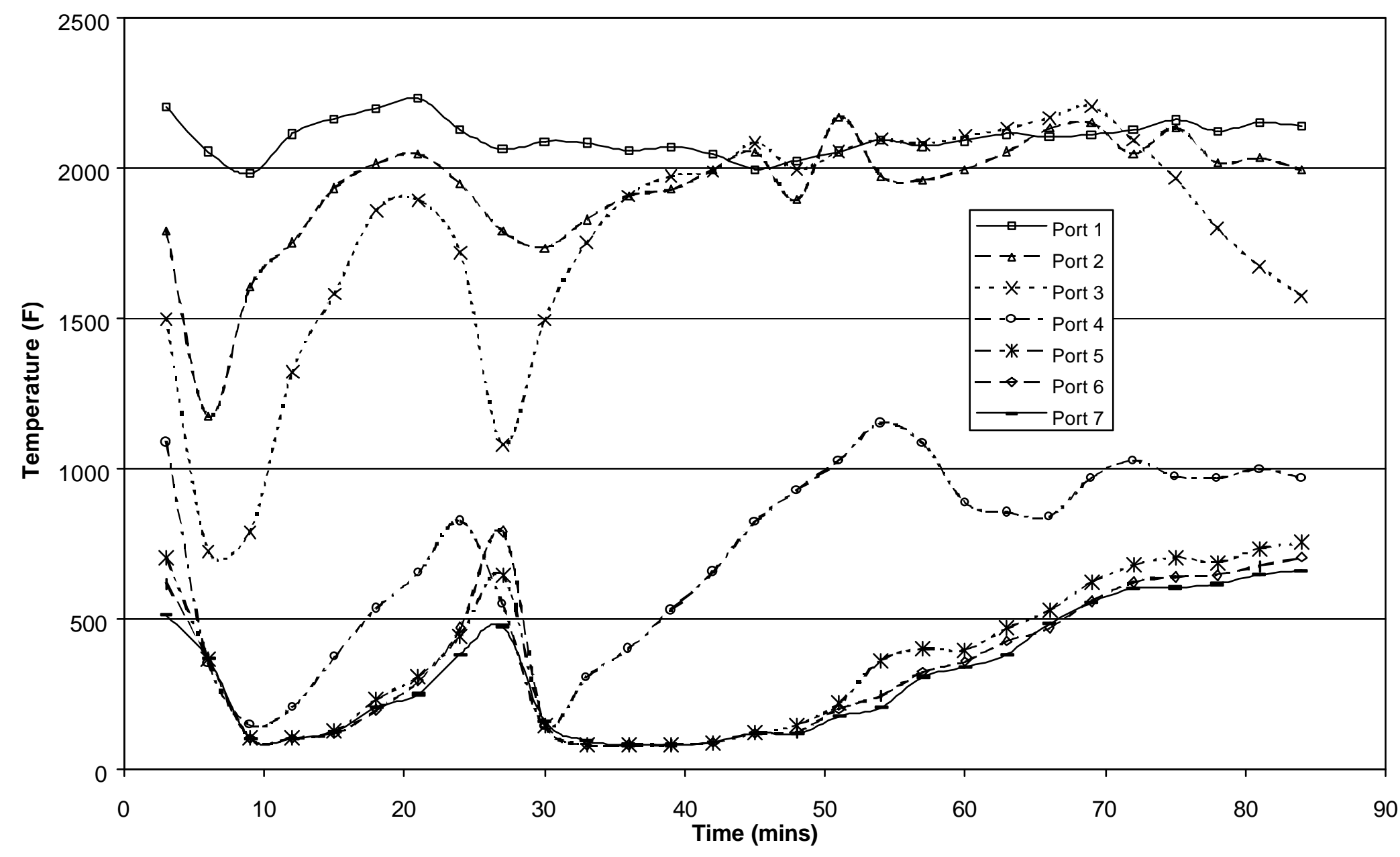

Figure 3.3.2: Temperature profiles 


\subsection{Task 4: Numerical Modeling of pf fired and fixed bed burners}

\subsubsection{Numerical Modeling of pf fired burners}

\section{Moisture evaporation modeling}

High moisture content of biomass may lower particle and gas phase temperature, and increase the flame standoff distance, which influences particle burnout and pollutant emissions. In the PCGC2 model by BYU (1988), it is assumed that moisture in fuel particles is released completely and instantly before particles enter burners. Moisture is thus added into primary stream and fuel particles are assumed dry. In reality, moisture is released gradually with heating after particles enter furnace. Rigorous treatment should employ one mixture fraction to track moisture vapor and other mixture fractions to track fuel off gases and air streams.

In a modified PCGC2 model for blend combustion of pulverized coal and biomass [Dhanapalan et al, 1997, Sami et al 1999], three mixture fractions were used to track primary air, coal offgas and biomass offgas respectively. Under this task, it was further modified with the three mixture fractions tracking primary air, fuel offgas, and moisture. They are denoted as $\eta_{1}, \eta_{2}$, and $\eta_{3}$ respectively and defined as

$\eta_{i}=\frac{m_{i}}{\sum_{k=0}^{i} m_{k}}$

where $m_{0}, m_{1}, m_{2}$, and $m_{3}$ represent mass from secondary air stream, primary air stream, fuel offgas, and moisture vapor at a local point. However the chemical elemental composition of fuel off gas is assumed the equivalence of the blend mixture of DAF coal and biomass. Although this implies these two fuels are assumed to have an equivalent ultimate analysis, they are actually treated as different fuels with respect to all other parameters including proximate analysis, heating values, particle sizes, mass densities, and etc.

To model moisture evaporation process, the following moisture evaporation rate equation [Annamalai et al, 1987c] is added to the PCGC2 code,

$r_{w j}=S h \rho D \pi d_{j}\left(Y_{w j s}-Y_{w}\right) F_{B, e}$

where $r_{w j}$ is water evaporation rate of particle $\mathrm{j}, \rho$ is gas phase density, $D$ is mass diffusivity, $d_{j}$ is diameter of particle $\mathrm{j}, Y_{w j s}$ is mass fraction of water vapor at surface of particle, $Y_{w}$ is the local water vapor mass fraction in gas phase, $S h$ is Sherwood number as [Bird et al, 1960],

$$
S h=2+0.654 \operatorname{Re}^{0.5} S c^{1 / 3}
$$

where $S c$ is the Schmidt number, $F_{B, e}$ is blowing correction factor for evaporation process,

$$
F_{B, e}=\frac{1}{B_{e}} \ln \left(1+B_{e}\right)
$$

and

$$
B_{e}=\frac{Y_{w j s}-Y_{w}}{1-Y_{w j s}}
$$

Water vapor mass fraction at particle surface, $Y_{w j s}$, is calculated by assuming thermodynamic equilibrium for evaporation process as [Saul and Wagner, 1986] 
$Y_{w j s}=\frac{X_{w j s} M_{w}}{M_{g}\left(1-X_{w j s}\right)+X_{w j s} M_{w}}$

where

$$
\begin{aligned}
& X_{w j s}=\frac{p_{w j s}}{p} \\
& p_{w j s}=p \exp \left[\frac{1}{T_{r}}\left(A_{1} \zeta+A_{2} \zeta^{1.5}+A_{3} \zeta^{3}+A_{4} \zeta^{3.5}+A_{5} v^{4}+A_{5} \zeta^{7.5}\right)\right]
\end{aligned}
$$

Subscript $j$ in above represents particle $\mathrm{j}, X_{w j s}$ is mole fraction of water vapor at particle surface, $M_{g}$ is molecular weight of gas phase, $M_{w}$ is molecular weight of water, $p_{w j s}$ is saturation pressure of water vapor, $p$ is gas phase pressure, $T_{r}$ and $\zeta$ are

$T_{r}=\frac{T_{j s}}{T_{C}}, \quad \zeta=1-T_{r}$

$p_{C}$ and $T_{C}$ are critical pressure and temperature of water respectively, $T_{j s}$ is particle surface temperature.

\section{Heterogeneous char reactions}

There exist four major heterogeneous char reactions in pf combustions

$$
\begin{aligned}
& 2 \mathrm{C}+\mathrm{O}_{2} \rightarrow 2 \mathrm{CO} \\
& \mathrm{C}+\mathrm{O}_{2} \rightarrow \mathrm{CO}_{2} \\
& \mathrm{C}+\mathrm{CO}_{2} \rightarrow 2 \mathrm{CO} \\
& \mathrm{C}+\mathrm{H}_{2} \mathrm{O} \rightarrow \mathrm{CO}+\mathrm{H}_{2}
\end{aligned}
$$

Reaction (I) is the dominant reaction under typical combustion temperature. Reaction (II) is significant under low temperature (e.g. ignition conditions). For high temperature, (II) is usually 100 to 1000 times slower than (I). Reactions (III) and (IV) can be significant under some conditions at high temperature. For example, in pf combustion, some regions near burner may have high temperature and low oxygen content due to VM oxidation while moisture content may be high due to moisture evaporation. In these regions reaction (IV) can be significant even dominant.

Previous computations with PCGC2 [Dhanapalan et al 1996; Sami et al, 1999] only consider reaction (I). Under this task, all the four major reactions are considered. PCGC2 code and input files are modified to include reactions (II), (III) and (IV). According to chemical kinetics, expression of char loss rate for a single char particle

$r_{j l}=\phi_{l} M_{h j} k_{j l} \zeta_{j} A_{j} C_{O \lg }^{n}$

where the subscript $\mathrm{j}$ and $l$ represent particle $\mathrm{j}$ and $l$-th reaction respectively, $C_{O l g}$ is the molar concentration of oxidizer (e.g., $\mathrm{O} 2$ for (I) and (II), $\mathrm{CO} 2$ for (III) and $\mathrm{H} 2 \mathrm{O}$ for (IV)) in gas phase at particle surface, $A_{j}$ is particle surface area, $\zeta_{\mathrm{j}}$ is the ratio of entire burning area (surface area plus internal burning area) to surface area of particle, $M_{h j}$ is molecular weight of carbon, and $\phi_{l}$ is stoichiometric ratio of mole of char to mole of oxidizer; the term $k_{j l}$ is specific reaction rate, evaluated by

$k_{j l}=A_{l} T_{j s}^{{ }^{n_{l}}} \exp \left(-\frac{E_{l}}{\bar{R} T_{j s}}\right)$ 
The activation energy $E_{l}$, pre-exponential coefficient $A_{l}$ and power index of temperature $n_{l}$ for reactions (I), are from PCGC-2 Manual (1989, and for (III) and (IV) are from Howard and Sarofim (1978). They are summarized in Table. 3.4.1.1. The specific reaction rate for reaction (II) is evaluated by Arthur (1951),

$k_{j 2}=2511 k_{j 1} \exp \left(-\frac{A_{2}^{\prime}}{\bar{R} T_{j s}}\right)$

where $A_{2}^{\prime}=5.155 \times 10^{7} \mathrm{~J} / \mathrm{kmole}$.

Table 3.4.1.1: Constants of specific reaction rate for char

\begin{tabular}{|l|l|l|l|}
\hline Reaction & A & E $(\mathrm{J} / \mathrm{kmole})$ & $\mathrm{n}$ \\
\hline I & $1.0051(\mathrm{~m} / \mathrm{s}-\mathrm{K})$ & $8.5354 \times 10^{7}$ & 1.0 \\
\hline III & $1.21 \times 10^{-3}\left(\mathrm{~m} / \mathrm{sK}^{0.34}\right)$ & $1.09 \times 10^{8}$ & 0.34 \\
\hline IV & $1.37 \times 10^{-2}(\mathrm{~m} / \mathrm{s}-\mathrm{K})$ & $1.42 \times 10^{8}$ & 1.0 \\
\hline
\end{tabular}

With consideration of both chemical kinetics and oxidizer diffusion, the final expressions for char reaction rates of (I) to (IV) are [Smoot et al, 1985]

$r_{h j l}=\frac{A_{j}^{2} M_{h j} M_{g} \phi_{l} k_{c j l} k_{j l} \zeta_{j} C_{O l j} C_{g}}{M_{g} A_{j} C_{g}\left(\zeta_{j} k_{j l}+k_{c j l}\right)+r_{j}}$

where $k_{c j l}$ is mass transfer coefficient, $C_{g}$ is the total mole concentration of gas phase, $r_{j}$ is the total mass loss rate of particle that equals sum of char loss rate, VM loss rate and moisture loss rate.

\section{Numerical modeling of phosphorous products}

Phosphorous elemental mass fraction is about 3.2\% in dry DAF litter biomass (LB). When LB burns as pf, phosphorous is oxidized mainly into $\mathrm{PO}_{2}$ and $\mathrm{P}_{4} \mathrm{O}_{10}$. According to Frandsen et al (1994), the $\mathrm{P}_{4} \mathrm{O}_{10}$ is stable between $670 \mathrm{~K}$ and $1250 \mathrm{~K}$, and $\mathrm{PO}_{2}$ is in significant amount above $1550 \mathrm{~K}$. From equilibrium calculation for phosphorous oxidation reviewed in Frandsen et al (1994), $\mathrm{P}_{4} \mathrm{O}_{10}$ accounts for all phosphorous below $1350 \mathrm{~K}$, while phosphorous exists mainly as $\mathrm{PO}_{2}$ above $1750 \mathrm{~K}$. $\mathrm{PO}_{2}$ and $\mathrm{P}_{4} \mathrm{O}_{10}$, react with moisture at low temperature (below $450 \mathrm{~K}$ ) to form $\mathrm{H}_{3} \mathrm{PO}_{4}$ which erodes metal material equipments and harms human health. Under this task, the PCGC2 was modified to include calculation of $\mathrm{PO}_{2}$ and $\mathrm{P}_{4} \mathrm{O}_{10}$ emissions. It is assumed that $\mathrm{PO}_{2}$ and $\mathrm{P}_{4} \mathrm{O}_{10}$ productions are mixing limited thus are calculated using chemical equilibrium coupled with turbulent fluctuation (PDF method). Enthalpies and entropies of $\mathrm{PO}_{2}$ and $\mathrm{P}_{4} \mathrm{O}_{10}$, required as input data, were obtained as functions of temperature by curve fitting based on JANAF database. Calculations show reasonable results of $\mathrm{PO}_{2}$ and $\mathrm{P}_{4} \mathrm{O}_{10}$.

\section{Boundary conditions}

The original PCGC2 model requires a constant temperature all over its wall boundary. However there are difficulties particularly for parametric studies in which wall temperature may vary and degree of variation may be unknown. Since the perfect condition for parametric study of pf combustion both experimentally and numerically is with adiabatic boundary condition, implementation of adiabatic boundary for PCGC2 is conducted. Under this task, adiabatic boundary condition was implemented into PCGC2 code. Dirichlet boundary condition for temperature will be used only to simulate experiments, while adiabatic boundary will be employed for parametric study. 


\section{Results and discussions}

Parametric studies were conducted for cofiring of coal and LB with coal and LB mass ratio 90:10. The fuel ultimate and proximate analyses, high heating values, adiabatic combustion temperatures, stiochoimeteric air-fuel mass ratios and heat of formation are listed in table 3.4.1.2 as input data for the computations. Corresponding to experiments with $10 \%$ excess air, the primary airflow rate is $109 \mathrm{SCFH}$ $(0.001012 \mathrm{~kg} / \mathrm{s})$ at temperature $298 \mathrm{~K}$, and the second airflow rate is $1113 \mathrm{SCFH}(0.008205 \mathrm{~kg} / \mathrm{s})$ at $373.15 \mathrm{~K}$. Swirl number is zero for primary air stream and 0.714 for secondary air stream. Four cases were studied with dry coal and moisture content in LB as $0 \%, 10 \%, 20 \%$ and $30 \%$ respectively. The total moisture content in fuel mixture is thus $0 \%, 1 \%, 2 \%$ and $3 \%$ respectively. The air pressure at both primary and secondary air stream inlets is assumed one atmosphere.

Figure 3.4.1.1 shows the calculated mixture fraction $\eta_{3}$, which is the fraction of evaporated moisture in gas phase. (a), (b) and (c) correspond to 10\%, $20 \%$ and 30\% moisture content in LB respectively. It is seen that the $\eta_{3}$ value is higher for higher moisture content as expected. The high value zones are in the central region of the quarl with the highest $\eta_{3}$ values in (a), (b) and (c) are 0.009956, 0.01928 and 0.03126 respectively. This implies that the moisture evaporates gradually but not instantly from LB particles. Figure 3.4.1.2 shows the calculated temperature distribution with (a), (b), (c) and (d) corresponding to $0 \%, 10 \%, 20 \%$ and $30 \%$ moisture content in LB. It is found that with increasing the moisture content in LB, the temperature decreases a little in the region just outside the quarl around furnace central axis (see the region less than 1200K). Flame standoff distance variation is not obvious from the figures, this is probably due to the little difference of total moisture content in fuel mixture for the four cases (only 0\% to 3\%). Figure 3.4.1.3 shows NO mole fraction distribution. With moisture increase in LB, the NO mole fraction increases a little downstream of the furnace. Figure 3.4.1.4 shows the flow field around the quarl region for the case with 30\% moisture content in LB. Strong flow recirculation zone can be found near the central axis. This recirculation can stabilize flame by mixing combustible gases from downstream with air from upstream. Another small recirculation zone can also be found in the corner just outside the quarl. This recirculation was not revealed by former researches of Dhanapalan et al (1997) and Sami et al (1999) due to their unreasonably coarse grid near wall.

Table 3.4.1.2: Fuel ultimate and proximate analyses and other parameters

\begin{tabular}{|c|c|c|}
\hline & Coal & LB \\
\hline $\mathrm{C}(\%)$ & 60.3 & 28.4 \\
\hline $\mathrm{H}(\%)$ & 3.62 & 3.7 \\
\hline $\mathrm{O}(\%)$ & 14.5 & 22.8 \\
\hline $\mathrm{N}(\%)$ & 0.96 & 3.04 \\
\hline $\mathrm{S}(\%)$ & 0.23 & 0.66 \\
\hline $\mathrm{Cl}(\%)$ & $<0.1$ & 0.93 \\
\hline $\mathrm{P}(\%)$ & 0.00 & 1.965 \\
\hline $\mathrm{DL}(\%)$ & 15.12 & 11.6 \\
\hline $\mathrm{FC}(\%)$ & 42.38 & 10.92 \\
\hline VM (\%) & 37.17 & 50.7 \\
\hline Ash (\%) & 5.33 & 26.8 \\
\hline HHV (DAF) (kJ/kg) & 29804.9 & 19581.3 \\
\hline Adiabatic Temperature (K) & 2178 & 1869 \\
\hline A:F stoich $(\mathrm{DAF})$ & 9.4461 & 5.941 \\
\hline Heat of Formation (kJ/kg)(DAF) & -1500.45 & -4881.87 \\
\hline
\end{tabular}




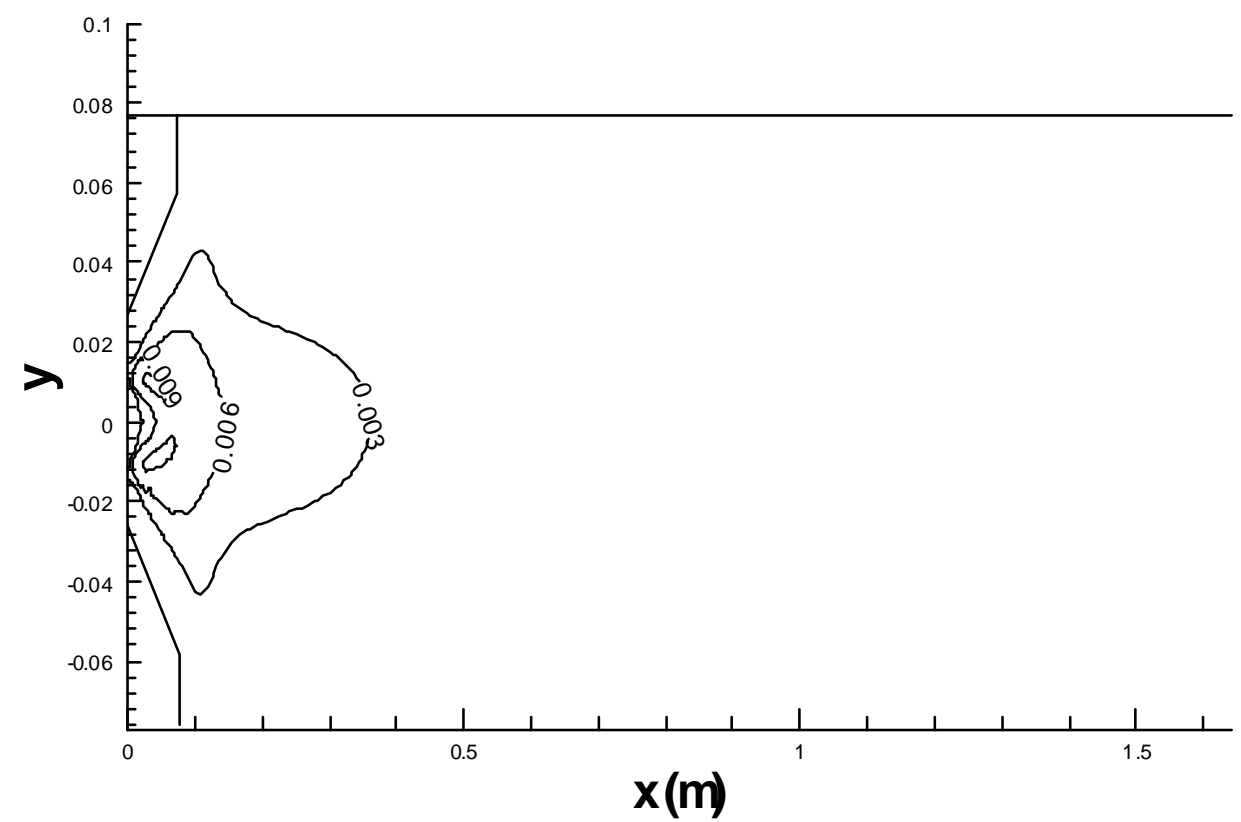

Fig. 3.4.2.1a: Distribution of mixture fraction $\eta_{3}$. Coal is dry.and Moisture in $L B=10 \%$

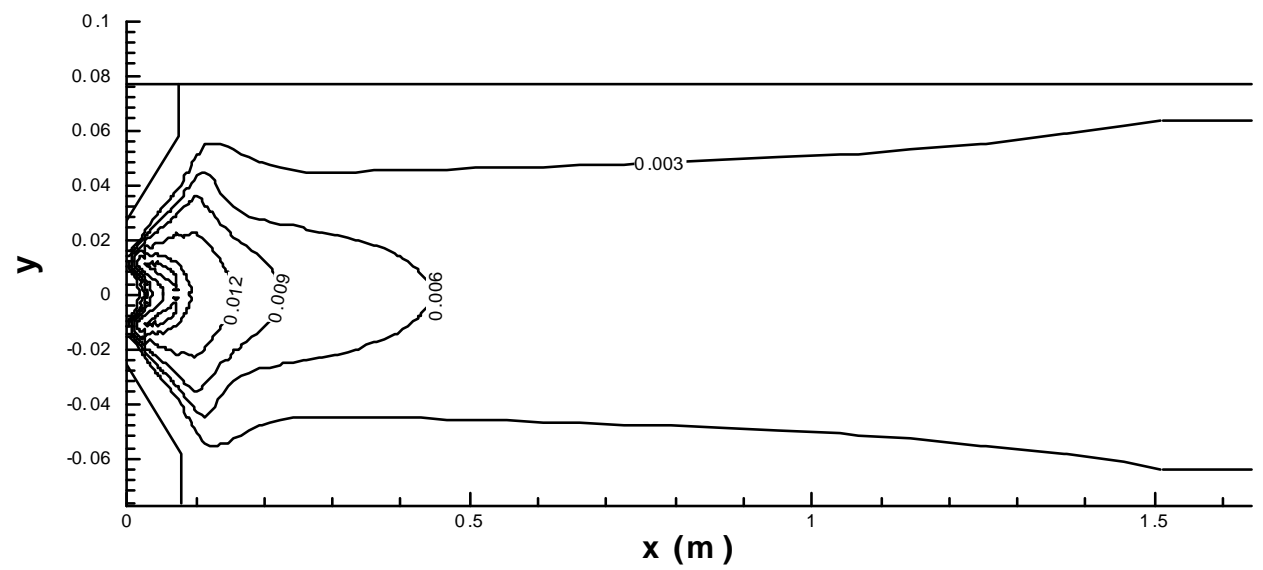

Fig. 3.4.2.1b: Distribution of mixture fraction $\eta_{3}$. Coal is dry and Moisture in $L B=20 \%$ 


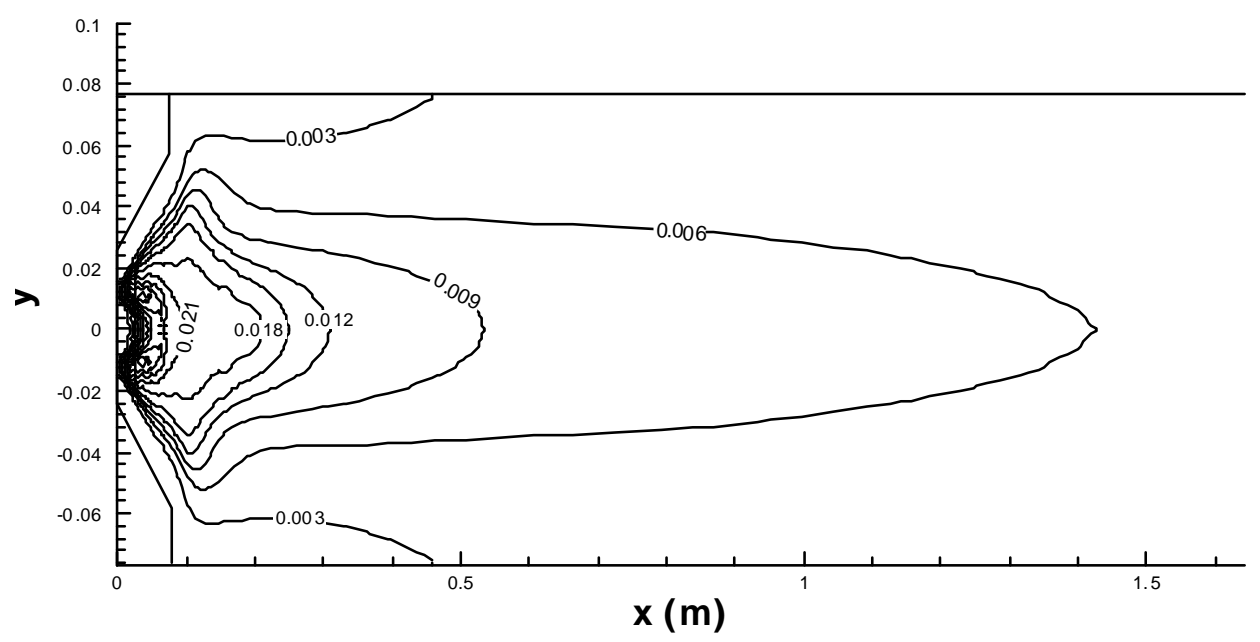

Fig. 3.4.2.1c: Distribution of mixture fraction $\eta_{3}$. Coal is dry.and Moisture in $L B=30 \%$

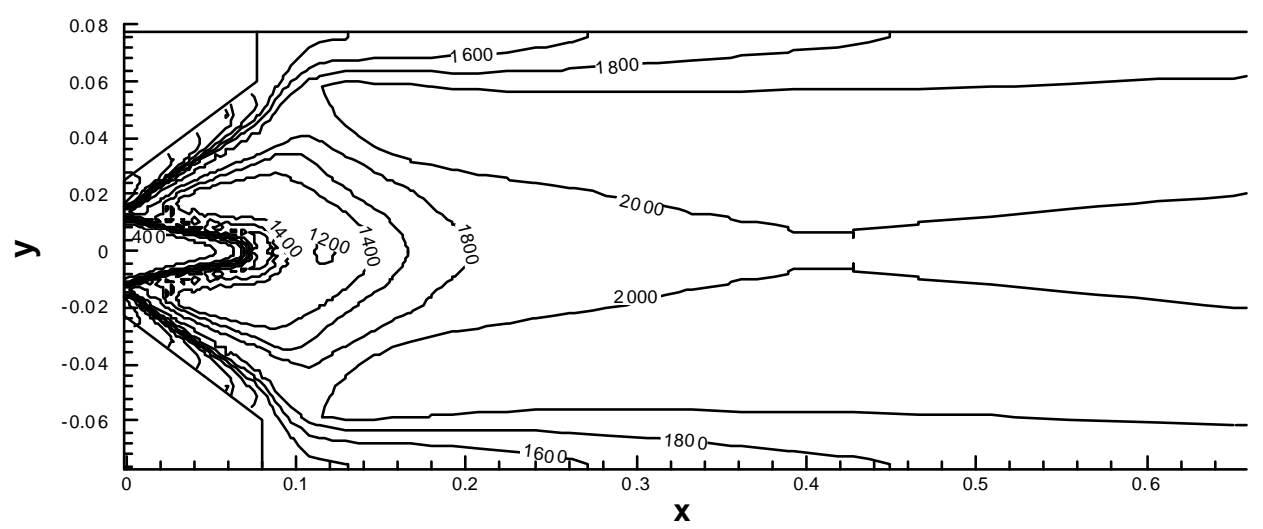

Fig. 3.4.1.2a: Distribution of temperature (K) when Coal is dry.and Moisture in $\mathrm{LB}=0 \%$

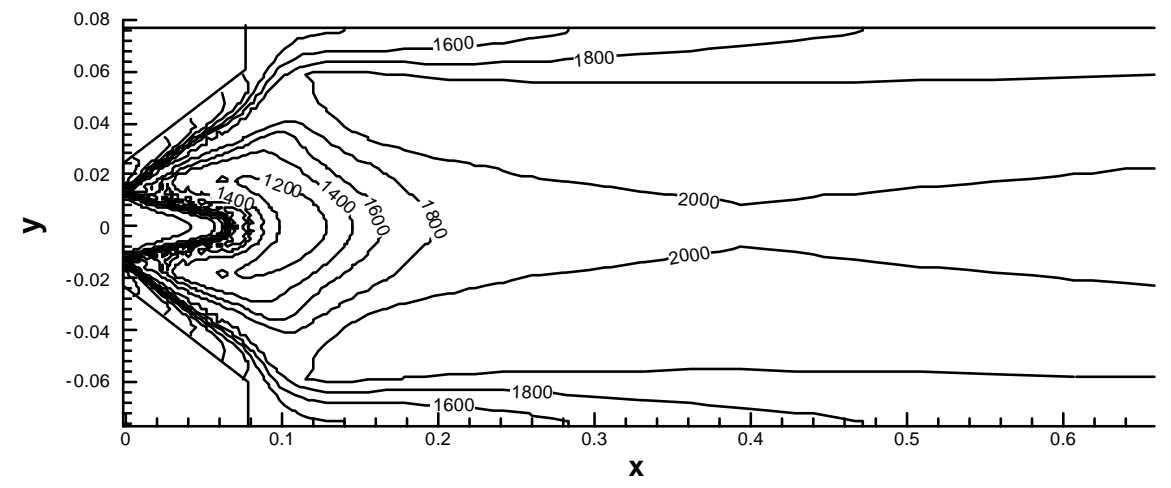

Fig. 3.4.1.2b: Distribution of temperature (K) when Coal is dry and Moisture in LB $=10 \%$ 


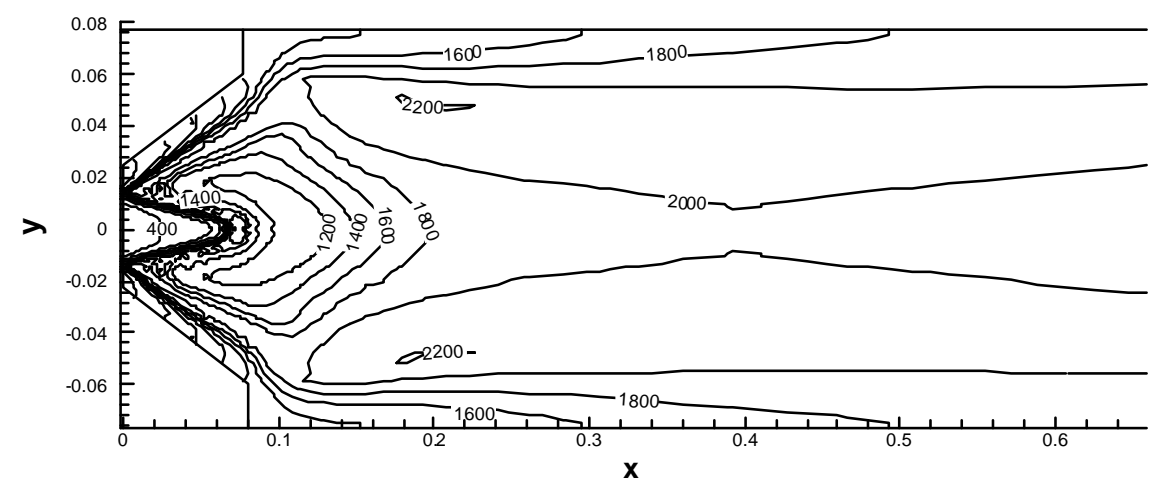

Fig. 3.4.1.2c: Distribution of temperature $(\mathrm{K})$ when Coal is dry and Moisture in $\mathrm{LB}=20 \%$

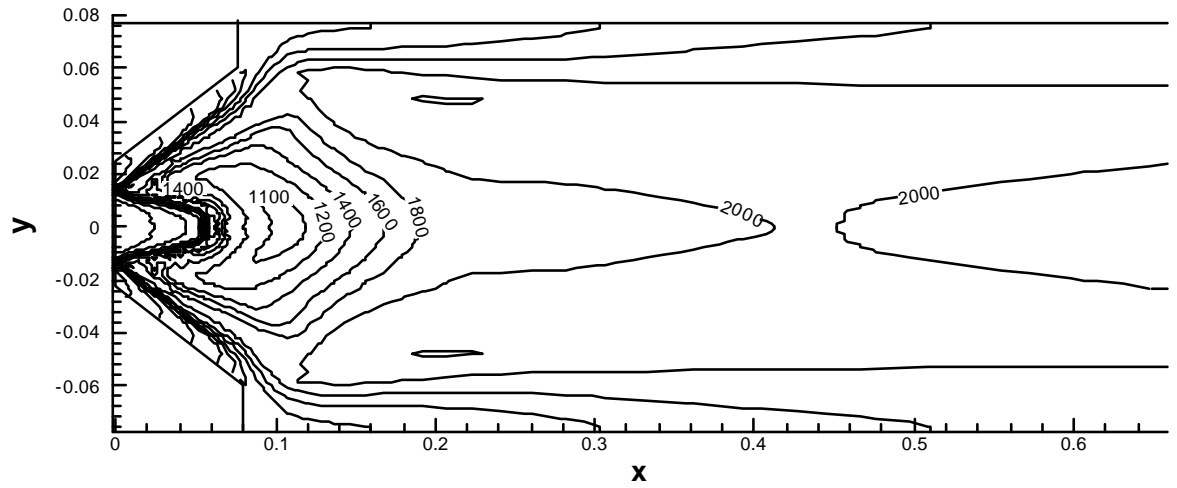

Fig. 3.4.1.2d: Distribution of temperature (K) when Coal is dry and Moisture in $\mathrm{LB}=30 \%$ 


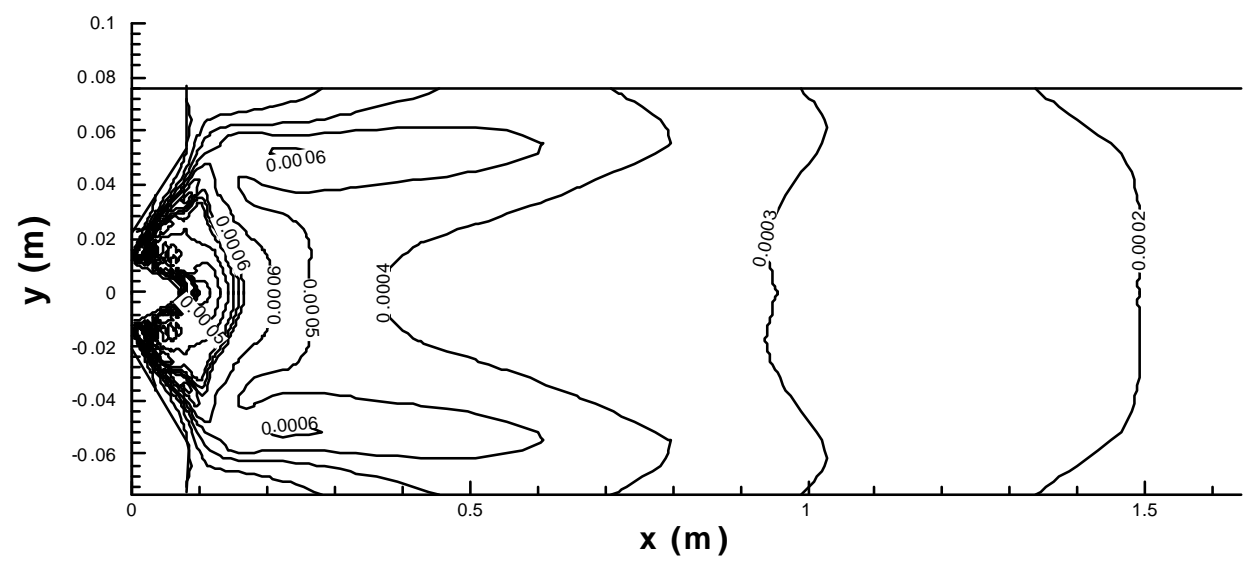

Fig. 3.4.1.3a: Distribution of NO mole fraction when Coal is dry and Moisture in LB $=0 \%$

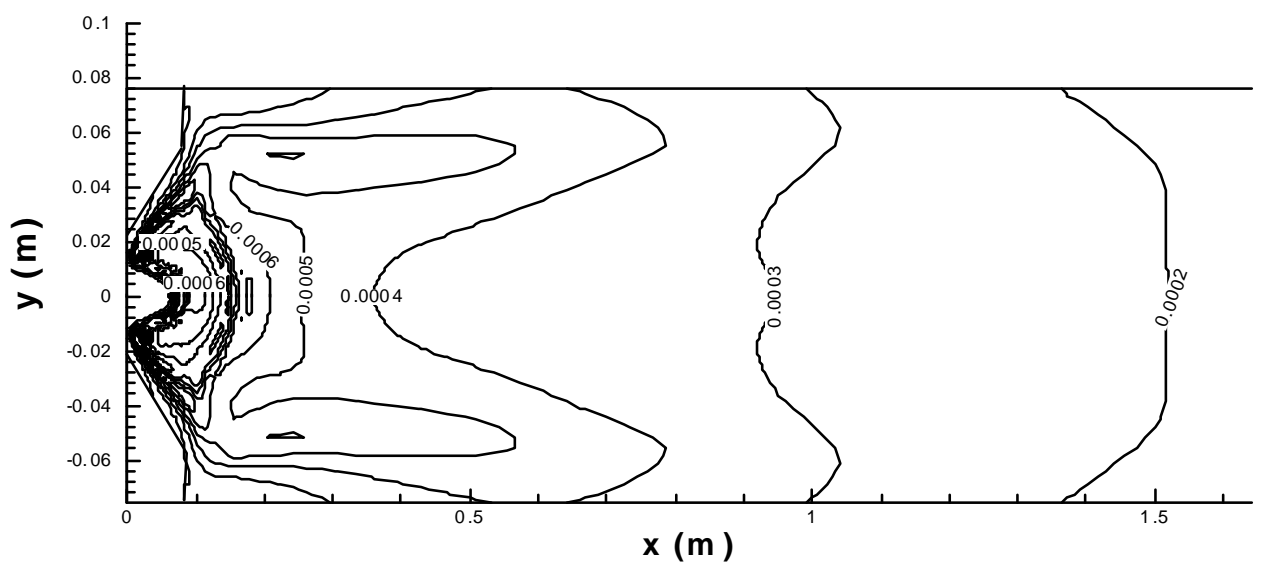

Fig. 3.4.1.3b: Distribution of NO mole fraction. Coal is dry. (a) Moisture in $\mathrm{LB}=10 \%$

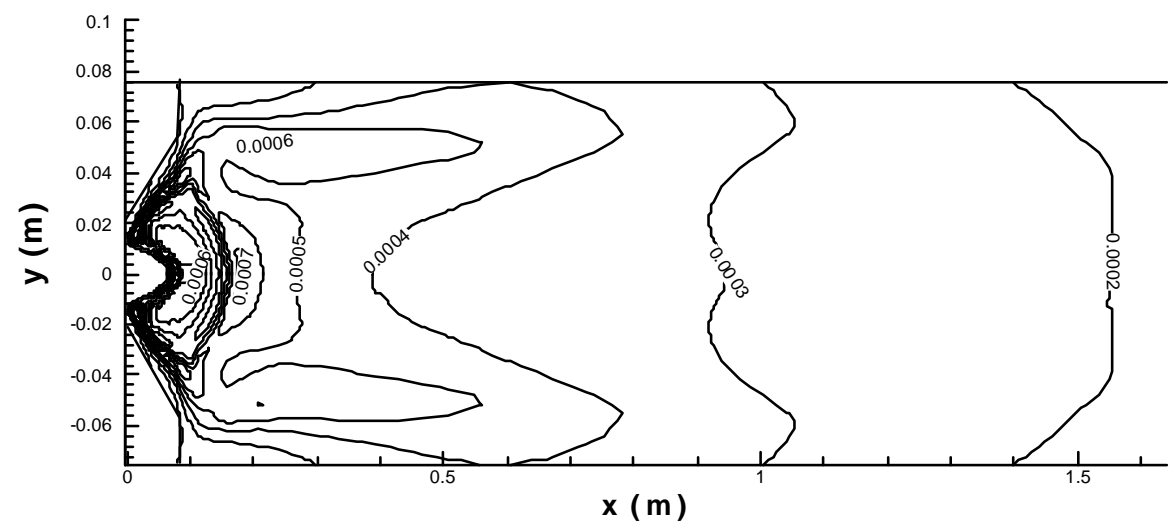

Fig. 3.4.1.3c: Distribution of NO mole fraction. Coal is dry. (a) Moisture in $\mathrm{LB}=20 \%$ 


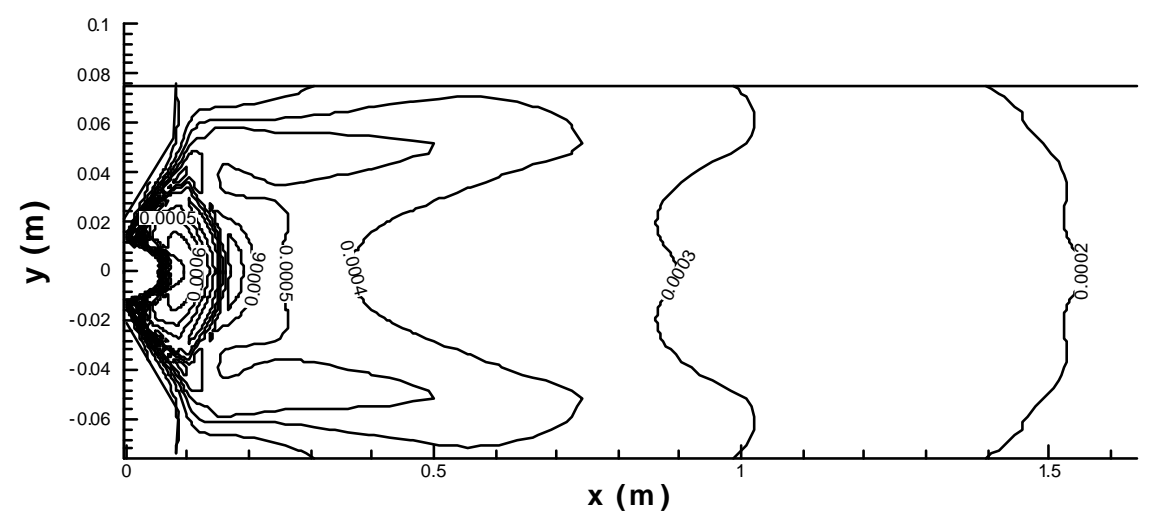

Fig. 3.4.1.3d: Distribution of NO mole fraction when Coal is dry and Moisture in LB $=30 \%$

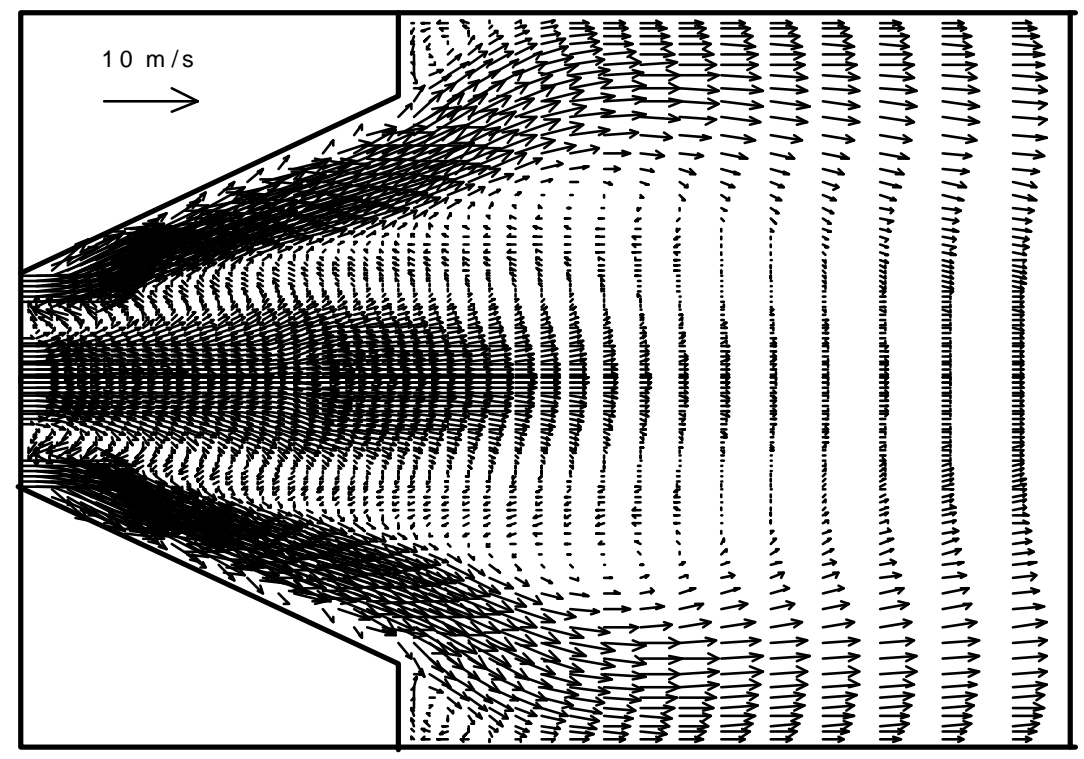

Fig. 3.4.1.3: Velocity vector distribution of cross section around burner for dry coal and 30\% moisture in LB 


\subsubsection{One Dimensional Modeling of the Fixed Bed Gasifier}

\subsubsection{Description of the model}

The model is a one dimensional, steady state model of a counter current fixed bed gasifier (3.4.2.1). Figures 3.4.2a and 3.4.2b show the various reaction zones in a countercurrent fixed bed gasifier. For details about the gasification process refer Annual Technical Report July 2001 [Annamalai, et al, 2001]. The formulation of the model is described in Appendix 6B. It has the same dimensions as the experimental setup (refer fig. 3.4.2.1), but in this case the heat loss from the bed to the refractory walls is neglected. The assumptions are:

1. The bed is characterized by a constant void fraction $\varepsilon$.

2. The moisture release is ignored.

3. The rate of pyrolysis is related to the rate of char burning, and it takes place at all heights in the bed.

4. The gas species considered are $\mathrm{CO}, \mathrm{CO}_{2}, \mathrm{O}_{2}, \mathrm{~N}_{2}, \mathrm{H}_{2}$, and $\mathrm{H}_{2} \mathrm{O}$.

5. The composition of the pyrolysis gas is derived from the proximate and ultimate analysis of the fuel.

6. A DAF fuel is considered for the model.

7. The diameter of the fuel particle is assumed to be zero at the grate.

8. The ratio of the particle surface area to the volume of the bed is calculated through out the bed.

9. The pyrolysis gas is assumed to burn to $\mathrm{CO}$ and water.

10. All the gas phase physical properties including specific heat and densities are functions of both species and temperature.

11. The fuel particle burns as a shrinking core, constant density solid.

12. Assumed $\mathrm{Sh}=2$ and $\mathrm{Le}=1$.

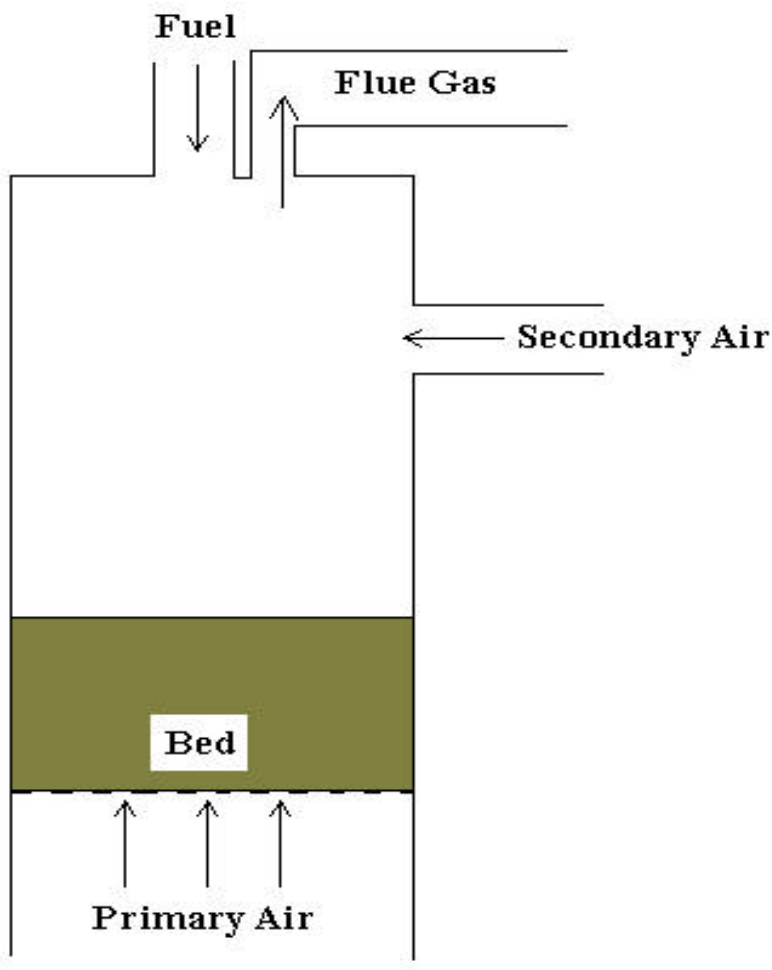

Figure 3.4.2.1: Schematic of the modeled Gasifier 


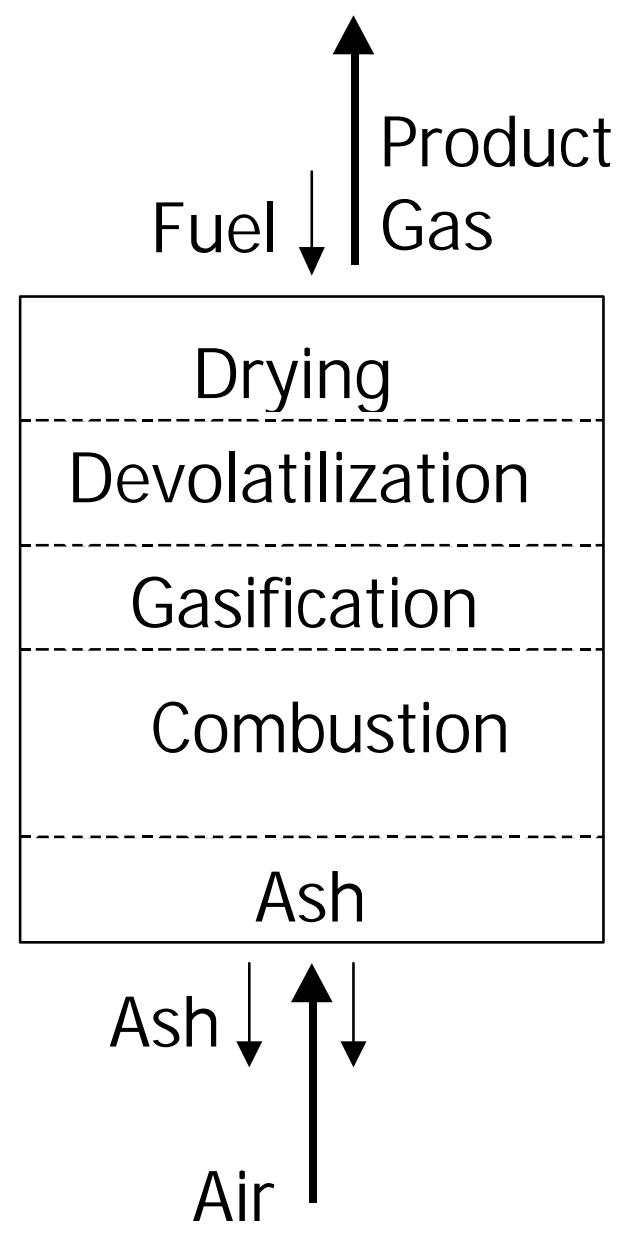

Figure 3.4.2.2a: A schematic of various stages of countercurrent gasification 
Products, CO2,

$\mathrm{H} 2 \mathrm{O}, \mathrm{CO}, \mathrm{N} 2$

Secondary/Overfire

Air

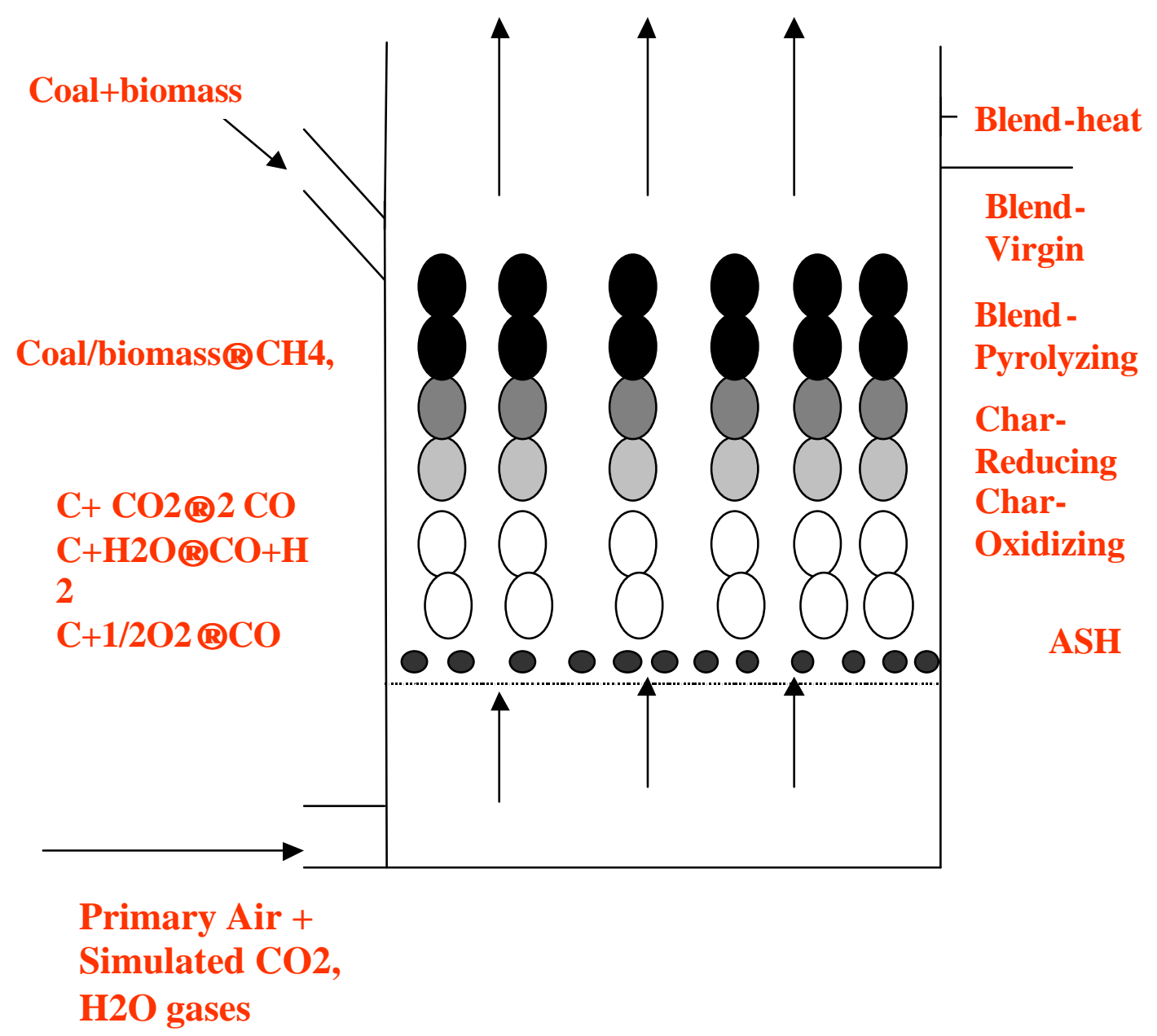

Figure 3.4.2.2b: A schematic of various stages and reactions within a countercurrent gasifier 


\section{Boundary Conditions \\ For the gas phase}

The temperature and the gas composition are specified at the grate.

For the solid (fuel)

The particle size and composition is specified at the top of the bed.

\section{Solution:}

All the equations from 1 to 40 are going to be solved iteratively. Since the diameter of the particle is known only at the top and bottom of the bed, a fuel particle diameter as a function of the bed height is assumed. Then the equations are solved for the entire bed. The resulting particle velocity as a function is then used to update the assumed fuel diameter and the iteration is repeated. The procedure is repeated until the solution converges.

The relationship used to update the particle diameter is:

$\frac{\left.V_{S}\right|_{\text {top }}}{d_{p, t o p}^{2}}=\frac{\left.V_{S}\right|_{z}}{d_{p, z}^{2}}$

Currently there are problems with the simulation as there is blow out. There seems to be a problem with the energy conservation equation for both the gas phase and the solid phase. The majority of the model is modeled on the model used by Bryden and Ragland (1996), but there seems to be a problem with the solid phase energy equation used by the authors. The energy conservation equation is under review; most probably the blow out problem may be solved with the corrections made to the energy equations. 


\subsection{Task 5:Fuel Collection, transportation, and Economic analyses of feedlot and litter biomass fuel}

\section{Manure Grinder}

In an effort to reduce the costs associated with grinding the manure fuels for firing, a grinder was purchased to grind the manure at the feedyard. A feed grinder was purchased from Jim Allison with New way Pork for $\$ 225$ on September 4, 2001. The components of the grinder include:

2-hammer mills

2-10 hp 3 phase electric motors

1-1 hp 3-phase electric motor

4-mm stationary screen

The feed grinder was converted into a manure grinder. An 8-hp gas motor was attached to drive the main hammer mill. The smaller hammer mill has not been used to this point. The grinder is belt driven with a belt driven auger attached to the underside of the grinder. A 3/4p electric motor was installed to supply power to the conveyor auger. A 2-mm screen was welded on top of the 4-mm to reduce the particle size. Upon examining the results of the modification a 1-mm screen replaced the 2-mm screen to further reduce particle size. At this point the $1 \mathrm{~mm}$ mesh screen is effective; however, there is a $.44-\mathrm{mm}$ screen available that may possibly be more effective depending on cost and permeability.

Two composite samples of partially composted manure from fly ash surface pen 11 (this manure is currently being dried down in the USDA greenhouse at Bushland as of Nov 29, 01) were micronized on November 16, 2001. These 2 samples received different treatments: a) one pass through the manure grinder, and b) two passes through the grinder. These tests were conducted to measure particle size and size distribution changes from multiple passes through the manure grinder. All sieve analysis test were conducted at Texas A\&M University, College Station. Manure was micronized at Amarillo facility. The results(figure 3.5.1) show that two pass grinding resulted in a smaller particle size than one pass grinding, but the particles were not exactly of the same size as previously ground samples. The results indicate that a better grinding methodology involving more grinding passes, or a smaller screen will be necessary. 
US Standard Sieve Size

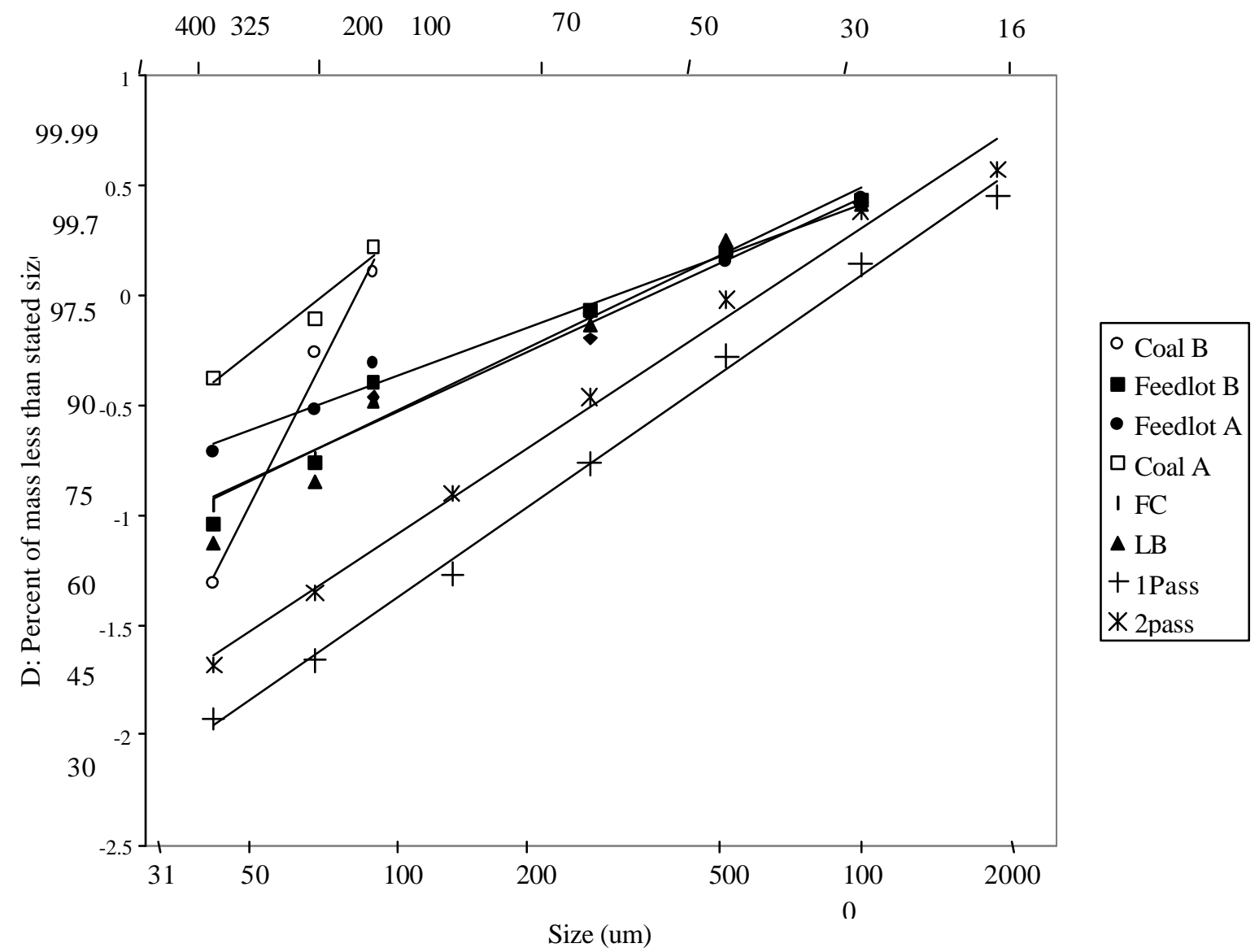

Acceptable parameters $75 \%$ pass through 100-micron sieve

Acceptable parameters 70\% pass through 70-mesh sieve

Feedlot A:

Feedlot B:

FC: fully composted cattle manure

LB: litter biomass

1 pass: Fly ash surfaced manure, one pass through the TAES manure grinder

2 pass: Fly ash surfaced manure, two passes through the TAES manure grinder

Figure 3.5.1: Size classification, of manure ground on-site.

\section{Unground manure collection}

Unground PC manure was collected for the gasification studies at A\&M. This manure was not micronized as requested because the rough product was needed. The partially composted manure was shipped via Central Freight in two 55-gallon drums on October 24, 2001. This manure was not dried down in the USDA greenhouse before shipment.

This manure was harvested from fly ash surfaced feedpens (pens 5, 6, 7, 8, 9, 10, 14,and 15) and soil surfaced feedpens (pens 2, 3, 16, and 17) at TAES/USDA-ARS Bushland (Feedyard C). The manure was removed from the feedpens on June 5-13, 2001 and placed in the manure storage area. No water was added at the time of collection because we did not want to start the composting process until College 
Station could tell us exactly what they needed for their co-fire projects (i.e. raw, partially or fully composted manure). All fly ash surfaced pens were combined into one windrow and all soil-surfaced pens were combined into one windrow in the manure storage area at TAES/USDA-ARS Bushland on 7-13-01 (no water added).

On August 24 and 25, 2001 water was added to the two windrows to start the process of composting. 2000 gallons of water were added to the manure from the fly ash surfaced pens and 1000 gallons were added to the manure from the soil surfaced pens. The water was added to the windrows while being turned by a skid-steer loader. The properties of the unground manure are shown in tables' 3.5.1 and 3.5.2.

Table 3.5.1: Ash content of unground manure

\begin{tabular}{|lc|}
\hline \multicolumn{1}{|c|}{ \% Ash d.b. } & Date \\
& G-23-01 \\
Manure from fly ash surfaced feedpens & $16.53+/-0.79$ \\
Manure from soil surfaced feedpens & $51.21+/-12.51$ \\
Fly ash powder & $89.47+/-0.19$ \\
\hline
\end{tabular}

Table 3.5.2: Moisture of unground manure

\begin{tabular}{|lccc|}
\hline \% Moisture d.b. & Date & $\begin{array}{c}7 / 13 / 01 \\
\text { Feedyard C }\end{array}$ & $\begin{array}{c}10 / 22 / 01 \\
\text { Grand mean +/- Std dev }\end{array}$ \\
\hline Manure from fly ash surfaced feedpens & $11.87+/-3.20$ & $9.55+/-4.11$ \\
Manure from soil surfaced feedpens & $12.27+/-3.87$ & $8.16+/-2.49$ \\
& & \\
\hline
\end{tabular}

Although this manure was not dried down in the USDA greenhouse, moisture levels were very low. This is due to the lack of precipitation from August to October. Moisture analysis performed by Kevin Heflin, Technician 1. Ash analysis performed by Joan Avampato (TAES technician).

Harrington power plant in Amarillo donated approximately $600 \mathrm{lbs}$ of Wyoming coal to the co-fire project. The uncrushed coal was collected from the storage area at Harrington as per TAMU request on 920-01. The coal was placed in five-gallon buckets to make shipping and handling easier and delivered to TAMU facility 


\section{Litter Biomass:}

Figure 3.5.2 shows the number of farms by county.

\section{Number of Farms by County, Sanderson Poultry Farms}

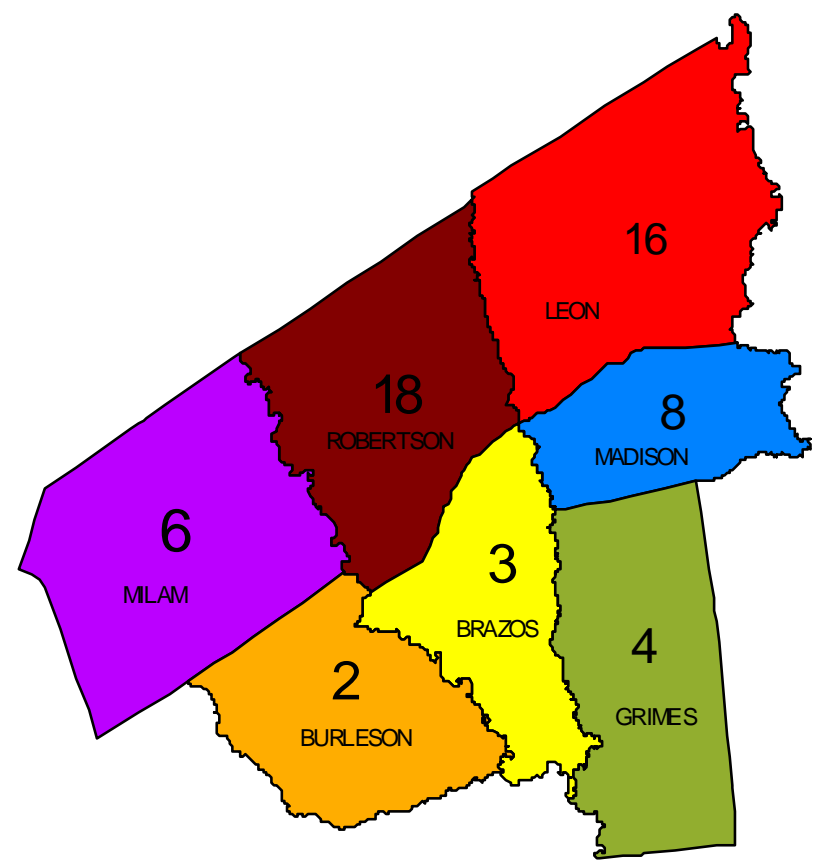

Counties

\begin{tabular}{|l|l}
\hline & BRAZOS \\
\hline & BURLESON \\
\hline & GRIMES \\
\hline & LEON \\
\hline & MADISON \\
\hline & MLAM \\
\hline & ROBERTSON \\
\hline
\end{tabular}<smiles>CC1(N)CCCCC1(C)N</smiles>

Figure 3.5.2: Number of farms by county 


\subsection{Schedule and Progress}

Figure 3.6.1 shows the degree of progress on the five tasks.

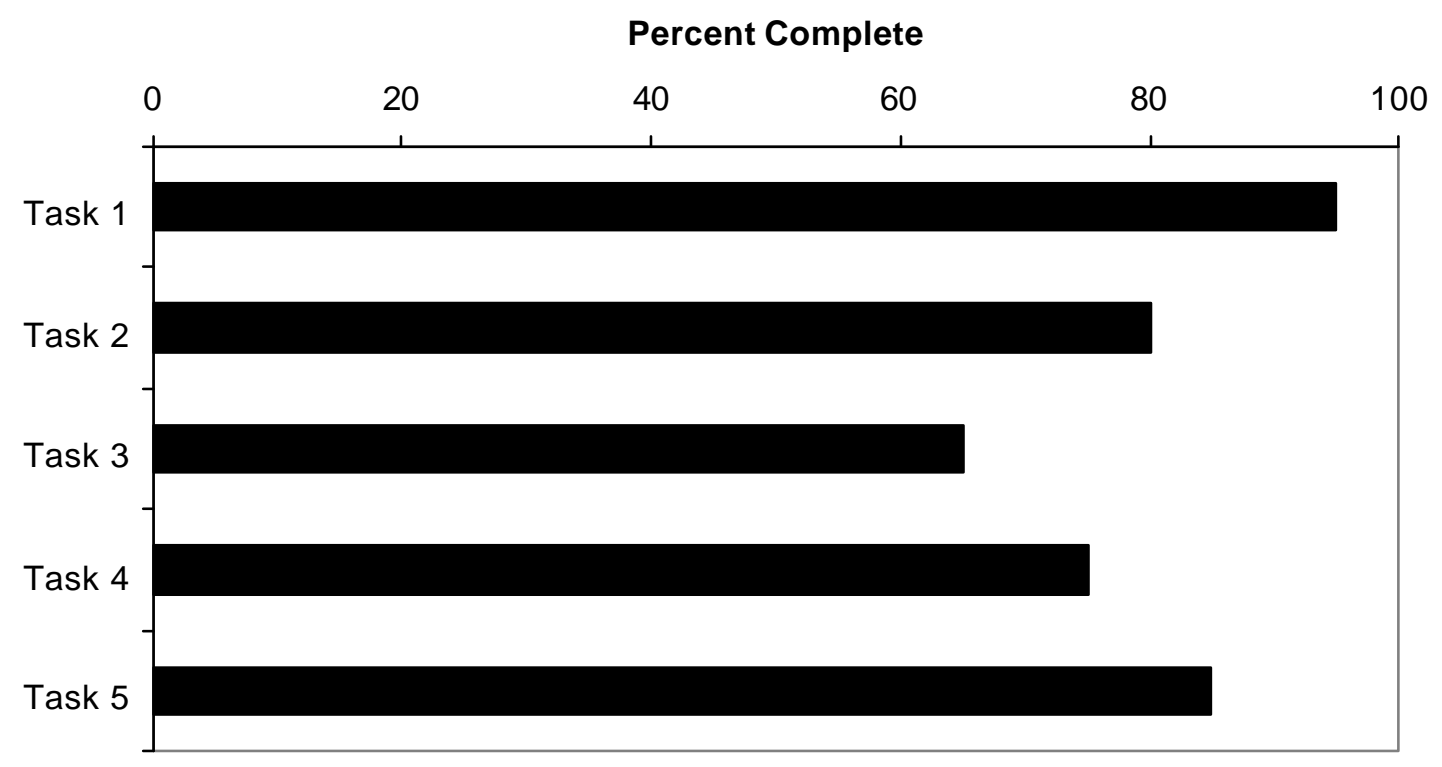

Figure 3.6.1: Progress on the five tasks 


\section{Conclusions and Future Work}

1. Fundamental experiments were performed on fuel characterization including ultimate and proximate analyses, TGA in $\mathrm{N}_{2}$ and air etc. Biomass releases volatiles at lower temperature compared to coal. The ash $\%$ from fly ash surfaced feedlot is found to be $2 \%$ while for ash from soil surfaced feedlot, it is found to be $43 \%$. Special low $\mathrm{P}$ ration was fed to cattle and $\mathrm{P}$ in manure is being investigated. Litter sample from the Brazos Valley were collected and shown to have little variation between samples.

2. The performance of the boiler burner was evaluated for coal, 90:10 coal:FB blend, and 90:10 coal:LB blends. Even though the biomass have higher volatile matter, the burnt mass fractions in the modified reactor are found to be similar probably due to having larger sized particles for biomass. The firing of coal-biomass blends does not result in a change in NO emission on a heat basis or a concentration basis at all excess air percentages even though N\% increased by 8-20\% when fired with blends. The reburn tests with LB indicate a reduction of $80 \%$ while for coal only $40 \%$ was achieved. The $\mathrm{N}$ fuel conversion efficiency when firing biomass blends is lower than when firing coal.

3. Construction of the gasifier has been completed. Preliminary gasifier experiments were run and temperature traces were obtained. Problems in gas sampling were detected due to high tar emission from the gasifier.

4. The PCGC code has been modified for the gradual release of water vapor with the fuel, the oxidation of phosphorus, oxidation of carbon to $\mathrm{CO}_{2}$ and reduction reactions with $\mathrm{CO}_{2}$ and $\mathrm{H}_{2} \mathrm{O}$. A simulation model for the gasifier is also being developed.

5. A feed grinding mill was obtained to allow for a more economical process of sample preparation. Grinding the manure with a $1 \mathrm{~mm}$ screen and 2 passes does not sufficiently grind the manure. Manure was harvested for the gasifier experiments, and analyzed for ash and moisture content. 


\section{References}

Adams, B., Harding, N., 1998, "Reburning Using Biomass for $\mathrm{NO}_{\mathrm{x}}$ Control”, Fuel Processing Technology, v. 54 , pp 249-263.

Annamalai, K. A., Caton, J. A., Roth, J., Ryan, W. and Schmidt, J., 1987c, "Performance and emissions of coal-fueled engines using combustion theory", Contract No. DE-AC21-86, Interim Report 1986-1987, Department of Mechanical Engineering, Texas A\&M University, College Station, Texas.

Annamalai, K., Ibrahim, Y.M., and Sweeten, J, 1987a,"Experimental Studies on the Combustion of Feedlot Manure in a Fluidized Bed Combustor," ASME Journal of Energy Resources and Technology, v.109, pp. 49-57.

Annamalai, K., J. M. Sweeten, and S. C. Ramalingam, 1987. "Estimation of Heating Values of Biomass Fuels," Transactions of the ASAE. 30 (4): 1205-1208.

Annamalai, K., Sweeten, J., Mukhtar, S., Thien, B., Wei, G., Priyadarsan, S., "Co-firing Coal, Feedlot, and Litter Biomass (CFB and LFB) Fuels in Pulverized Fuel and Fixed Bed Burners", Annual Technical Report, July 2001, DEFG26-00NT40810, DOE-National Energy Technology Laboratory, Pittsburgh, Pa.

Anthony, D., Howard, J., Hottel, H., Meissner, H.,1974, “Rapid Devolatilzation of Pulverized Coal.”, Fifteenth Symposium (International) on Combustion, Vol. 15, pp 1317-1303.

Arthur, J.R.,"Reactions Between Carbon and Oxygen" Trans.Faraday Soc., v 47,164-178, 1951

Bilboa, R., Alzueta, M., Angela, M., 1995, "Experimental Study of the Influence of the Operating Variables on Natural Gas Reburning Efficiency," Industrial and Engineering Chemistry Research, v 34, p 4531-4539.

Bilboa, R., Alzueta, M., Millera, A., Prada, L.,1997, "Dilution and Stoichiometric Effects on Gas

Reburning: An Experimental Study", Industrial and Engineering Chemistry Research, v. 36, p. 2440-2444, 1997.

Bilboa, R., Millera, A., Alzueta, M., 1994,"Influence of the Temperature and Oxygen Concentrations on $\mathrm{NO}_{\mathrm{x}}$ Reduction in the Natural Gas Reburning Process", Industrial and Engineering Chemistry Research, v. 33 , p. 2846-2852.

Bird, W. D., Steward, W. E. and Lightfoot, N. E., 1960, Transport Phenomena, Wiley, New York, NY.

Brewster, B. S., et al. In Coal Science And Technology, vol. 20, Fundamentals of Coal Combustion for Clean and Efficient Use; Smoot, L. D., Ed.; Elsevier: New York, 1993; Chapter 8.

Bryden, M.K., and Ragland, W.K., 1996, "Numerical modeling of a deep, fixed bed combustor," Energy \& Fuels, vol. 10, 269-275

Chen, W., Ma, L., 1996, "Effect of Heterogeneous Mechanisms During Reburning of Nitrogen Oxide," AIChE Journal, v. 24, pp. 1968-1976.

Dhanapalan, S. V., 1996, Turbulent Combustion Modeling of Coal:Biomass Blends in a Swirl Burner, $\mathrm{PhD}$ Dissertation, Texas A\&M University, College Station, TX.

Dhanapalan, S., Annamalai, K. and Daripa, P., 1997, "Turbulent combustion modeling of coal:biomass blends in a swirl burner I-Preliminary results", $8^{\text {th }}$ Annual Energy Week, ETCE, ASME, pp.415-423.

Eghball, B., Power, J., 1994, "Beef Cattle Feedlot manure Management", Journal of Environmental Quality, v.49, pp.113-22, 1994. 
Evans, D.D., Emmons, H. W., Fire Res. 1977, 1, 57-66.

Frandsen, F., Kim, D. and Rasmussen, P., 1994, “Trace element from combustion and gasification of coal an equilibrium approach”, Progress in Energy Combust. Science., vol. 20, pp. 115-138,

Heflin, K., MS Thesis in preparation, WTAMU,2001

Howard, J. B. and Sarofim, A. F., 1978, "Gasification of coal char with carbon dioxide and stream at 12001800C”, Energy Laboratory Report, Dept. of Chem. Eng, Massachusetts Institute of Technology.

Hutchinson, D., Rauh, W., Amosson, S.,1995, "The Effects of Pen Surface Management on Cattle Performance," Chapter 3, Total Quality Manure Management Manual, Texas Cattle Feeders Association.

John M. Sweeten, K. Annamalai, and B. Thien, and Lanny, A. McDonald, "Co-Firing of Coal and Cattle Feedlot Biomass (FB) Fuels: Part I: Feedlot Biomass (Cattle Manure) Fuel Quality and Characteristics," under Review; see also Proceeding of the Pittsburgh International Coal Conference, Pittsburgh, (2000).

Kicherer, A., Spliethoff, H., Maier, H., Hein, K., 1994, “The Effect of Different Reburning Fuels on $\mathrm{NO}_{\mathrm{x}}$ Reduction," Fuel, v. 73 pp 1443-1446.

Malay, P., Zamansky, V., Ho, L., Payne, R., 1999, “Alternative fuel Reburning,” Fuel, vol. 78, 327-334

Miller, C., Lemieux, P., Touati, A., 1996,"Evaluation of Tire-Derived Fuel for Use in Nitrogen Oxide Reduction by Reburning," Journal of the Air and Waste Management Association, v 48 pp: 729-735.

PCGC2, 1988, Revised User's Manual, Advanced Combustion Engineering Research Center, Brigham Young University and University of Utah.

Sami M, Annamalai, K, Senthil, D., and Wooldridge, M., 1999, "Numerical simulation of blend combustion of coal and feedlot waste in a swirl burner" ASME HTD 364-2, Edited by L C Witte, pp363371.

Sami M., 2000, "Numerical Modeling of Coal-Feedlot Biomass Blend Combustion And $\mathrm{NO}_{\mathrm{x}}$ Emissions In Swirl Burner", PhD Dissertation, Texas A\&M University, 2000.

Sami, M., Annamalai, K., Dhanapalan, S. and Wooldridge, M., 1999, "Numerical simulation of blend combustion of coal and feedlot waste in a swirl burner," ASME HTD 364-2, Edited by L C Witte, pp363371.

Saul, and Wagner, 1986, ASME.

Smoot, L. D. and Smith, P. J, 1985, Coal combustion and gasification, Plenum Press, New York, NY.

Sweeten J., Korenberg, J., LePori, W., Annamalai, K., and Parnell, C.B. 1986,"Combustion of Cattle Manure for Energy Production," Energy in Agriculture, vol. 5, 55-72

Sweeten, J., "Manure Management for Cattle Feedlots", Texas Agricultural Extension Service Publication L-1094.

Thien at al. 2002, "Cofiring of Coal:feedlot biomass and coal:litter biomass Blends in a Boiler Burner, “ $\mathrm{Ph} \mathrm{D}$ Thesis ( in preparation).

Thien, B., and Annamalai, K., 2001"Reduction of NO Through Reburning With Coal and Feedlot Biomass" Proceedings Of The Second Joint Meeting Of The Combustion Institute, Oakland, CA, march 25 -28 . 
Thien, B., Annamalai, K., Bukur, D., 2001, "Thermo gravimetric Analysis of Coal, Feedlot Biomass and Blends in Inert and Oxidizing Atmospheres," Proceedings of IJPGC, New Orleans, LA.

Yoon, H., et al. AIChe J. 1978, 24, 885-903.

Yunas, A. Cengel; Michael A. boles, Thermodynamics An Engineering Approach, Primis Custom Publishing, 1998, pg. 901. 


\section{Appendixes Appendix 6A - Gasifier details}

\section{Fabrication}

The overall set up is shown schematically in figures 3.3.3a and 3.3.3b, and the photograph in figure 3.3.3c. Figures 3.3.3d and 3.3.3e show the important dimensions of the gasifier. For the design and modeling details refer Annual Technical Report July 2001 [Annamalai, et al, 2001].

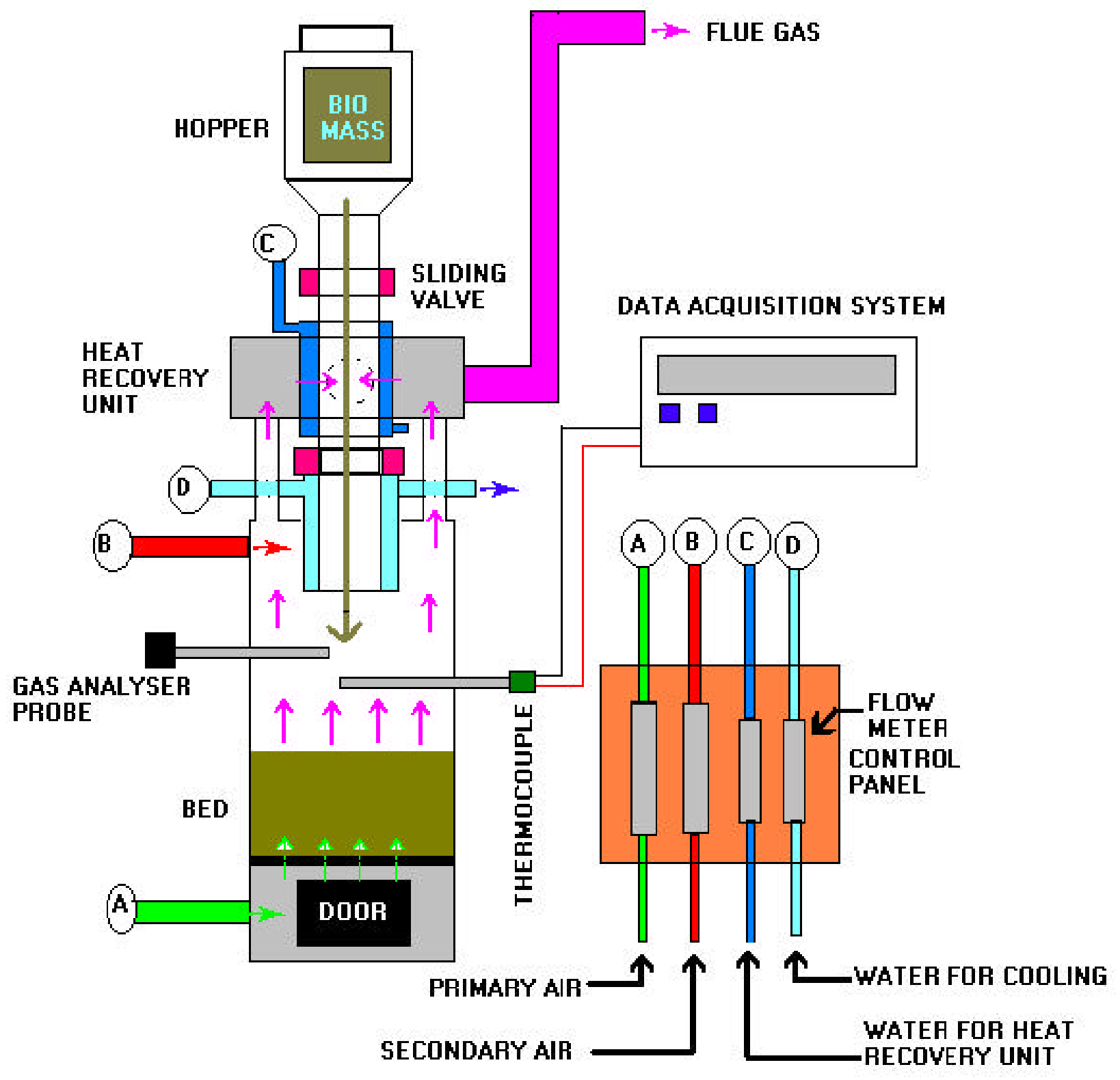

Figure 3.3.3a: Schematic view of the setup 


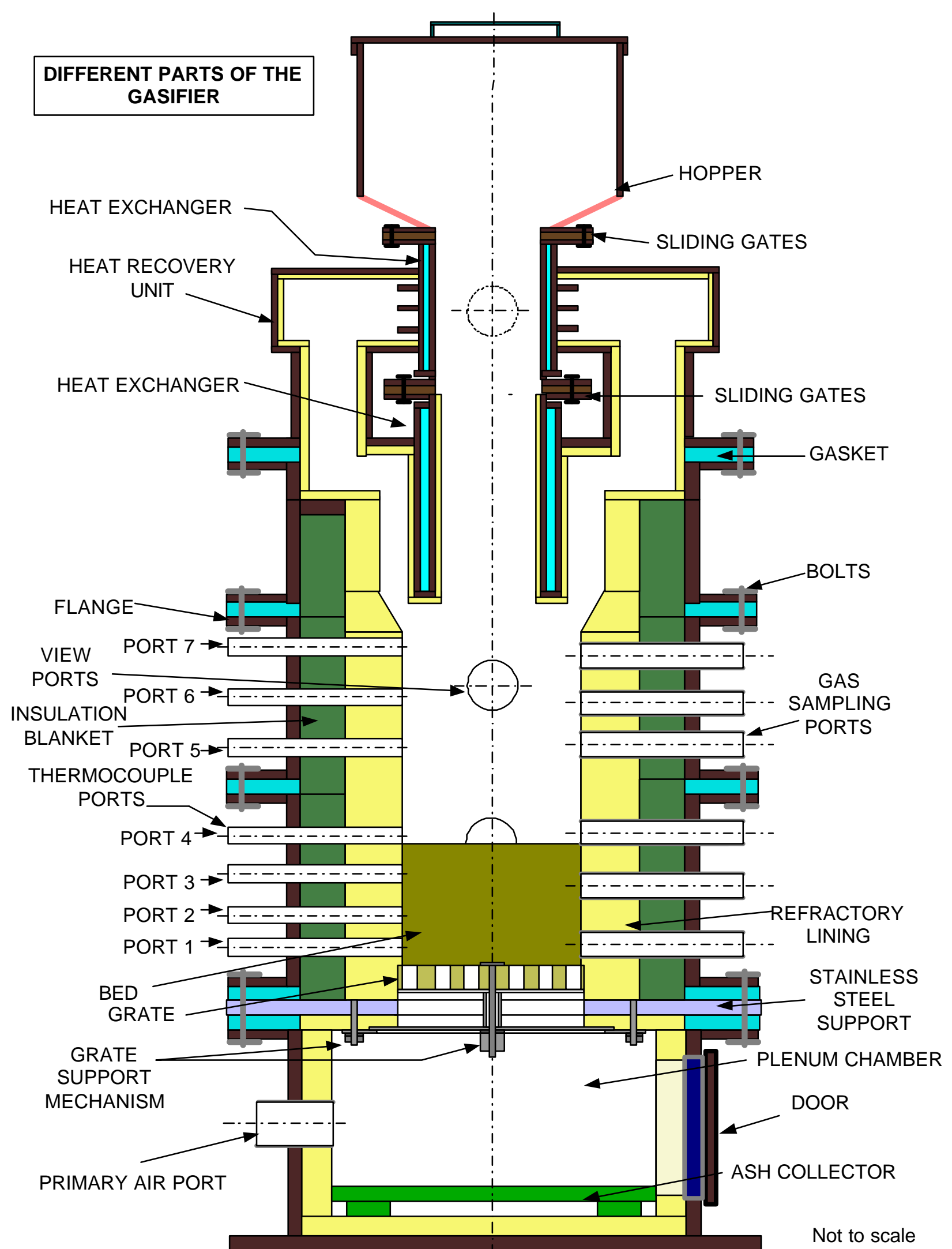

Figure 3.3.3b: Main parts of the setup 


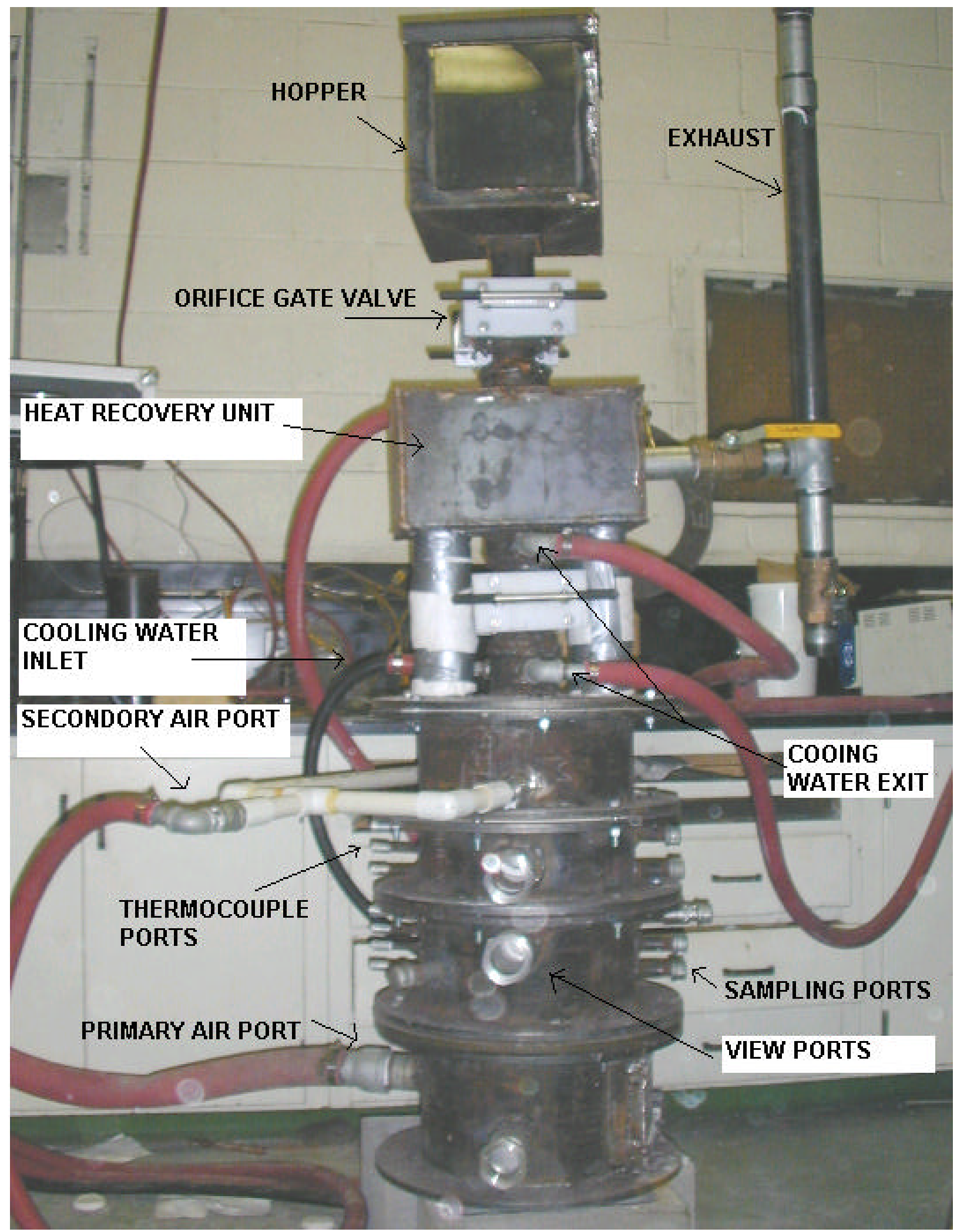

Figure 3.3.3c: View of the setup 


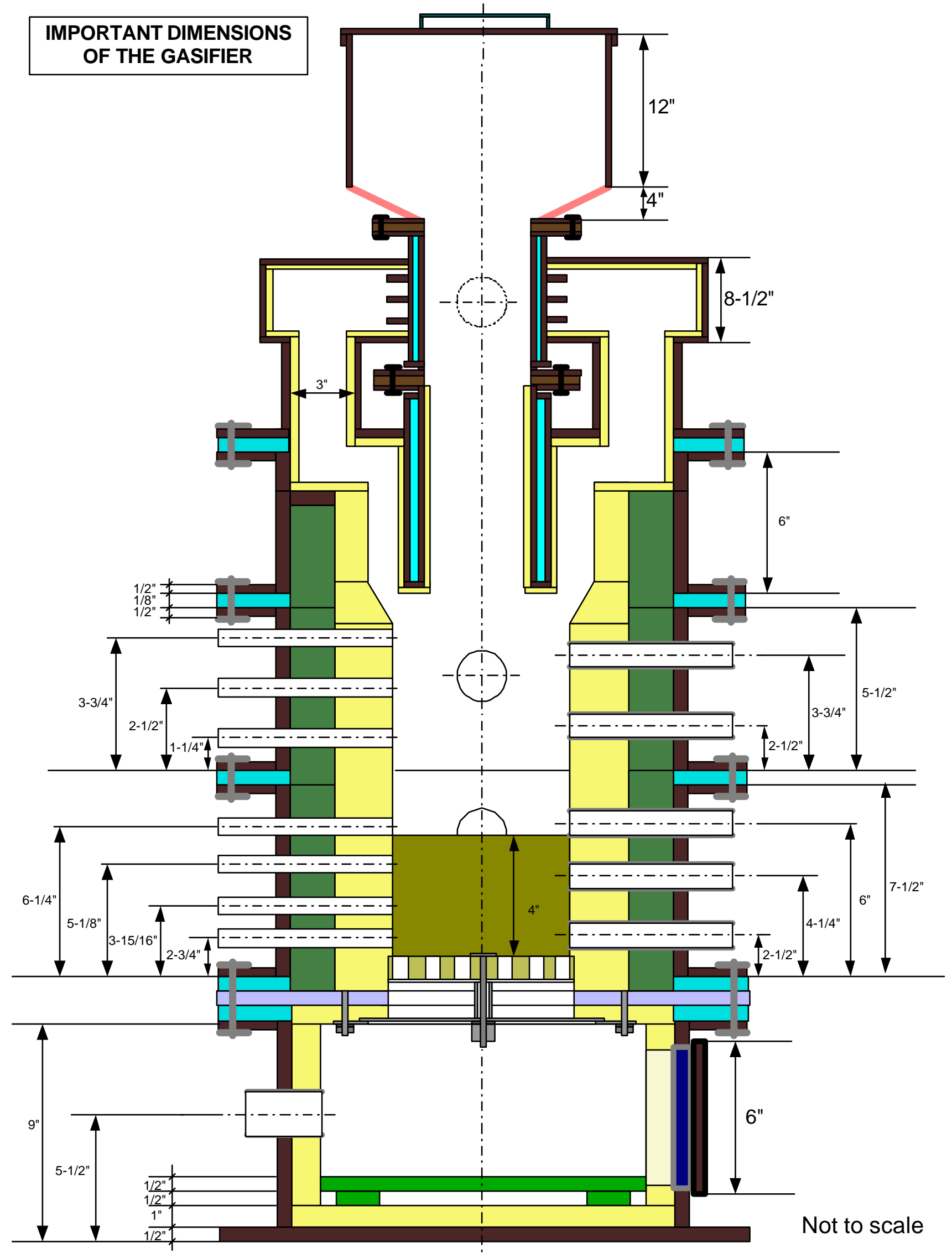

Figure 3.3.3d: Important dimensions of the gasifier 


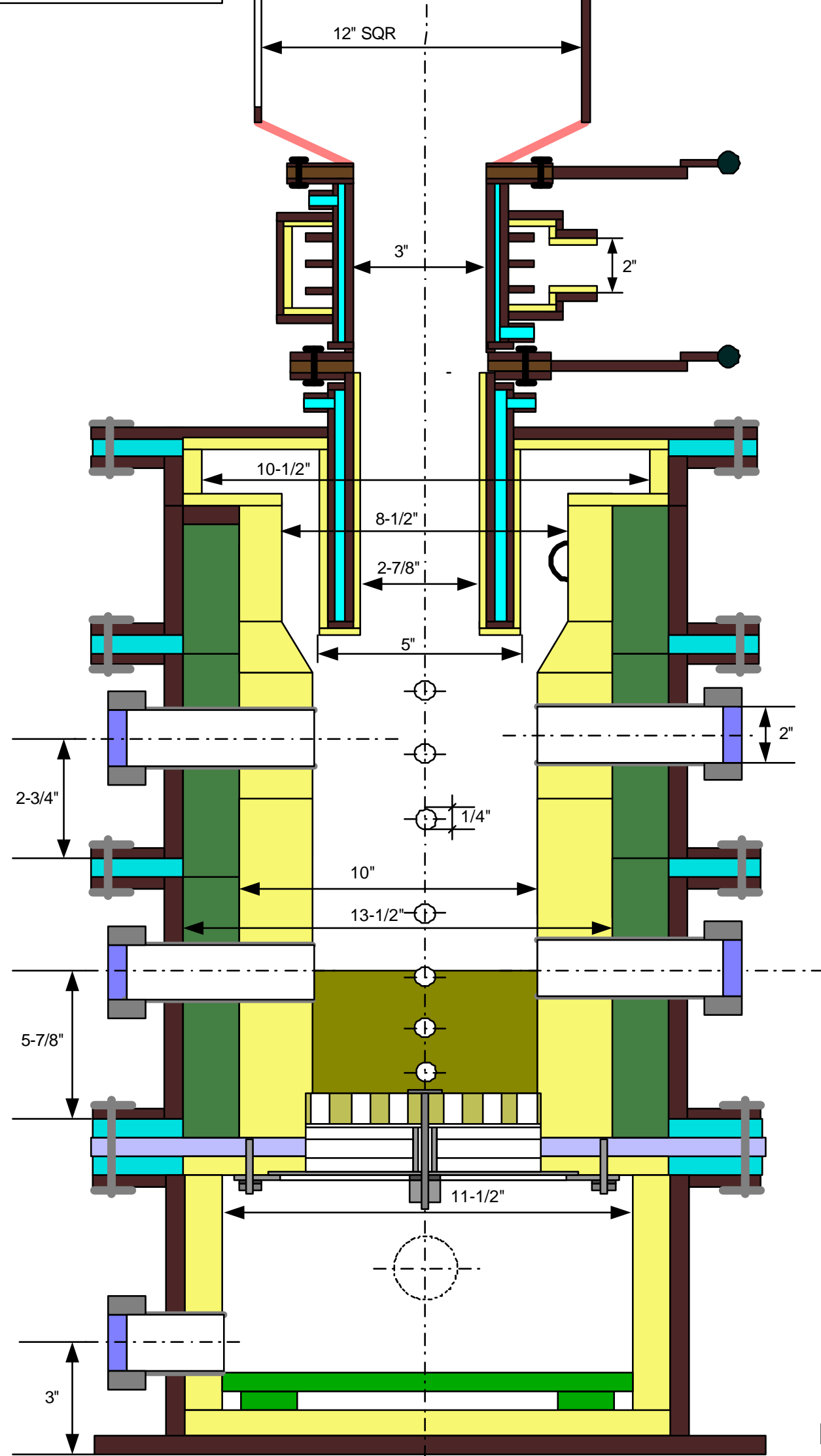

Not to scale

Figure 3.3.3e: Important dimensions of the gasifier 


\section{Gasifier:}

Ring type flanges of $\mathrm{k} / 2 \times 13-\mathrm{p} / 2 \times 20$ ”, made of plain carbon st eel are used to join the various sections of the gasifier. In each of these there are six drilled holes of 0.6 " in diameter, having a pitch circular diameter of 18". These drilled holes are used to bolt two flanges together (fig 3.3.4). These are welded to the outer shell of the gasifier using the metal inert gas welding process. Since in some cases the outer and inner rings of the flanges were not concentric, the flanges had to be modified. Generally the inner ring had to be cut to the desired shape u sing an oxy -acetylene blowtorch. While welding the flanges to the different section, it was ensured that drilled holes in the flanges are concentric with the ones in the next and previous sections. This is needed to ensure that the different sections of the gasifier are concentric. Otherwise, due to the central axis mismatch of the various sections there would have been a problem while casting the inner refractory lining of the gasifier. The flanges of two different sections are bolted using $\mathrm{p} / \mathrm{x} \quad-\mathrm{r} / \mathrm{p}$ lain, steel hexagonal machine bolts.

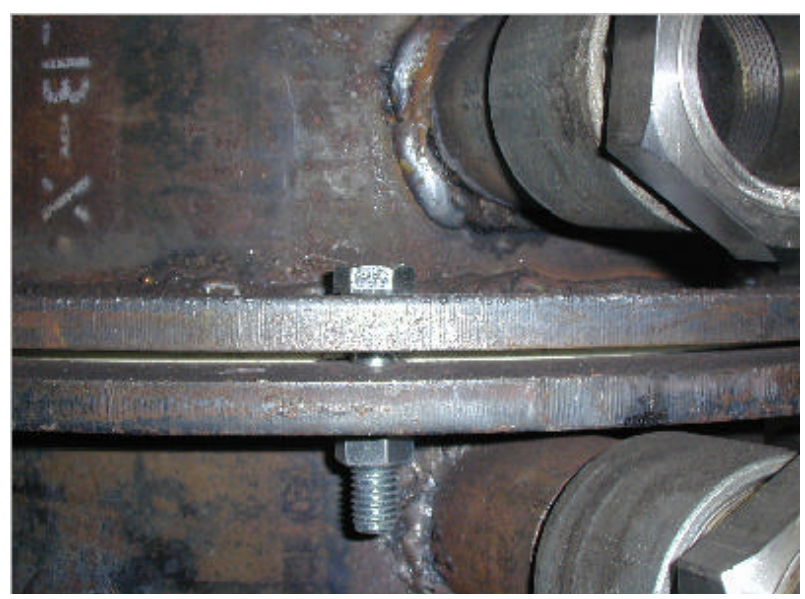

Figure 3.3.4: Joined Flanges

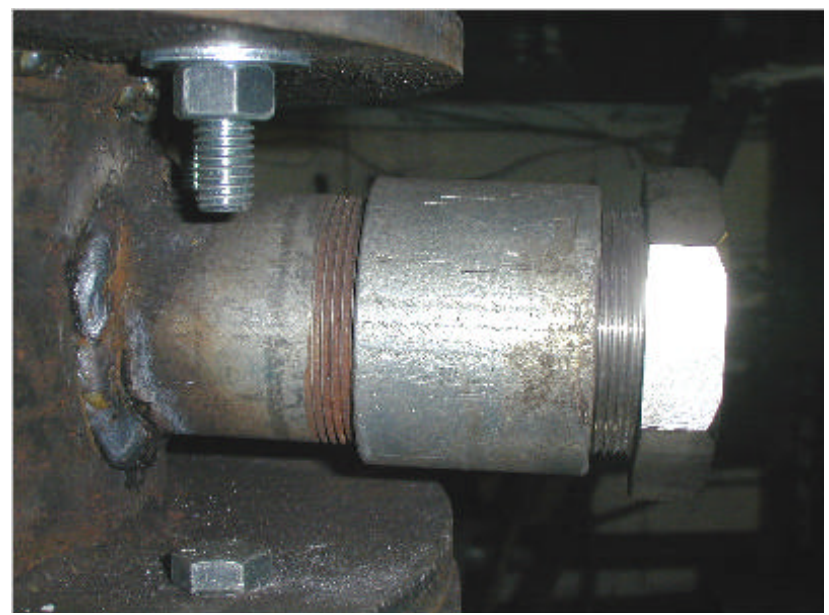

Figure 3.3.5: View port mounting

View port mountings are standard 2" $\mathrm{x}$ 4-8\%2(length) nominal size, galvanized pipes that are cut to lengths of 3". These are welded to the gasifier outer shell using an inert gas welding process. The threaded ends of the pipes receive a 2" standard galvanized coupling, which in turn receives the view ports (fig 3.3.5). This assembly was used so that the view ports can be easily removed for cleaning purposes. The insides of the view port mountings are coated with a refractory paste, to improve its life and minimize the heat loss.

Gas sampling ports are standard 3\%4x 4"(length) nominal size, galvanized pipes. These pipes are welded to the gasifier at the designed locations and have their inner sides coated with a refractory paste. 
The threaded ends of the ports receive a standard $3 / 4$ cap. These caps are removed to insert the gas analyzer probe while running the experiments.

Temperature measurement ports are standard 1/4" x 3" (length) nominal pipes. These are also coated with refractory insulating material. The threaded ends of the pipes receive a standard $3 \% / 4$ coupling. The thermocouples are threaded to the coupling (fig 3.3.6).

The heat recovery unit is cubical in shape and is made up of plain carbon steel sheets of $1 / 8$ " in thickness. The sheets are cut to the required dimensions and are welded using the metal inert gas welding process. The heat recovery unit has an internal insulation of $\$ / 2$ hic $\mathrm{k}$ ceramic boards. The flue gases from the gasifier come in to the heat recovery unit through two openings in the base of the unit and they exit through an opening at the back of the unit. The flue gases are conveyed to the heat recovery unit via two

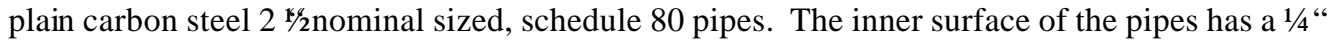
refractory coating. The outer surface of the conveying pipes is covered with 1" thick ceramic blanket insulation. The flue gas exit form the heat recovery unit is through a standard plain carbon steel 2" nominal size pipe (refer fig. 3.3.7). Adjacent to the exhaust gas opening there is a second 2" diameter opening. The function for the second opening shall be described in the later part of the report.

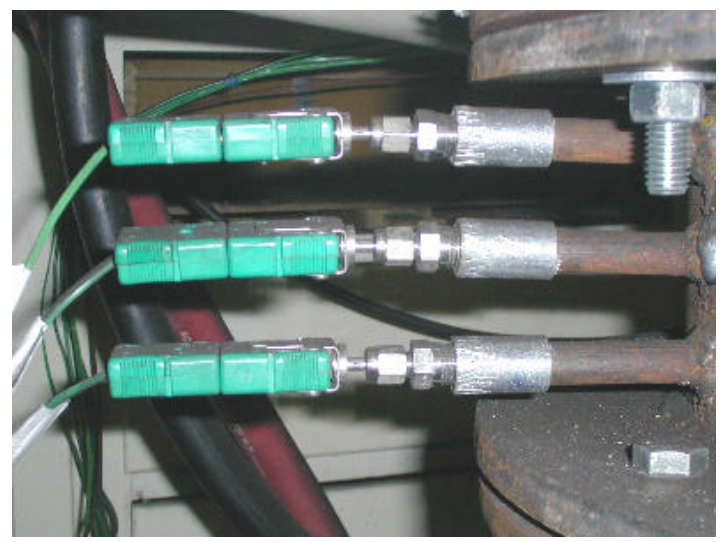

Figure 3.3.6: Thermocouple mounting
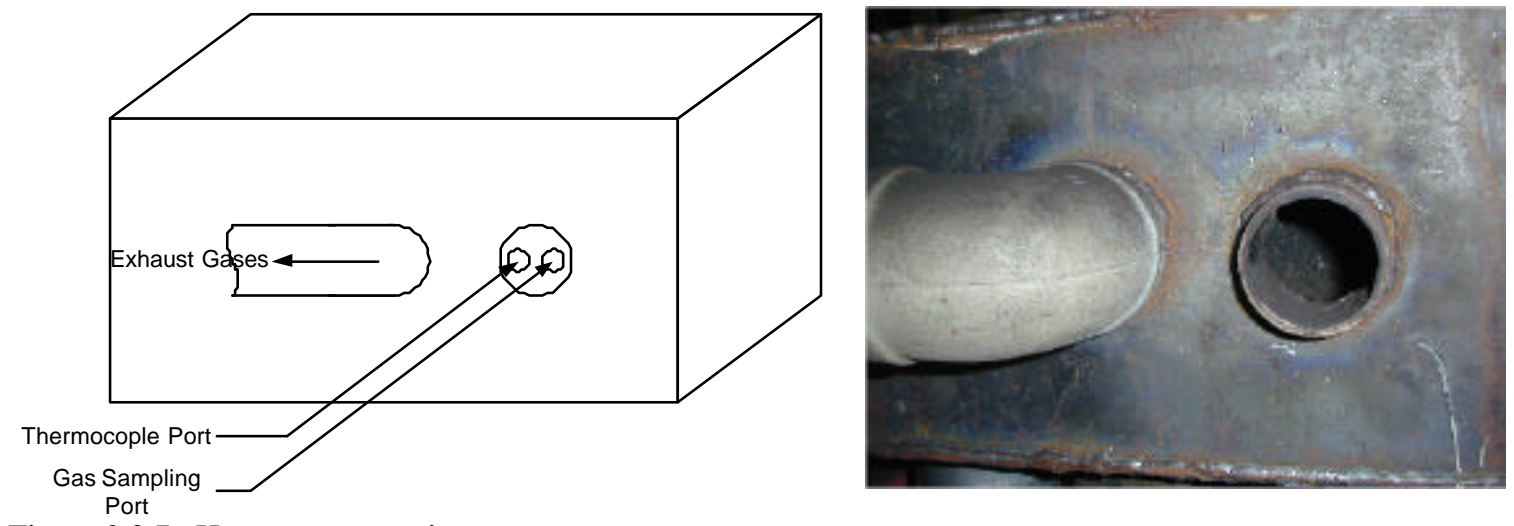

Figure 3.3.7: Hear recovery unit

The hopper is assembled from 1/8" thick, plain carbon steel sheets. It has a cubical upper portion and a tapering base. The tapering base is used to direct the flow of the fuel towards the center of the base. At the center of the base is a $2 \%$ pening which connects to the slide gate valve. On one side of the hopper is an acrylic sheet, window to check the fuel level inside the hopper. The hopper has a lid to prevent the contamination of the fuel inside the hopper.

The first shell and tube heat exchanger, which conveys the heat from the flue gases to the incoming fuel, is made up of plain carbon steel. The shell is a 4 " nominal size, schedule 80 pipe with the inside surface treated to prevent rusting. The heat exchanger is a single pass system. The cooling water 
enters the system at the top of the exchanger, and exits at the bottom. The tube, which carries the fuel, is a

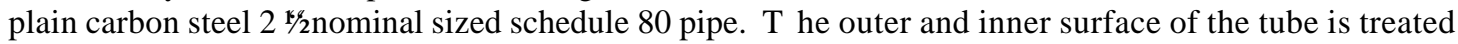
to prevent rusting. The tube has two flanges at both the ends. The flanges are $1 / 4$ " x $2-7 / 8$ " x 6 " ring type and are made up of plain carbon steel. The flanges are welded to the ends of the tube. The flanges at both the ends of the heat exchanger have four drilled holes of $\$ / 2$ sizes with a pitch circle diameter of $51 / 4$ '. The flanges at both the ends receive the studs of the slide gate valve. The gate valve has four $3 / 8$ " x 2 " studs. A gasket in between the flange and the slide gate valve is used make the assembly air tight.

The second shell and tube heat exchanger is used to cool the feeder tube, which is directly exposed to the hot flue gases leaving the gasifier. It is partly inside the gasifier and partly outside. The cooling water exits and inlets are on the outside. The shell is 4 " nominal size, schedule 80 pipe with the inside surface treated to prevent rusting. The heat exchanger is a two-pass system. The cooling water enters and exits the system at the top of the exchanger, but the openings are diametrically opposite. The cooling water flows down from the inlet through the first pass and then flows up towards the exit through the second pass. The tube, which feeds the fuel, is a plain carbon steel $2 \frac{\mathrm{k}}{2} \mathrm{n}$ nominal size, schedule 80 pipe. The outer and inner surface of the tube is treated to prevent rusting. The heat exchanger has only one flange of $1 / 4$ ' $\mathrm{x} 2$ $7 / 8$ " x 6 " at the top. This again has four drilled holes of $\$ /$ sizes with a pitch circle diam eter of $51 / 4$ ' which accept the studs of the slide gate valves. The outer surface of the shell is covered with wrappable refractory sheets of $\$$ / $/$ hickness. Since the wrappable sheets are porous they are coated with a refractory paste, which also increases the strength of the sheets.

Figure 3.3.8 shows the schematic of the exhaust system. The exhaust system, which starts at the heat recovery unit, is primarily made up of standard 2" nominal size, galvanized pipes. Since the exhaust is connected to a central suction system, it is essential to control the system pressure. The exhaust system circuit is used to control the static pressure inside the gasifier. It has two flow regulating valves. The air flow into the blower is through two circuits. One is the flue gas circuit from the gasifier, and the other is a atmospheric air circuit that is open to the atmosphere. Each circuit has a flow-regulating valve. By controlling the opening of the valves, the back pressure or the pressure inside the gasifier can be varied. The static pressure inside the gasifier is measured by a U-tube manometer, which is connected to the exhaust circuit. The pressure inside the system is kept at around - 0.3 " of water. This is done so that in case of a leak the flue gases do not leak out of the system.
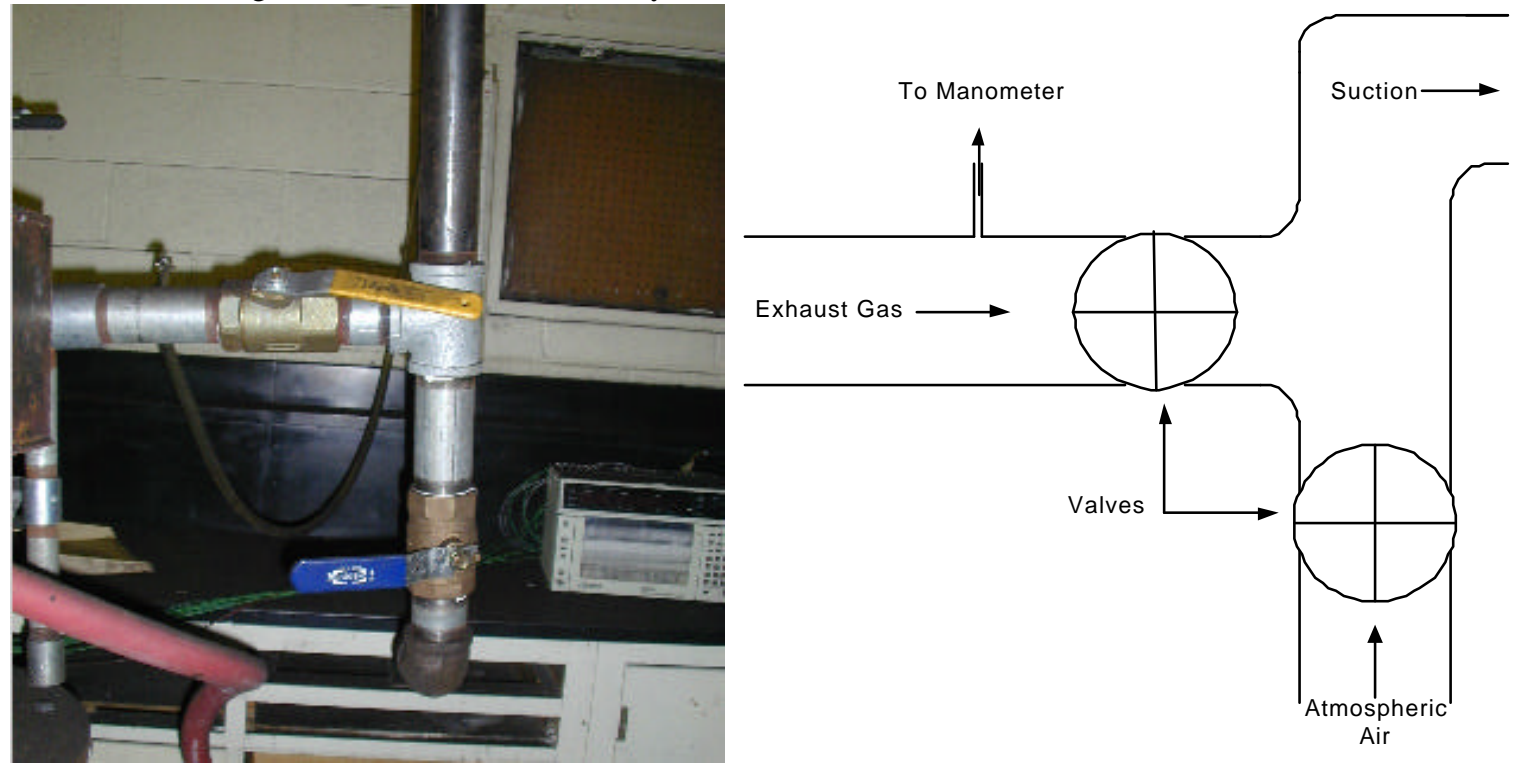

Figure 3.3.8: flue gas exhaust circuit

The plenum chamber door is a $7 / 2 \times 6$ " 5 " plain carbon steel sheet. The inner surface has 3" thick ceramic board insulation. The door is not hinged to the system and can be easily removed. It is kept in place by two $1 / 4$ ' bolts, which run along the width of the door at the top and bottom (fig 3.3.9a). The door is made air tight by lining the door and the door base with ceramic broads, which not only acts as a gasket but also acts as an insulator and prevents the heat loss from the system (fig 3.3.9b). 
The grate support plate is a ring type flange of $\mathrm{T} / \mathrm{x} 7 \mathrm{P} / 2 \mathrm{x} 20^{\prime \prime}$ dimensions. It is bolted in between the first section and the plenum chamber. The main function of the grate support plate is to support the weight of the refractory castings and separate the combustion zone from the plenum chamber. It is also used to support the grate-support ring. The ceramic board grate passes through the central hole in the grate support plate. Four standard studs of $\mathrm{p} / 2 \mathrm{x} 3$ " are welded to the bottom of the flange. They have a pitch circle diameter of 8 ". The grate-support ring has matching drilled holes and it is held in place by the standard hexagonal nuts, which are screwed to the bolts of the grate support plate. The grate-support ring is $1 / 8$ " $x$ 7.5" $\mathrm{x} 9$ " in dimensions. The grate-support ring holds the ceramic board grate tightly in place against the refractory casting. This is needed to ensure that the primary air does not leak out through the gap between the grate and the refractory casting.
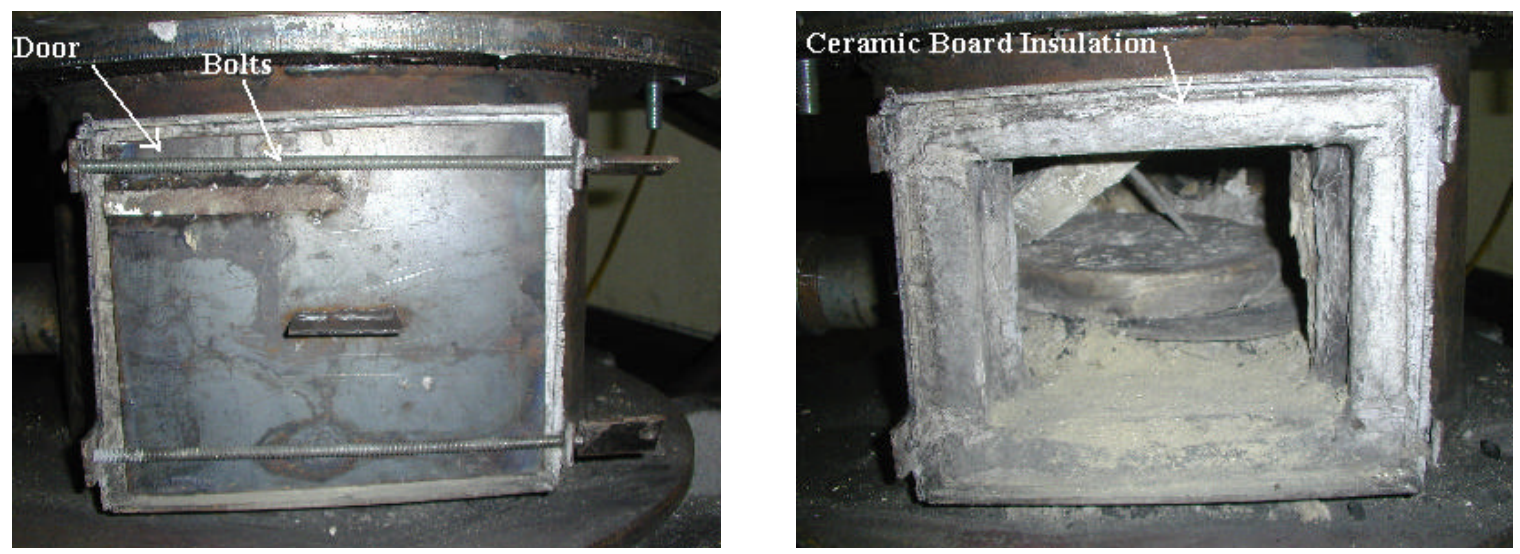

Figures 3.3.9a and 3.3.9b: Plenum door and bolts

\section{Refractory Casting}

The inner insulation layer is a castable alumina refractory. Since the gasifier is fabricated in sections, there was a need to cast the refractory insulation in the same manner. This would ensure easy removal of any section as a whole unit rather than having to dismantle the whole set up. Different design requirements of each section make the casting for each section unique. There was a need to have holes in the castable refractory that matched perfectly with the various ports, so that the thermocouples and gas analyzer probe could be inserted with ease. The view port holes had to be in alignment with the insulating refractory holes. The casting of the insulating refractory is complicated due to the configuration of the holes (refer fig. 3.3.10).

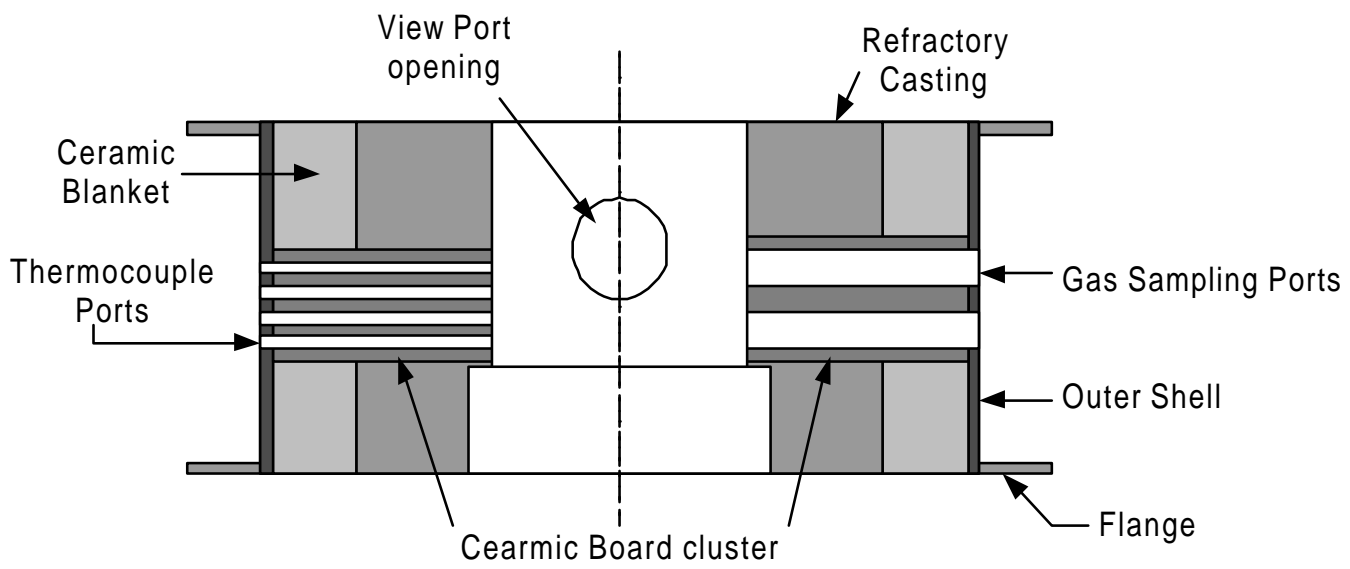

Figure 3.3.10: Cross section of section 1 of the gasisfier 


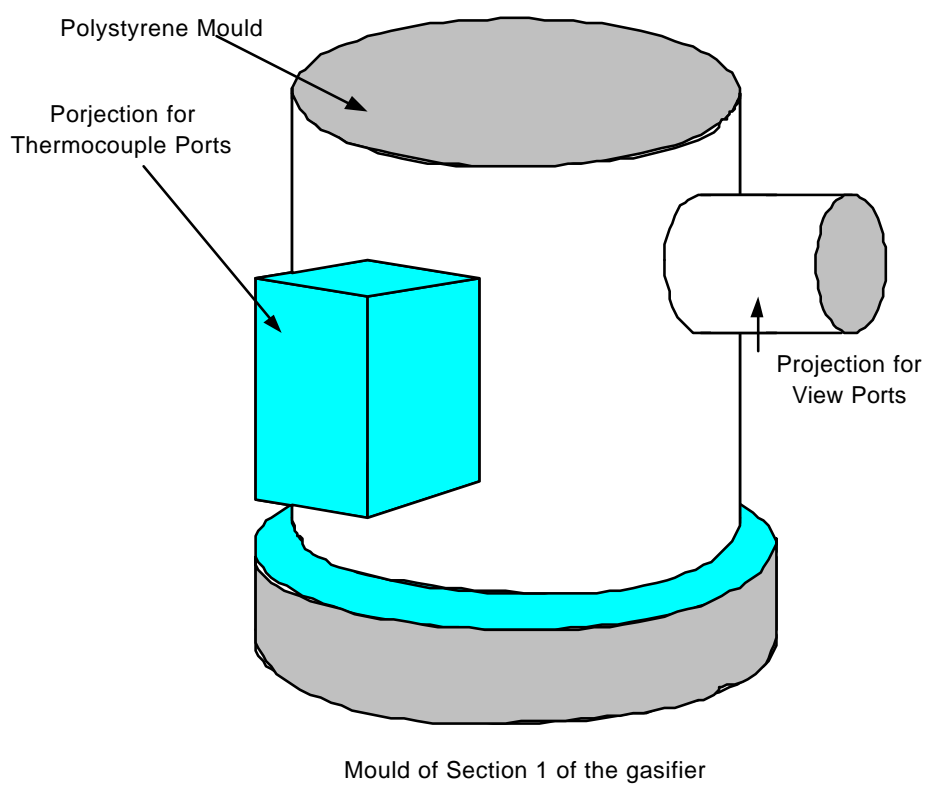

Figure 3.3.11: Schematic of the inner mold of section 1

The mould for the cast was made up of high-density polystyrene and PVC pipe. The high-density polystyrene was used to form the inner core of the refractory, while the PVC pipe was used to form the outer shell of the casting. The polystyrene was cut to the required dimensions and then it was placed on a waterproof base. The PVC pipe was placed on the out side. The gap between the polystyrene core and the shell was slowly filled with a liquid paste of the refractory material. It was ensured that there is no air trapped inside the cast. The mould was covered from the top and allowed to dry for at least 24 hours. After that the PVC pipe was sawed and taken out. The polystyrene core was chipped out slowly. Care was taken to see that there were not obvious cracks in the cast. Then the cast was baked in a prescribed manner, as described by the supplier. On average it took a total of $30 \mathrm{hrs}$ of heating. Heating not only dried and imparted strength to the casting, but it also burned away the left over polystyrene. The cast was slowly heated up to $2400^{\circ} \mathrm{F}$. This was needed to ensure that the cast did not break during actual working conditions. The holes for the thermocouple ports are only $1 / 2$ ' in diameter while those for the view ports are 2 " in diameter. The holes of the view port were incorporated into the mold. They were cast as a block (refer fig 3.3.11). This was done so that while assembling, the block could be made up of ceramic boards cut to the required configurations. This procedure was used for casting all the sections.

The grate is made up of ceramic boards. Holes are drilled into the boards in a prescribed pattern. This allowed for the passage of air into the combustion zone and ash out of the combustion zone.

\section{Assembly}

The assembly is done using the bottom to top method. Different sections are assembled on top of one another. The plenum chamber has a 2" thick refractory insulation. For sections above the grate the space in between the castable refractory and the shell is filled with insulating blankets. These are cut in sheets and then wrapped around the castable refractory. Instead of making holes in the blanket, which are necessary for the various ports. The holes in the castable refractory and the shell are connected using ceramic boards. This minimizes the leakage of flue gases from the combustion zone into the blanket and then subsequently out of the gasifier.

After totally assembling one section, the next section assembly is started by joining the castable refractory of the current section with the one in the previous section. The two castable refractory castings are joined with a refractory paste and allowed to dry for two hours. After that the ceramic boards are used to connect the ports in the casting and the outer shell. Then the ceramic blankets are cut in pieces and wrapped around the casting. The remaining sections are assembled in the same sequence. In between two successive flanges there is a gasket sandwiched between the flanges. These gaskets are used to make the joint air tight and leak proof. 
The R type sheathed, ungrounded thermocouples have a sheath material covering of inconel 600 . The connectors are compression fittings with stainless steel ferrules, and the terminations are quick disconnecting plugs. They have an outer diameter of 1/8" (refer figure 3.3.6). 


\section{Appendix 6B - Model Formulation}

\section{Reaction Rate Equations}

$\mathrm{C}+\mathrm{Q}_{2} \rightarrow \mathrm{CO}$

(R1)

$m_{C, 1}^{\prime \prime \prime}=\rho_{O 2} A_{V}\left(\frac{2 M_{C}}{M_{O 2}}\right) k_{O 2} \frac{S h D_{1}}{d_{P}}\left[\frac{1}{\frac{S h D_{1}}{d_{P}}+k_{O 2}}\right]$

$\mathrm{HV}_{1}=9211(\mathrm{~kJ} / \mathrm{kg})$

$k_{\mathrm{O} 2}=1.74 \mathrm{~T}_{\mathrm{S}} \exp \left(-9000 / \mathrm{T}_{\mathrm{S}}\right)$ [Evans et al, 1977]

$m_{C O, 1}^{\prime \prime \prime}=m_{C, 1}^{\prime \prime \prime}\left(\frac{M_{C O}}{M_{C}}\right)$

$m_{O 2,1}^{\prime \prime \prime}=m_{C, 1}^{\prime \prime \prime}\left(\frac{M_{O 2}}{2 M_{C}}\right)$

$\mathrm{C}+\mathrm{CO}_{2} \rightarrow 2 \mathrm{CO}$

$m_{C, 2}^{\prime \prime \prime}=\rho_{\mathrm{CO} 2} A_{V}\left(\frac{2 M_{C}}{M_{\mathrm{CO} 2}}\right) k_{\mathrm{CO} 2} \frac{S h D_{2}}{d_{P}}\left[\frac{1}{\frac{S h D_{2}}{d_{P}}+k_{\mathrm{CO} 2}}\right]$

$\mathrm{HV}_{2}=-14372(\mathrm{~kJ} / \mathrm{kg})$

$k_{\mathrm{CO} 2}=3.42 \mathrm{~T}_{\mathrm{S}} \exp \left(-15600 / \mathrm{T}_{\mathrm{S}}\right)$ [Brewster et al , 1993]

$m_{C O, 2}^{\prime \prime \prime}=m_{C, 2}^{\prime \prime \prime}\left(\frac{2 M_{C O}}{M_{C}}\right)$

$m_{\mathrm{CO} 2,2}^{\prime \prime \prime}=m_{C, 2}^{\prime \prime \prime}\left(\frac{M_{\mathrm{CO} 2}}{M_{C}}\right)$

$\mathrm{CO}+\mathrm{C}_{2} \rightarrow \mathrm{CO}_{2}$

$\mathrm{HV}_{3}=10107(\mathrm{~kJ} / \mathrm{kg})$

$w_{3}^{\prime \prime \prime}\left(M_{C O}\right)=M_{C O} 10^{17.6} \exp \left(\frac{-20000}{T_{g}}\right)\left[C O J O_{2}\right]^{0.25}\left[\mathrm{H}_{2} \mathrm{O}\right]^{0.5}$ [Smoot et al, 1985]

$m_{C O, 3}^{\prime \prime \prime}=w_{3}^{\prime \prime \prime}\left(M_{C O}\right)$

$m_{O 2,3}^{\prime \prime \prime}=m_{C O, 3}^{\prime \prime \prime}\left(\frac{M_{O 2}}{2 M_{C O}}\right)$

$m_{\mathrm{CO} 2,3}^{\prime \prime \prime}=m_{\mathrm{CO}, 3}^{\prime \prime \prime}\left(\frac{M_{\mathrm{CO} 2}}{M_{\mathrm{CO}}}\right)$

$\mathrm{C}+\mathrm{H}_{2} \mathrm{O} \rightarrow \mathrm{H}_{2}+\mathrm{CO}$

$\mathrm{HV}_{4}=-14609(\mathrm{~kJ} / \mathrm{kg})$

$K_{\mathrm{H} 2 \mathrm{O}}=1.67 k_{\mathrm{CO} 2}$ [Yoon et al , 1978] 


$$
\begin{aligned}
& m_{C, 4}^{\prime \prime \prime}=\rho_{H 20} A_{V}\left(\frac{M_{C}}{M_{H_{2} O}}\right) k_{H 2 O} \frac{S h D_{4}}{d_{P}}\left[\frac{1}{\frac{S h D_{4}}{d_{P}}+k_{H 2 O}}\right] \\
& m_{H 2 O, 4}^{\prime \prime \prime}=m_{C, 4}^{\prime \prime \prime}\left(\frac{M_{H 2 O}}{M_{C}}\right) \\
& m_{H 2,4}^{\prime \prime \prime}=m_{C, 4}^{\prime \prime \prime}\left(\frac{M_{H 2}}{M_{C}}\right) \\
& \mathrm{CH}_{2.5468} \mathrm{O}_{0.7387} \mathrm{~N}_{0.1731}(\mathrm{~g})+0.76735 \mathrm{O}_{2} \rightarrow \mathrm{CO}+1.2734 \mathrm{H}_{2} \mathrm{O}+0.8655 \mathrm{~N}_{2} \\
& \mathrm{HV}_{5}=20980(\mathrm{~kJ} / \mathrm{kg}) \\
& m_{V M, 5}^{\prime \prime \prime}=w^{\prime \prime \prime}\left(M_{V M}\right)=M_{V M} 9.2 x 10^{6} T_{g} \exp \left(\frac{-9650}{T_{g}}\right)\left[\frac{\rho_{V M}}{M_{V M}}\right]^{0.5}\left[\frac{\rho_{O 2}}{M_{O 2}}\right]^{a} \\
& m_{H 2 O, 5}^{\prime \prime \prime}=m_{V M, 5}^{\prime \prime \prime}\left(\frac{1.2734 M_{H 2 O}}{M_{V M}}\right) \\
& m_{C O, 5}^{\prime \prime \prime}=m_{V M, 5}^{\prime \prime \prime}\left(\frac{M_{C O}}{M_{V M}}\right) \\
& m_{O 2,5}^{\prime \prime \prime}=m_{V M, 5}^{\prime \prime \prime}\left(\frac{0.76735 M_{O 2}}{M_{V M}}\right) \\
& m_{N 2,5}^{\prime \prime \prime}=m_{V M, 5}^{\prime \prime \prime}\left(\frac{0.8655 M_{N 2}}{M_{V M}}\right)
\end{aligned}
$$

Overall production rates of the species:

$$
\begin{aligned}
& m_{C, T}^{\prime \prime \prime}=-m_{C, 1}^{\prime \prime \prime}-m_{C, 2}^{\prime \prime \prime}-m_{C, 4}^{\prime \prime \prime} \\
& m_{C O, T}^{\prime \prime \prime}=m_{C O, 1}^{\prime \prime \prime}+m_{C O, 2}^{\prime \prime \prime}-m_{C O, 3}^{\prime \prime \prime}+m_{C O, 4}^{\prime \prime \prime}+m_{C O, 5}^{\prime \prime \prime} \\
& m_{\mathrm{CO} 2, \mathrm{~T}}^{\prime \prime \prime}=-m_{\mathrm{CO} 2,2}^{\prime \prime \prime}+m_{\mathrm{CO} 2,3}^{\prime \prime \prime} \\
& m_{O 2, T}^{\prime \prime \prime}=-m_{O 2,1}^{\prime \prime \prime}-m_{O 2,3}^{\prime \prime \prime}-m_{O 2,5}^{\prime \prime \prime} \\
& m_{\mathrm{H} 2 \mathrm{O}, \mathrm{T}}^{\prime \prime \prime}=-m_{\mathrm{H} 2 \mathrm{O}, 4}^{\prime \prime}+m_{\mathrm{H} 2 \mathrm{O}, 5}^{\prime \prime \prime} \\
& m_{H 2, T}^{\prime \prime \prime}=m_{H 2,4}^{\prime \prime \prime} \\
& m_{N 2, T}^{\prime \prime \prime}=m_{N 2,5}^{\prime \prime \prime}
\end{aligned}
$$

Rate of pyrolysis of Feedlot biomass

$m_{V M, \operatorname{Rel}}^{\prime \prime \prime}=\left(\frac{\operatorname{MaSS}_{V M, I N T I A L}}{\operatorname{MasS}_{C, I N I T I A L}}\right) m_{C, T}^{\prime \prime}$

$m_{V M, T}^{\prime \prime \prime}=m_{V M, \operatorname{Re} l}^{\prime \prime \prime}-m m_{V M, 5}^{\prime \prime \prime}$

The gaseous species conservation equations in differential form are:

$\frac{d\left(\rho Y_{k} V_{g}\right)}{d z}=\frac{d\left(\rho_{k} V_{g}\right)}{d z}=m_{k, T}^{\prime \prime \prime}$ 
$\rho V_{g} \frac{d\left(Y_{k}\right)}{d z}=m_{k, T}^{\prime \prime \prime}-m_{g}^{\prime \prime \prime} Y_{k}$

The mass flux of the gas is:

$\rho_{g} V_{g}=\left(\rho_{N 2}+\rho_{C O 2}+\rho_{C O}+\rho_{H 2}+\rho_{H 2 O}\right) V_{g}$

Conservation of energy for the gas phase is:

$\rho_{g} V_{g} c_{p, g} \frac{d T_{g}}{d z}+h_{g} m_{g}^{\prime \cdot "}=H V_{1} m_{C, 1}^{\prime \prime \prime}+H V_{2} m_{C, 2}^{\prime \prime \prime}+H V_{3} m_{C O, 3}^{\prime \prime \prime}+H V_{4} m_{C, 4}^{\prime \prime \prime}+H V_{5} m_{V M, 5}^{\prime \prime \prime}-A_{V} h_{c o n}\left(T_{g}-T_{S}\right)$

Conservation of energy for the solid phase is:

$(1-\varepsilon) \rho_{S} C_{S} V_{S} \frac{d T_{S}}{d z}=H V_{1} m_{C, 1}^{\prime \prime \prime}+H V_{2} m_{C, 2}^{\prime \prime \prime}+H V_{4} m_{C, 4}^{\prime \prime \prime}+A_{V} h_{c o n}\left(T_{g}-T_{S}\right)$

The particle velocity is:

$(1-\varepsilon) \rho_{S} \frac{d V_{S}}{d z}=m_{C, T}^{\prime \prime \prime}$

Mass fraction of the gas species is:

$Y_{K}=\frac{\rho_{K}}{\rho_{g}}$

Specific Heat of the gas is:

$c_{p, g}=\sum_{K} Y_{K} c_{p, K}$

Specific Heat of the Species is

$c_{p, K}=a_{K}+b_{K} T_{g}+c_{K} T_{g}^{2}+d_{K} T_{g}^{3} \quad$ [Yunas et al, 1998]

Density of the gas is:

$\rho_{g}=\frac{P_{g} M_{g}}{R_{u} T_{g}}$

Molecular weight of the gas mixture is:

$M_{g}=\sum_{K} X_{K} M_{K}=\rho_{g}\left[\sum_{K} \rho_{K} / M_{K}\right]^{-1}$

Assumed:

$S h=\frac{h_{i} d_{p}}{D_{i}}=2.0$

where $D_{i}$ is calculated at mean temperature and assumed constant

The mean solid surface are per unit bed volume is:

$A_{V}=\frac{6(1-\varepsilon)}{d_{p}}$ 


\section{Nomenclature}

a,b,c,d Thermodynamic constants used to determine the specific heat of a gas species at a given temperature.

$\mathrm{A}_{\mathrm{V}} \quad$ Surface area per unit volum $3, \mathrm{~m}^{-1}$

$\mathrm{c}_{\mathrm{p}} \quad$ Specific Heat, $\mathrm{kJ} / \mathrm{kg}-\mathrm{K}$

D Diffusivity, $\mathrm{m}^{2} / \mathrm{s}$

$d_{p} \quad$ Diameter of the particle, $m$

$\mathrm{h} \quad$ Enthalpy per unit mass, $\mathrm{kJ} / \mathrm{kg}$

$h_{\text {conv }} \quad$ Heat transfer coefficient, $\mathrm{W} /\left(\mathrm{m}^{2} \mathrm{~K}\right)$

HV Heating Value, $\mathrm{kJ} / \mathrm{kg}$

$k \quad$ Reaction rate constant, $\mathrm{m} / \mathrm{s}$

Le Lewis number

M Molecular weight, $\mathrm{kg} / \mathrm{lMol}$

m.", Reaction rate per unit volume, $\mathrm{kg} / \mathrm{m}^{3}-\mathrm{s}$

$\mathrm{P} \quad$ Pressure, $\mathrm{kPa}$

$R_{u} \quad$ Universal gas constant, $\mathrm{kJ} / \mathrm{kMol}-\mathrm{K}$

Sh Sherwood number

$\mathrm{T} \quad$ Temperature, $\mathrm{K}$

V Velocity, $\mathrm{m} / \mathrm{s}$

$Y \quad$ Mass fraction

z Height, $\mathrm{m}$

$\varepsilon \quad$ Void fraction

$\rho \quad$ Density, $\mathrm{kg} / \mathrm{m}^{3}$

Subscripts

g gas

$k \quad$ Species

Rel Released

$s \quad$ solid

$T \quad$ Total 